The role of endocannabinoid and kynurenine systems in the pathomechanism of migraine: animal experimental data

Gábor Nagy-Grócz M.Sc.

Ph.D. Thesis

Doctoral School of Clinical Medicine

Department of Neurology

Faculty of Medicine

Albert Szent-Györgyi Clinical Center

University of Szeged

Supervisor: Árpád Párdutz M.D., Ph.D.

Szeged

2017 
Original publications directly related to the Ph.D. thesis:

I. Nagy-Grócz G, Tar L, Bohár Z, Fejes-Szabó A, Laborc KF, Spekker E, Vécsei L, Párdutz Á.

The modulatory effect of anandamide on nitroglycerin-induced sensitization in the trigeminal system of the rat

Cephalalgia. 2016 Aug;36(9):849-61. doi: 10.1177/0333102415613766.

IF: 3.609

II. Nagy-Grócz G, Laborc KF, Veres G, Bajtai A, Bohár Z, Zádori D, Fejes-Szabó A, Spekker E, Vécsei L, Párdutz Á.

The effect of systemic nitroglycerin administration on the kynurenine pathway in the rat Front Neurol. 2017 Jun 14;8:278. doi: 10.3389/fneur.2017.00278. eCollection 2017.

IF: 3.552 (2016)

Cumulative impact factor of the publications directly related to the thesis: 7.161 
Publications not directly related to the Ph.D. thesis:

Nagy-Grócz G, Zádor F, Dvorácskó S, Bohár Z, Benyhe S, Tömböly C, Párdutz Á, Vécsei L. Interactions between kynurenines and endocannabinoids with special emphasis on migraine Int. J. Mol. Sci. 2017;18:1617. doi:10.3390/ijms18081617.

IF: 3.226 (2016)

Nagy-Grócz G, Bohár Z, Fejes-Szabó A, Laborc F. K, Spekker E, Tar L, Vécsei L, Párdutz Á.

Nitroglycerin increases serotonin transporter expression in rat spinal cord but anandamide modulated this effect

J Chem Neuroanat. 2017 Jun 15;85:13-20. doi: 10.1016/j.jchemneu.2017.06.002. [Epub ahead of print]

IF: 1.925 (2016)

Tajti J, Szok D, Nagy-Grócz G, Tuka B, Petrovics-Balog A, Toldi J, Vécsei L. Kynurenines and PACAP in migraine: medicinal chemistry and pathogenetic aspects Curr Med Chem. 2017 Feb 27. doi: 10.2174/0929867324666170227115019. [Epub ahead of print]

\section{IF: 3.249 (2016)}

Veres G, Fejes-Szabó A, Zádori D, Nagy-Grócz G, László M. A, Bajtai A, Mándity I, Szentirmai M, Bohár Zs, Laborc F. K, Szatmári I, Fülöp F, Vécsei László, Párdutz Á. A comparative assessment of two kynurenic acid analogs in the formalin model of trigeminal activation: a behavioral, immunohistochemical and pharmacokinetic study J Neural Transm. 2017 Jan;124(1):99-112. doi: 10.1007/s00702-016-1615-5.

IF: 2.392 (2016) 
Bohár Z, Nagy-Grócz G, Fejes-Szabó A, Tar L, László AM, Büki A, Szabadi N, Vraukó V, Vécsei L, Párdutz Á.

Diverse effects of Brilliant Blue $G$ administration in models of trigeminal activation in the rat. J Neural Transm. 2015 Dec;122(12):1621-31.

\section{IF: 2.587}

Fejes-Szabó A, Bohár Z, Nagy-Grócz G, Vámos E, Tar L, Pődör B, Tajti J, Toldi J, Vécsei L, Párdutz A.

Effect of Probenecid on the Pain-Related Behaviour and Morphological Markers in Orofacial Formalin Test of the Rat.

CNS Neurol Disord Drug Targets. 2015;14(3):350-9.

\section{IF: 2.188}

Fejes-Szabó A, Bohár Z, Vámos E, Nagy-Grócz G, Tar L, Veres G, Zádori D, Szentirmai M, Tajti J, Szatmári I, Fülöp F, Toldi J, Párdutz Á, Vécsei L.

Pre-treatment with new kynurenic acid amide dose-dependently prevents the nitroglycerineinduced neuronal activation and sensitization in cervical part of trigemino-cervical complex. J Neural Transm. 2014 Jul;121(7):725-38. doi: 10.1007/s00702-013-1146-2.

\section{IF: 2.402}

Cumulative impact factor of publications not directly related to the thesis: $\mathbf{1 7 . 9 6 8}$ Total impact factor: 25.129 


\section{Table of contents}

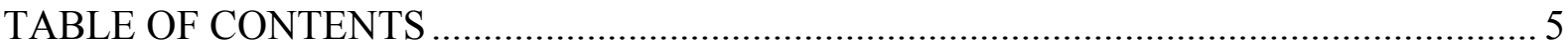

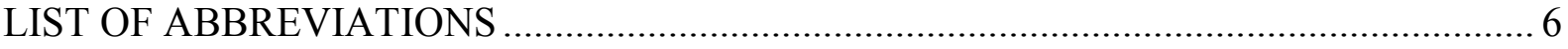

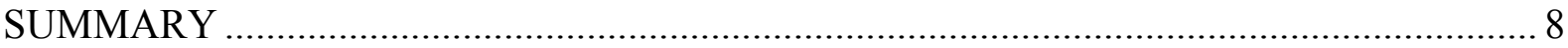

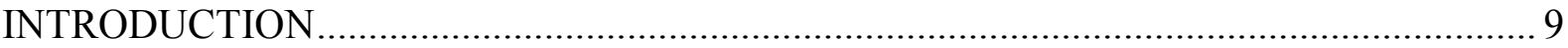

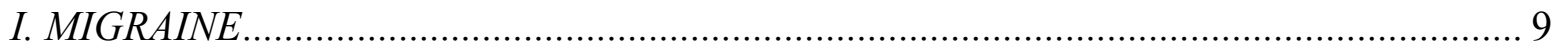



III. THE CANNABINOID SYSTEM AND ENDOCANNABINOIDS .................................. 13

IV. ANIMAL MODELS OF MIGRAINE: THE NITROGLYCERIN MODEL....................... 14

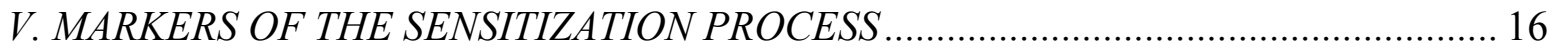

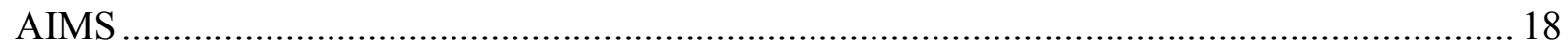

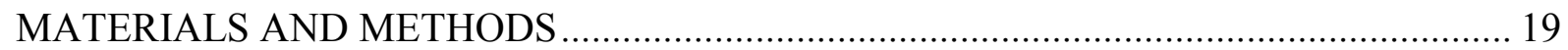

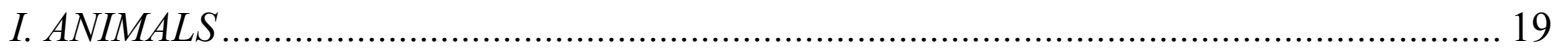

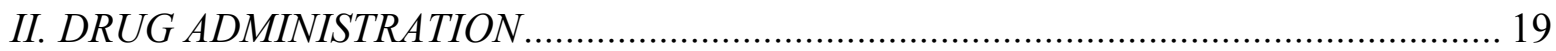

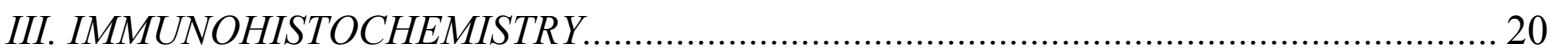

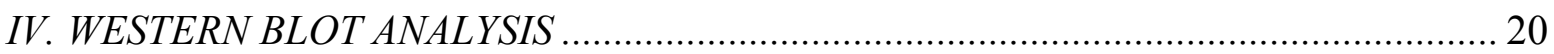

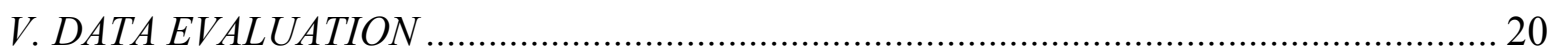

A. IMMUNOHISTOCHEMISTRY (TRPV1, nNOS, NF-KB) ................................ 21

B. WESTERN BLOT ANALYSIS (nNOS, COX-2, TDO, IDO, KAT-II, KYNU, KMO) 22





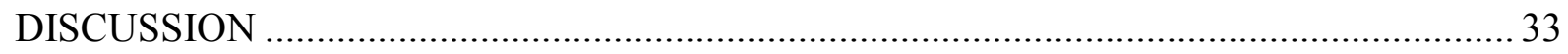

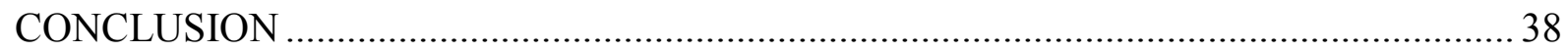

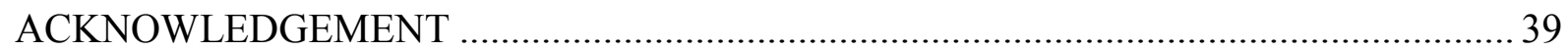

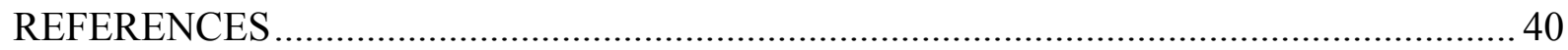




\section{LIST OF ABBREVIATIONS}

$\begin{array}{ll}\text { AEA } & \text { anandamide } \\ \text { AMPA } & \text { a-amino-3-hydroxy-5-methyl-4-isoxazole propionic acid } \\ \text { C1-C2 } & \text { upper cervical spinal cord } \\ \text { CB } & \text { cannabinoid receptor } \\ \text { CB1 } & \text { cannabinoid receptor1 } \\ \text { CB2 } & \text { cannabinoid receptor2 } \\ \text { CGRP } & \text { calcitonin gene-related peptide } \\ \text { COX-2 } & \text { cyclooxygenase-2 } \\ \text { CSD } & \text { cortical spreading depression } \\ \text { GAPDH } & \text { glyceraldehyde 3-phosphate dehydrogenase } \\ \text { i.p. } & \text { intraperitoneal } \\ \text { IDO } & \text { indoleamine 2,3-dioxygenase } \\ \text { KAT-II } & \text { kynurenine aminotransferase-II } \\ \text { KMO } & \text { L-kynurenine 3-monooxygenase } \\ \text { KYNA } & \text { kynurenic acid } \\ \text { KYNU } & \text { L-kynurenine hydrolase } \\ \text { L-KYN } & \text { L-kynurenin } \\ \text { NF- } \text { KB } & \text { nuclear factor kappa B } \\ \text { NMDA } & \text { N-methyl-D-aspartate } \\ \text { NOS } & \text { nitric oxide synthase } \\ \text { nNOS } & \text { neuronal nitric oxide synthase } \\ \text { NO } & \text { nitric oxide } \\ \text { NSAIDS } & \text { non-steroidal anti-inflammatory drugs } \\ \text { NTG } & \text { nitroglycerin } \\ \text { PACAP } & \text { pituitary adenylate cyclase-activating peptide } \\ \text { pho } & \text { phosphate-buffered saline } \\ \text { THinolinic acid } \\ \text { Tris-buffered saline containing Tween 20 }\end{array}$


TNC caudal trigeminal nucleus

TRPV1 transient receptor potential vanilloid 1 


\section{Summary}

Primary headache disorders include migraine, which is one of the most frequent neurological diseases and affects more than $14 \%$ of the whole population. Despite the research efforts, its exact pathomechanism is not fully revealed, but evidence points to the role of glutamate and its receptors as key players. Kynurenic acid (KYNA) is an endogenous glutamate receptor antagonist produced by the kynurenine pathway. Tryptophan 2,3-dioxygenase (TDO2) and indoleamine 2,3-dioxygenase (IDO1,2) convert L-tryptophan to N-formyl-L-kynurenine, to be further transformed to L-kynurenine (L-KYN). Kynurenine aminotransferase-II (KAT-II), L-kynurenine hydrolase (KYNU) and L-kynurenine 3-monooxygenase (KMO) are key enzymes in the later steps of the kynurenine pathway.

Recent studies suggest that the endocannabinoid system is involved in nociceptive signal processing and cannabinoid receptor (CB) agonists are able to attenuate nociception in animal models of pain.

One of the human and animal models of migraine is the systemic administration of the nitric oxide donor (NO) nitroglycerin (NTG). NTG can provoke migraine like attacks in migraineurs and besides its activation it initiates a self-amplifying process in the trigeminal system, probably leading to central sensitization.

We used the NTG model of migraine in rats to study the role of endocannabinoids and kynurenines in the pathomechanisms of migraine.

Our results show that NTG is able to increase the markers of the sensitization process in the upper cervical spinal cord, namely transient receptor potential vanilloid type 1 (TRPV1), neuronal nitric oxide synthase (nNOS), nuclear factor kappa B (NF- $\kappa \mathrm{B})$ and cyclooxygenase2 (COX-2) in the trigemino-cervical complex. On the other hand, we have found that AEA modulates the NTG-induced changes, thus it influences the activation and central sensitization process in the trigeminal system, probably via CBs.

It has been also demonstrated that NTG is able to down-regulate the kynurenine pathway, with a potential influence on the glutamatergic system as well, contributing to the development of trigeminal activation and sensitization in animals. 


\section{Introduction}

\section{Migraine}

Migraine is a chronic neurological disorder characterized by recurrent headaches lasting for 472 hours and commonly accompanied by nausea, photophobia and phonophobia. The word derives form the Greek hemicrania-,,pain on one side of the head", introduced by Galen in 200 AD. This syndrome affects $16 \%$ of the total population (Smitherman and Gadda, 2013) and its incidence is three times more common in women than in men. The total cost of healthcare for patients with migraine in Europe in 2010 was 18.4 billion $€$ (Olesen et al., 2012).

It is well-known, that the activation and sensitization of the trigeminal system is essential during the attack (Edvinsson and Uddman, 2005). Continuous activation of peripheral trigeminal afferents leads to peripheral (first order) sensitization, which manifests as a throbbing pain worsening during physical activity (Burstein et al., 2011). Sustained nociceptive inputs can lead to sensitization of the second and ultimately to the third order neurons, so called central sensitization (Goadsby, 2005) manifested as allodynia when non

painful stimuli are perceived as painful. Previous data have shown, that after the onset of central sensitization during the migraine attack, the acute treatment becomes less effective (Burstein et al., 2004). Although, this theory has been contested recently, stating that the severity of headache might be a better indicator, than the symptoms of sensitization (DiazInsa et al., 2011; Goadsby et al., 2008), it is generally accepted that the latter plays an essential role in the genesis of migraine (Burstein et al., 2000).

Besides the trigeminal system, the key players in the pathomechanism of migraine are the brainstem migraine generators including periaqueductal grey matter, locus coeruleus, dorsolateral pons, nucleus raphe magnus and the nucleus raphe dorsalis (Weiller et al., 1995). Another important process in migraine is the cortical spreading depression (CSD), which is a self-propagating wave of depolarization that spreads across the cerebral cortex. It is widely accepted that CSD is the basis of the migraine aura (Lauritzen, 1994; Moskowitz, 2008). CSD can activate the trigeminal system (Moskowitz et al., 1993), enhance persistent blood flow and induce plasma protein extravasation in dura mater in rats (Bolay et al., 2002), which phenomena are also present under the migraine attack. The possible connection between CSD 
and migraine may be glutamate and its receptors, since they have a relevant role in the propagation and generation of CSD (Lauritzen et al., 1988).

The role of glutamate seems pivotal in many other aspects of migraine. Glutamate receptors are found throughout in the trigeminal system. N-methyl-D-aspartate (NMDA), $\alpha$-amino-3hydroxy-5-methyl-4-isoxazole propionic acid (AMPA), kainate receptors are present within the brainstem nuclei of the trigeminal system (Tallaksen-Greene et al., 1992) and NMDA receptor mRNA was found in the trigeminal ganglion (Watanabe et al., 1981), as well. NMDA, AMPA, kainate receptors can also be found in the superficial layers of the spinal cord (Furuyama et al., 1993), where the brainstem trigeminal nuclei extend. Activation of NMDA receptors is one of the most important step in initiating and maintaining the central sensitization (Latremoliere and Woolf, 2009), which can be blocked by competitive (D-CPP) and non-competitive (MK801) NMDA receptor antagonists in rats (Ma and Woolf, 1995). In addition, a conditional deletion of the NR2 subunit of NDMA receptors inhibits the synaptic inputs trough NMDA receptors and the central sensitization in rats (Hughes et al., 2003), as well. Besides NMDA, the metabotropic glutamate receptors also contribute to the mechanical allodynia (Soliman et al., 2005). Data from human studies showed, that the levels of glutamate were higher in the plasma, cerebrospinal fluid and platelets in migraine patients compared with non-migraineurs (D'Andrea et al., 1991; Martinez et al., 1993; Rothrock et al., 1995), which could indicate an increased activation of their receptors, thus hyperexcitability (Vecsei et al., 2015). One of the endogenous glutamate receptor antagonists is kynurenic acid (KYNA), which is produced by the kynurenine pathway.

\section{The kynurenine system}

KYNA is believed to be a neuroprotective metabolite of tryptophan (Vecsei et al., 2013) that interacts with glutamate receptors, aryl hydrocarbon receptor, G protein-coupled receptor 35 and elicits anti-glutamatergic actions. KYNA was discovered by Justus von Liebig in 1853 in the urine, and half a century later, the substance was identified as a byoproduct of tryptophan metabolism. Several lines of data confirm that KYNA and its analogues have anti-nociceptive effects in different migraine-models (Csati et al., 2015; Fejes-Szabo et al., 2014a; Lukacs et al., 2016), probably by attenuating the trigeminal activation and sensitization. The first step in the kynurenine pathway is the conversion of tryptophan to $\mathrm{N}$-formyl-L-kynurenine by 
tryptophan 2,3-dioxygenase (TDO2) and indoleamine 2,3-dioxygenase (IDO1,2): the ratelimiting enzymes of tryptophan metabolism. IDO was discovered in 1957 as heme protein (Hayaishi et al., 1957), which can be activated through IFN- $\gamma$ (Heyes et al., 1997) and which is present in the central nervous system (Watanabe et al., 1981), while TDO occurs primarily in the peripheral tissues, especially in the liver (Knox and Mehler, 1950). IDO and TDO convert tryptophan to $\mathrm{N}$-formyl-L-kynurenine by opening tryptophan ring in a reaction, which produces peroxides and highly reactive oxygen and hydroxyl radicals (Reyes Ocampo et al., 2014). N-formyl-L-kynurenine is further degraded by formamidase to L-kynurenine (LKYN), which is converted to KYNA by kynurenine aminotransferases (KAT)s, to 3hydroxykynurenine by L-kynurenine 3-monooxygenase (KMO) and to anthranilic acid by Lkynurenine hydrolase (KYNU). The other metabolite of the kynurenine pathway is quinolinic acid (QUIN). In contrast to KYNA, QUIN is an agonist of the NMDA receptors and can provoke neuronal death and also causes lipid peroxidation and generates reactive oxygen species (Behan et al., 1999; Guidetti and Schwarcz, 1999). QUIN is then converted into $\mathrm{NAD}^{+}$in the final step of this branch of the kynurenine pathway. Figure 1. 
12
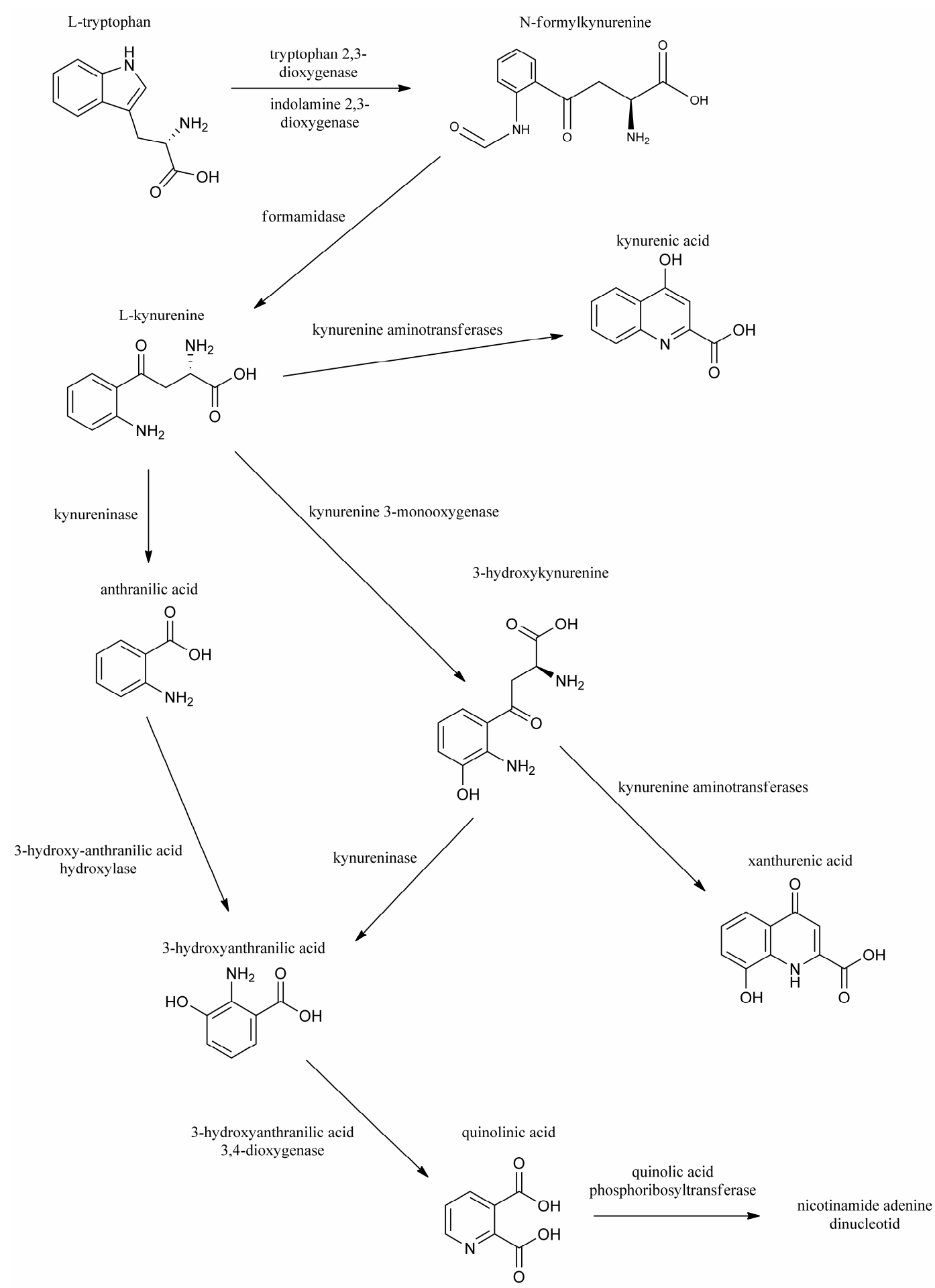

Figure 1. The kynurenine pathway (Nagy-Grocz et al., 2017) 


\section{The cannabinoid system and endocannabinoids}

Cannabis has been used for a long time to reduce nausea and vomiting in chemotherapy and to treat pain, migraine and muscle spasticity (Borgelt et al., 2013). Cannabinoid receptor1 (CB1) is present in the central nervous system, liver, lung and cannabinoid receptor2 (CB2) is expressed primarily in the immune system (Pettit et al., 1996), but also can be found in the central nervous system specially in microglia (Van Sickle et al., 2005). Robbins and coworkers have demonstrated, that recreational cannabis and dronabinol (a synthetic tetrahydrocannabinoid) aborted cluster attacks in human patients (Robbins et al., 2009). Combinations of a small-dose cannabinoid with non-steroidal anti-inflammatory drugs (NSAIDs) have a more pronounced antinociceptive effect in mice than large-dose cannabinoid or NSAIDs alone, thus combinations of cannabinoids and NSAIDs may give a new perspective in the pharmacotherapy of pain (Ulugol et al., 2006).

Animal models of pain have shown that fluctuations in the endocannabinoid levels in the nervous system are related to pain processing and antinociception (Guindon and Hohmann, 2009). CB1 is present in the trigeminal ganglion (TG) and on the axon terminals of primary sensory neurons in the nociceptive areas in the spinal cord in rats (Pertwee, 2001). CB1 is able to inhibit the responses of trigeminal neurons with $\mathrm{A} \delta$ - and $\mathrm{C}$-fiber inputs from the dura mater (Akerman et al., 2007), pointing to the importance of the endocannabinoid system in pain processing (Wilson and Nicoll, 2002).

Although the psychoactive properties of cannabinoids (Crawley et al., 1993), restrict their therapeutic application, the interactions between the endocannabinoid system and pain mediation is intensively studied in several laboratories.

N-Arachidonylethanolamide or anandamide (AEA) is the first discovered endocannabinoid, an agonist of CBs and transient receptor potential vanilloid type 1 (TRPV1), which is a nonselective cation channel activated by numerous stimuli, such as heat and vanilloids (Caterina et al., 1999; Caterina et al., 1997). AEA has vasodilatatory actions (Pertwee, 1997), which are not mediated by CBs (White and Hiley, 1998). It is well known that AEA is able to reduce nitroglycerin (NTG)-induced hyperalgesia and c-Fos expression in the caudal trigeminal nucleus (TNC) in rats (Greco et al., 2010), which means that AEA is capable of modulating the activation of the trigeminal system. Another nitric oxide (NO) donor, sodium nitroprusside is able to stimulate AEA transport (Maccarrone et al., 2000), suggesting a strong 
interaction between NO and AEA. In the rat mesencephalon, NTG increased the activity of fatty acid amide hydrolase, degrading enzyme of AEA (Greco et al., 2010).

\section{Animal models of migraine: the nitroglycerin model}

NTG or glyceryl trinitrate is a highly lipophilic organic nitrate, which has been used, for more than 150 years, for the treatment of angina pectoris and myocardial infarction (Chiariello et al., 1976). It readily crosses biological membranes, including the blood-brain barrier (Torfgard et al., 1989) and is converted to NO in the body mainly enzymatically probably by mitochondrial aldehyde dehydrogenase (Chen et al., 2005). The importance of NO is shown by the fact, that it was proclaimed Molecule of the Year in 1992.

One of the side-effects of NTG is headache (Iversen and Olesen, 1994) due to vasodilatation induced by NO, which occurs immediately after its administration, but about four hours later it is followed by a typical migraine without aura in migraine patients (Sicuteri et al., 1987), which can not be attributed to NO's prompt vasodilator effect (Di Clemente et al., 2009; Sicuteri et al., 1987). This observation and the results of a pilot study showing that treatment with a nitric oxide synthase (NOS) inhibitor attenuates spontaneous migraine headaches in $67 \%$ of subjects (Lassen et al., 1997), contributed to the implication of NO in migraine pathogenesis. An increasing amount of evidence suggests that NTG is able to activate and sensitize the trigeminal system in humans. NTG was able to trigger reproducible migraine with aura (Afridi et al., 2005; Afridi et al., 2004), during which activation in the primary visual area of the occipital cortex was demonstrated using positron emission tomography (Afridi et al., 2005). In healthy volunteers, sublingual NTG caused changes in trigeminal nociceptive blink reflex, pain thresholds and evoked cortical response, which are specifically due to the action NO on central nervous system structures (Di Clemente et al., 2009). Furthermore, similar changes to the first phenomenon has been reported during migraine attacks and thought to reflect sensitisation of neurons in TNC (Kaube et al., 2002), thus NTG seems to be able to sensitize the trigeminal system. The NTG-induced changes in evoked cortical response are comparable to those found immediately before and during a migraine attack (Afra et al., 2000; Siniatchkin et al., 1999). Based on above mentioned data NTG administration can be used as an animal experimental model of migraine. This was justified by experiments, since NTG can induce changes in animals similar to phenomena happening in humans during the NTG-induced attack. 
Administration of NTG was able to trigger scratching head reactions, climbing cage, red ear and photophobia in rats (Gao et al., 2014; Markovics et al., 2012; Zhu et al., 2011). NTG injection induces dural and pial artery dilation (Gozalov et al., 2007; Read et al., 1997) and leakage of plasma proteins from dural blood vessels in rats (Reuter et al., 2001).

NTG is able to increase c-Fos-immunoreactivity (a marker of the neuronal activation process) in the TNC in rats suggesting the activation of the second order trigeminal neurons there (Tassorelli and Joseph, 1995). A significant upregulation of c-fos mRNA followed by an upregulation of Fos protein was observed also in the TNC after NTG infusion in rats, which were attenuated by pre-treatment with sumatriptan, demonstrating the specificity of this model for migraine (Ramachandran et al., 2012).

NTG treatment can trigger a release of neurotransmitters present in the trigeminal system. It caused a decrease in medullary and pontine levels of serotonin, which may result from the interaction of NTG-released NO and serotonin in central areas devoted to the modulation of nociception (Tassorelli et al., 2002). Systemic administration of NTG in male rats produced a significant increase of neuronal NOS (nNOS) and calmodulin-dependent protein kinase II immunoreactive neurons and the area covered by serotonin-immunoreactive fibres and a significant decrease of the area innervated by calcitonin gene-related peptide (CGRP)immunoreactive afferents in the cervical part of TNC but not in the thoracic dorsal horn (Pardutz et al., 2007; Pardutz et al., 2000; Pardutz et al., 2002). These observations obviously show that the effect of NTG is specific to the trigeminal system, and confirm that NTG is really suitable model for examination of the trigeminal system.

Pituitary adenylate cyclase-activating peptide (PACAP)-38 and -27 immunoreactivity was also increased in the TNC of rats after NTG injection (Tuka et al., 2012), and similar tendency was observed in the plasma of migraineurs during the attack compared to the interictal period (Tuka et al., 2013). PACAP is present in the trigeminal system (Tajti et al., 1999) and it has a vasodilatatory effect (Chan et al., 2011). In addition, similar to NTG, PACAP-38 can induce headache in volunteers and migraine without aura in migraineurs (Schytz et al., 2009).

NO is also involved in the central sensitization process in the trigeminal system (Pardutz et al., 2000), probably acting via the activation of trigeminal $\mathrm{A} \delta$ and $\mathrm{C}$ fibres, since the destruction of the latter with capsaicin abolishes the effect of NTG (Tassorelli et al., 1997). 
A dose-dependent and delayed NTG-induced thermal and mechanical allodynia was identified in mice, which were reduced by sumatriptan (Bates et al., 2010). NTG caused a hyperalgesic response to the tail-flick test (Greco et al., 2014; Greco et al., 2008), which was inhibited by treatment with non-peptide CGRP receptor antagonist MK-8825 (Greco et al., 2014). Chronic intermittent administration of NTG to mice caused acute and chronic hyperalgesia, where the acute but not the chronic one was significantly reduced by sumatriptan, whereas both the acute and chronic hyperalgesia was significantly attenuated by topiramate which is effective in migraine prophylaxis (Pradhan et al., 2014).

To summarize, many experimental data in human and animals demonstrate that NTG is able to activate and sensitize the trigeminal system - phenomena also observed during migraine attacks - making NTG administration an applicable animal experimental model of migraine headache.

\section{Markers of the sensitization process}

TRPV1 is present in the spinal cord and is considered as a molecular integrator of chemical and physical stimuli that elicit pain (Tominaga et al., 1998). In addition, NO donors can activate TRPV1 resulting in an increase of intracellular calcium concentration in different cell types (Miyamoto et al., 2009; Pan et al., 2013), which suggests that TRPV1 may be modulated by NO.

NO is synthesized from arginine by nitric oxide synthase, neuronal isoform of which (nNOS) has an outmost importance in nociception and sensitization and it is present in the trigeminal system as described earlier (Dohrn et al., 1994). NO donors may trigger a self-amplifying process at the level of central projection site of the trigeminal system by increasing endogenous NO synthesis, which might be relevant in the central sensitization phenomenon (Burstein et al., 2000).

Nuclear factor kappa B (NF- $\mathrm{B})$ has a crucial role in inflammation process by controlling many genes including cytokynes. Several studies have shown that proinflammatory cytokynes contribute to the development of pain and hyperalgesia (Kress and Reeh, 1996). Cyclooxygenase-2 (COX-2) is present in the dorsal horn of spinal cord too and it has a substantial role in the processing of pain (Mazario et al., 2001). COX formally known as prostaglandin-endoperoxide synthase, is an enzyme that is responsible for formation of 
prostanoids, including thromboxane and prostaglandins such as prostacyclin. Gao and Duan have found that COX-2 expression increased in the TNC after orofacial nociception (Gao and Duan, 2010). 


\section{Aims}

1. The purpose of our studies was to investigate the modulatory effects of a CB agonist AEA on the NTG-induced expression of the markers of the sensitization process, namely TRPV1, nNOS, NF- $\kappa \mathrm{B}$ and COX-2.

2. Furthermore, our aim was to examine the effect of NTG on the expression of the enzymes of the kynurenine pathway, as TDO2, IDO1, KAT-II, KYNU and KMO. 


\section{Materials and methods}

\section{Animals}

The procedures utilized in this study followed the guidelines for the Use of Animals in Research of the International Association for the Study of Pain and the directive of the European Economic Community (86/609/ECC). They were permitted by the Committee of the Animal Research of University of Szeged (I-74-12/2012) and the Scientific Ethics Committee for Animal Research of the Protection of Animals Advisory Board (XI./352/2012). 54 adult male Sprague-Dawley rats weighing 200-250 g were used. The animals were raised and maintained under standard laboratory conditions with tap water and regular rat chow available ad libitium on a 12 hour dark-12 hour light cycle.

\section{Drug administration}

\section{Examination of the sensitization markers:}

The animals were divided into four groups ( $n=6$ per group for immunohistochemistry, $n=5$ per group for Western blot analysis).

The animals in the first group, called placebo group, received only the vehicle solution (physiological saline) as treatment. In the second group, the rats were treated with an intraperitoneal (i.p.) injection of NTG (10 mg/kg bodyweight, Pohl Boskamp). In the third and fourth group, animals received i.p. AEA (2x5 mg/kg bodyweight, Sigma Aldrich) half hour before and one hour after the placebo or NTG treatment. Greco and colleagues have demonstrated that single $20 \mathrm{mg} / \mathrm{kg}$ doses of AEA before the NTG administration are able to reduce NTG-induced c-Fos expression in the caudal part of spinal trigeminal nucleus (Greco et al., 2010). AEA was dissolved in physiological saline. In the case of the first and second groups, animals were treated with physiological saline instead of AEA.

\section{Kynurenine pathway experiment:}

The animals were separated into two groups $(n=5)$. The animals in the first group, called placebo group, received only the vehicle solution (physiological saline) as treatment. In the second group, the rats were treated with an i.p. injection of NTG $(10 \mathrm{mg} / \mathrm{kg}$ bodyweight, Pohl Boskamp). 


\section{Immunohistochemistry}

Four hours after the placebo/NTG injection, the rats were perfused transcardially. The upper cervical spinal cord (C1-C2) segments of the cervical spinal cord between (-5) and (-11) mm from the obex were removed and postfixed overnight for immunohistochemistry in the same fixative. After cryoprotection, $30 \mu \mathrm{m}$ cryostat sections were cut and serially collected in wells containing cold phosphate-buffered saline (PBS). The free-floating sections were rinsed in PBS and immersed in $0.3 \% \mathrm{H}_{2} \mathrm{O}_{2}$ in methanol or PBS for 30 minutes. After several rinses in PBS containing 1\% Triton X-100, sections of C1-C2 were kept overnight at room temperature in anti-TRPV1 antibody (Santa Cruz, s.c.28759) at a dilution of 1:500, or for two nights at 4 ${ }^{\circ} \mathrm{C}$ in anti-nNOS antibody (EuroProxima, 2263B220-1) at a dilution of 1:5000, or for two nights at $4{ }^{\circ} \mathrm{C}$ in anti- NF- $\mathrm{B}$ antibody (Abcam, ab97726) at a dilution of 1:100. The immunohistochemical reaction was visualized by the Vectastain avidin-biotin kit of Vector Laboratories (PK6101), and nickel ammonium sulphate-intensified 3,3'-diaminobenzidine. The specificity of the immune reaction was controlled by omitting the primary antisera.

\section{Western blot analysis}

Four hours after the placebo/NTG injection, the animals were perfused transcardially with $100 \mathrm{~mL}$ PBS and the dorsal horns of C1-C2 and TNC between 1 and (-5) mm from the obex segments were extracted. Until the measurements, they were stored at $-80{ }^{\circ} \mathrm{C}$. The samples were sonicated in ice cold lysis buffer containing $50 \mathrm{mM}$ Tris- $\mathrm{HCl}, 150 \mathrm{mM} \mathrm{NaCl}, 0.1 \%$ igepal, $0.1 \%$ cholic acid, $2 \mu \mathrm{g} / \mathrm{mL}$ leupeptin, $2 \mathrm{mM}$ phenylmethylsulphonyl fluoride, $1 \mu \mathrm{g} / \mathrm{mL}$ pepstatin, $2 \mathrm{mM}$ EDTA and $0.1 \%$ sodium dodecyl sulphate. The lysates were centrifuged at 12000 RPM for 10 minutes at $4{ }^{\circ} \mathrm{C}$ and supernatants were aliquoted and stored at $-20{ }^{\circ} \mathrm{C}$ until use. Protein concentration was determined with BCA Protein Assay Kit using bovine serum albumin as a standard. Previous to loading, each sample was mixed with sample buffer, and denaturated by boiling for 3 minutes. Equal amounts of protein samples ( $20 \mu \mathrm{g} / \mathrm{lane})$ were separated by standard SDS polyacrylamide gel electrophoresis on 10\% Tris-Glycine gel and electrotransferred onto Amersham Hybond-ECL nitrocellulose membrane $(0.45 \mu \mathrm{m}$ pore size). We used the Page Ruler Prestained Protein Ladder (10-170 kDa) to define approximate molecular weights. Following the transfer, membranes were blocked for one hour at room temperature in Tris-buffered saline containing Tween 20 (TBST) and 5\% non fat dry milk powder. Then, they were incubated in TBST containing $1 \%$ non fat dry milk and nNOS 
antibody (BD Biosciences, 610308, dilution: 1:2000, incubation: overnight at room temperature), or COX-2 antibody (Proteintech, 12375-1-AP, dilution: 1:1000, incubation: overnight at room temperature), or $\beta$-actin antibody (Calbiochem, CP01, dilution: 1:100 000, incubation: overnight at room temperature) or TDO2 antibody (LifeSpan BioSciences, LSC111058, dilution: 1:500, incubation: overnight at room temperature), or IDO1 antibody (Abcam, ab106134, dilution: 1:500, incubation: overnight at room temperature), or KAT-II antibody (Santa Cruz, sc-67376, dilution: 1:10 000, incubation: overnight at room temperature) or KYNU antibody (Abcam, ab96365, dilution: 1:500, incubation: overnight at room temperature) or KMO antibody (Abcam, ab83929, dilution: 1:4000, incubation: overnight at room temperature) or glyceraldehyde 3-phosphate dehydrogenase (GAPDH) antibody (Cell Signaling Technologies, 8884, dilution: 1:1000, incubation: overnight at room temperature). Next day, membranes were incubated in TBST containing $1 \%$ non fat dry milk and horseradish peroxidase-conjugated anti-rabbit or anti-mouse secondary antibody (Santa Cruz Biotechnology, sc-2030, sc-2031) for two hours at room temperature. Protein bands were visualized after incubation of membranes with the SuperSignal West Pico Chemiluminescent Substrate using Carestream Kodak BioMax Light film.

\section{Data evaluation}

All evaluations were implemented by an observer blind to the experimental groups. The detailed methods were described previously (Gundersen et al., 1988; Vamos et al., 2010; Vamos et al., 2009).

\section{a. Immunohistochemistry (TRPV1, nNOS, NF-кB)}

The photomicrographs of the stained sections of C1-C2 were taken using Zeiss AxioImager microscope supplied with an AxioCam MRc Rev.3 camera (Carl Zeiss Microscopy, Jena, Germany).

The area covered by TRPV1-immunoreactive fibres and nNOS-immunoreactive cells was determined by Image Pro Plus 6.2® image analysis software (Media Cybernetics). After image acquisition, the laminae I-II in dorsal horn were defined manually as area of interest and a threshold grey level was validated with the image analysis software, as described in an earlier study (Fejes-Szabo et al., 2014b; Vamos et al., 2010). The program calculated the area innervated by the immunoreactive fibres and cells as the number of pixels with densities 
above the threshold, the data were expressed as area fractions (\%) of the corresponding immunolabelled structures.

We used the unbiased optical dissector method to calculate the volume densities of the NFкB-immunoreactive cells (Gundersen et al., 1988).

\section{b. Western blot analysis (nNOS, COX-2, TDO2, IDO1, KAT-II, KYNU, KMO)}

For densitometric analyses, films were scanned and quantified using Java ImageJ $1.47 \mathrm{v}$ analysis software (National Institutes of Health). The results were normalized to $\beta$-actin or GAPDH. In the case of nNOS, COX-2 and KAT-II, we used the C1-C2 segments of the animals, but in TDO, IDO, KYNU and KMO Western blots, we used TNC segments for the examinations.

\section{Statistical analysis}

Statistical analysis of measurements were performed in SPSS Statistics software (Version 20.0 for Windows, SPSS Inc.) using one-way analysis of variance (ANOVA) followed by the Tukey or Tamhane or Fishers Least Significant Difference post hoc test depending on variances of data, with $\mathrm{P}<0.05$ taken as statistically significant. Group values are reported as means \pm SEM. 


\section{Results}

\section{NTG induced an increase in TRPV1 expression in the C1-C2 - AEA inhibited this}

\section{phenomenon}

On transverse sections of the C1-C2 segments, there were abundant TRPV1-positive fibres in the superficial layers of the dorsal horn. The TRPV1-immunoreactive area in the NTG-treated group was significantly higher compared to the placebo-treated group $(\mathrm{p}<0.05)$. The NTGinduced increase was attenuated by treatment with AEA $(p<0.05)$. (Figure 2.)
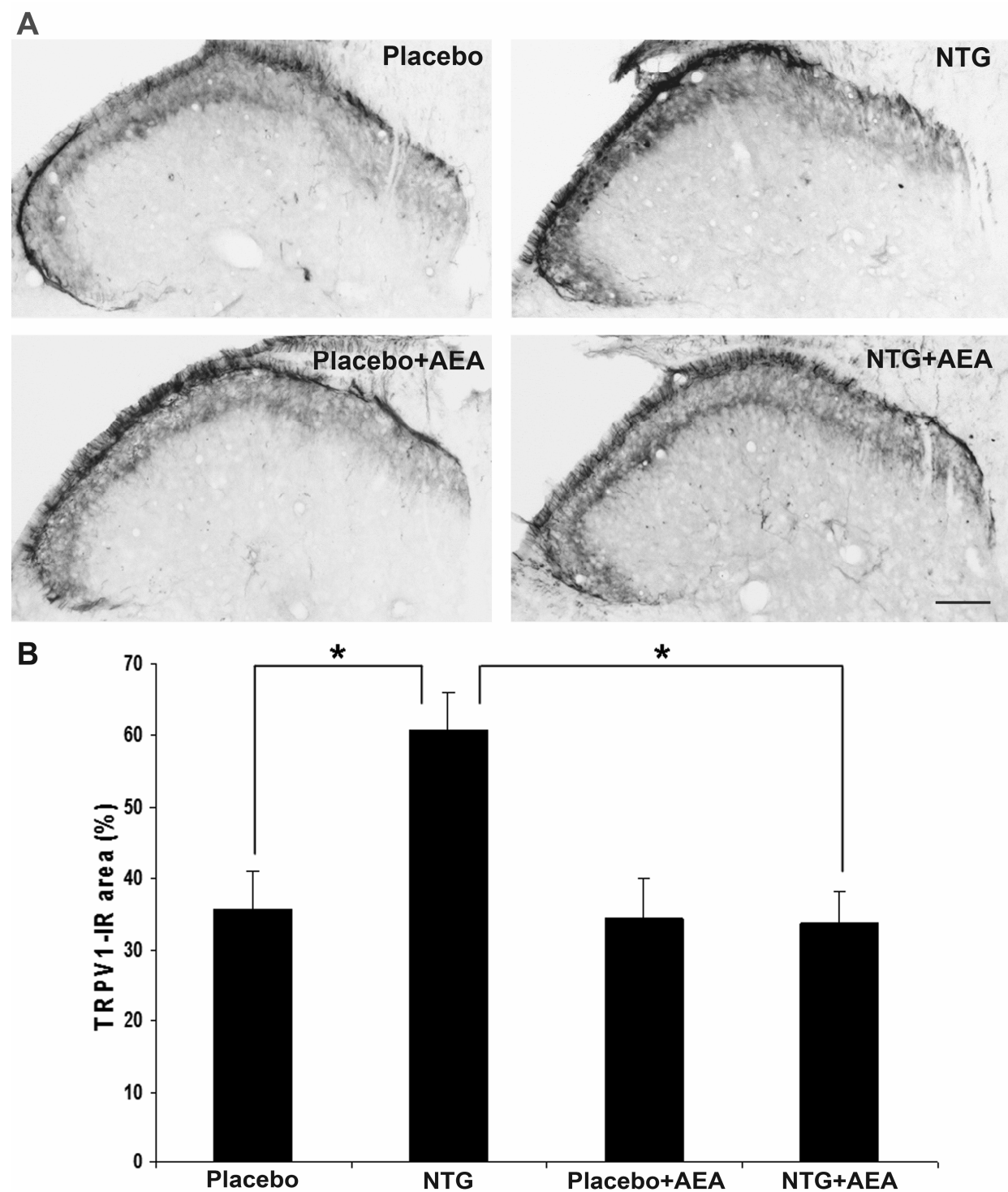

Figure 2. A. Representative photomicrographs of the TRPV1 expression in the $\mathrm{C} 1-\mathrm{C} 2$ segments. $\mathrm{B}$. Changes in area fractions of TRPV1-immunoreactive fibers in superficial laminae I and II of the C1-C2 segments. In the NTG group, the area covered by TRPV1 was significantly higher than in the placebo group. AEA seemed to block this effect. Scale bar: $100 \mu \mathrm{m},{ }^{*} \mathrm{p}<0.05$; AEA: anandamide, $\mathrm{C} 1-\mathrm{C} 2$ : upper cervical spinal cord, NTG: nitroglycerin, TRPV1-IR: transient receptor potential vanilloid 1 immunoreactive 


\section{NTG increased $n N O S$ expression in the C1-C2 and AEA attenuated this effect}

On transverse sections of the C1-C2 segments, nNOS-immunoreactive neurons and processes with cytoplasmic staining can be observed in the superficial layers of the dorsal horn. In the NTG group, the area fraction of nNOS-immunoreactive structures was significantly higher than in the placebo-treated group $(\mathrm{p}<0.01)$. AEA treatment resulted in a decrease of nNOS-immunopositive structures $(\mathrm{p}<0.001)$. (Figure 3.)

A
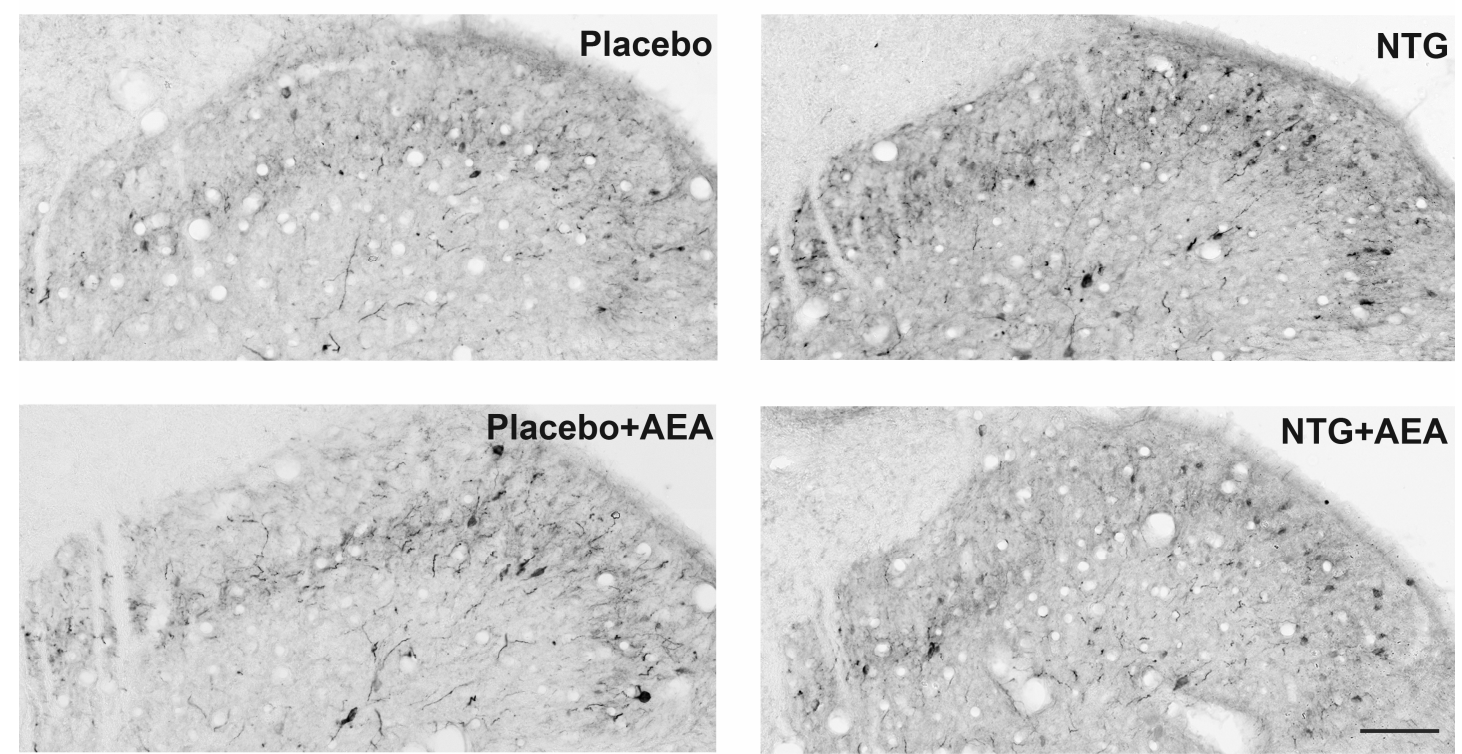

B

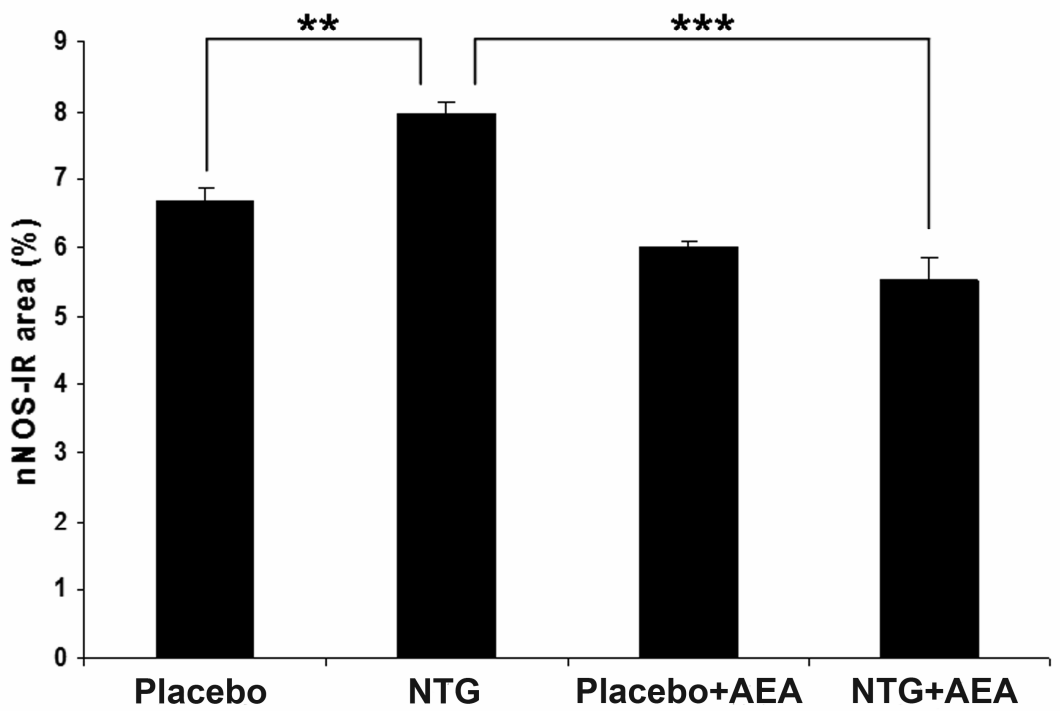

Figure 3. A. Representative photomicrographs of nNOS expression in the C1-C2 segments. B. Changes in the nNOS-immunoreactive area fractions. In the NTG group, the area fraction of nNOS-IR structures was increased compared to the placebo-treated group. AEA was able to attenuate this effect. Scale bar: $100 \mu \mathrm{m}, * * \mathrm{p}<0.01$; $* * * \mathrm{p}<0.001$; AEA: anandamide, C1-C2: upper cervical spinal cord, nNOS-IR: neuronal nitric oxide synthase immunoreactive, NTG: nitroglycerin 
Western blot analysis of the C1-C2 region confirmed the results obtained by nNOS immunohistochemistry. A band characteristic of the nNOS protein was identified at $155 \mathrm{kDa}$. Densitometric analyses confirmed that the nNOS bands were significantly enhanced $(p<0.01)$ in C1-C2 after NTG administration as compared with the placebo-treated animals. This effect was blocked by the treatment with AEA $(p<0.05)$. (Figure 4.)

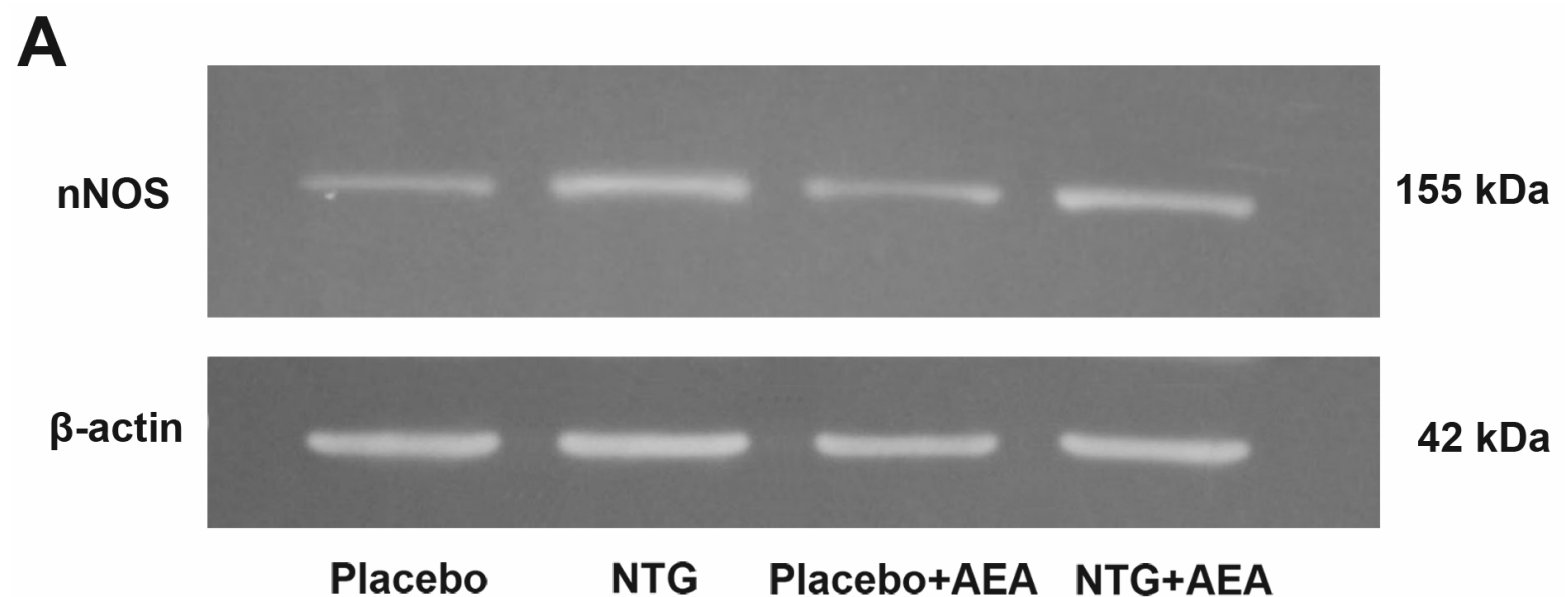

B



Figure 4. A. Western blot of nNOS and $\beta$-actin expression in the $\mathrm{C} 1-\mathrm{C} 2$. B. The quantitative analysis shows that in the NTG group, the relative optical density of nNOS specific band was significantly higher than in the placebo group. AEA treatment weakened this effect. ${ }^{*} \mathrm{p}<0.05 ;{ }^{*} \mathrm{p}<0.001$ AEA: anandamide, C1-C2: upper cervical spinal cord, NTG: nitroglycerin 


\section{NTG treatment enhanced NF-KB expression and AEA mitigated this phenomenon}

In transverse sections of the $\mathrm{C} 1-\mathrm{C} 2$ region, high number of $\mathrm{NF}-\mathrm{\kappa B}$-positive cells can be seen in the superficial layers of the dorsal horn. In the NTG treated animals the volume density of NF- $\kappa$ B-positive cells was significantly higher than in the placebo group $(p<0.05)$. This value decreased in the AEA injected group $(\mathrm{p}<0.05)$. (Figure 5.)
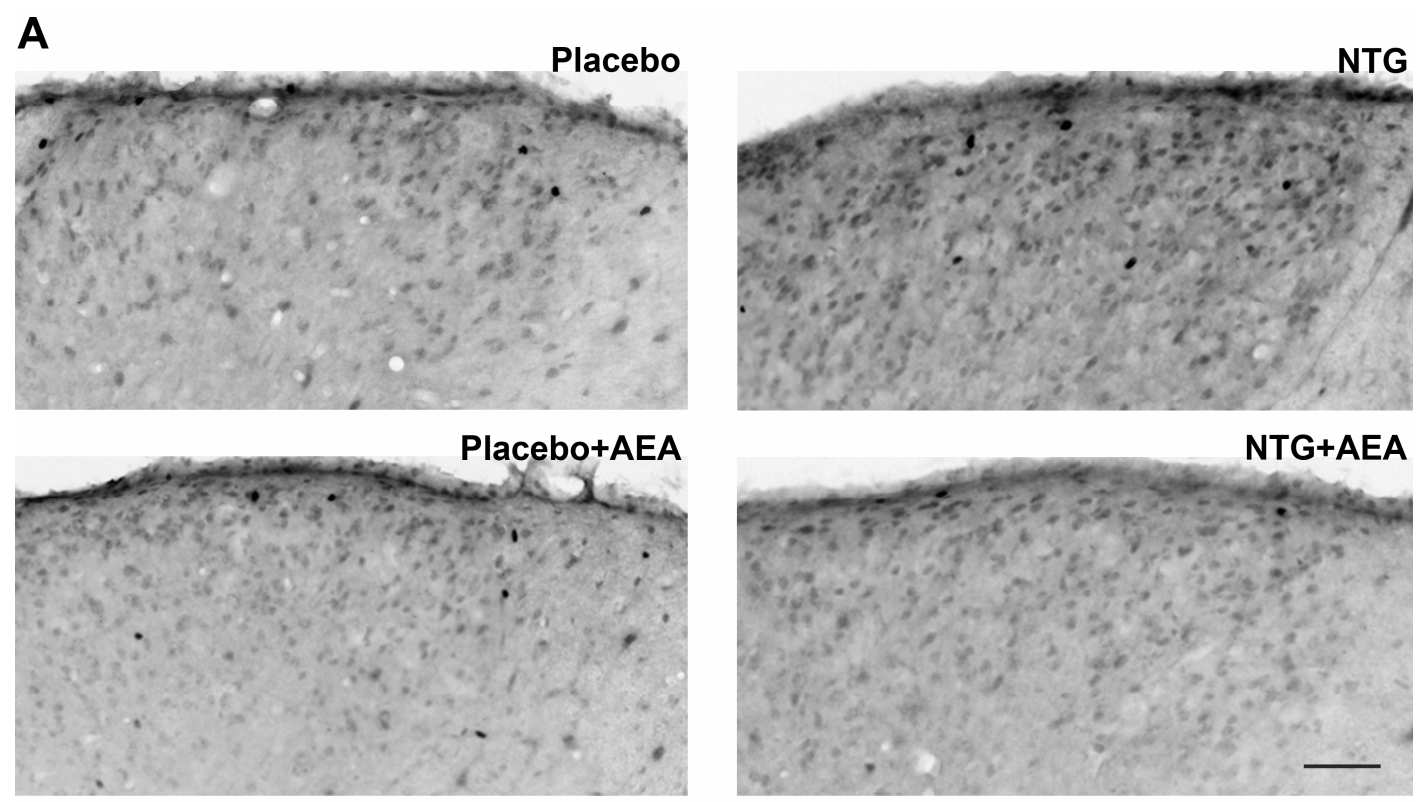

B

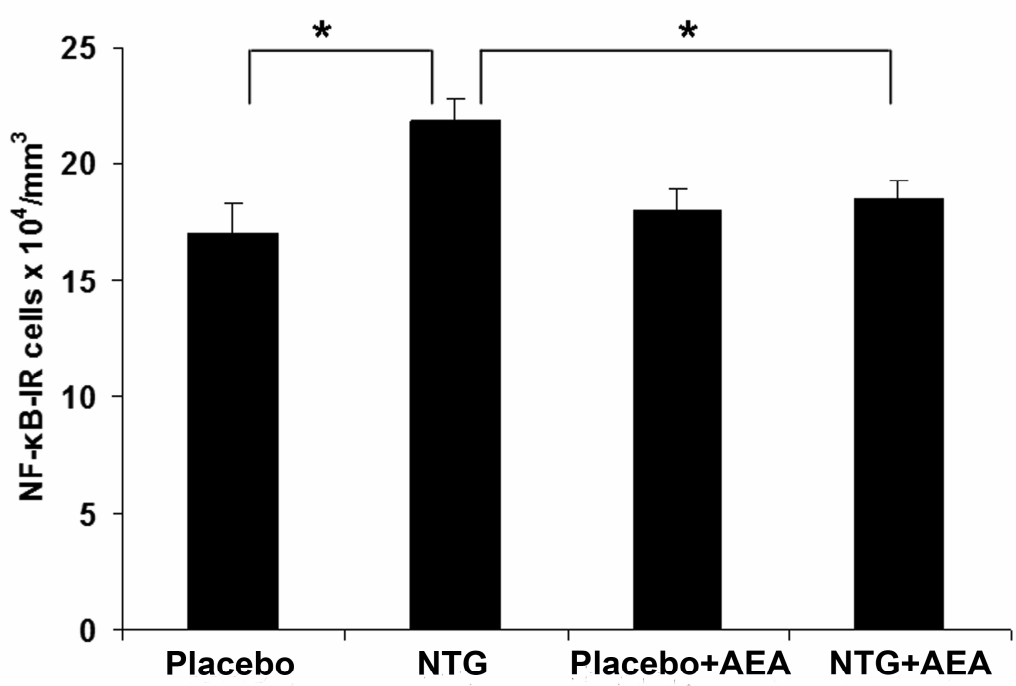

Figure 5. A. Photomicrographs of the NF- $\mathrm{kB}$ expression in the C1-C2 segment. B. Diagram shows that NTG treatment resulted in a significant increase in the volume density of NF-kB-immunoreactive cells. This effect was not observed in AEA-injected animals. Scale bar: $50 \mu \mathrm{m},{ }^{*} \mathrm{p}<0.05$, AEA: anandamide, C1-C2: upper cervical spinal cord, NF-kB-IR: nuclear factor kappa B-immunoreactive, NTG: nitroglycerin 


\section{NTG enhanced expression of COX-2 enzyme and AEA inhibited this action}

A band characteristic of the COX-2 protein was identified at $68 \mathrm{kDa}$ in Western blot assay. Densitometric analyses showed that the COX-2 bands were significantly enhanced $(\mathrm{P}<0.01)$ in segments $\mathrm{C} 1-\mathrm{C} 2$ after NTG administration as compared with the placebo-treated animals. The effect of NTG was decreased by the AEA treatment $(p<0.01)$. (Figure 6.)

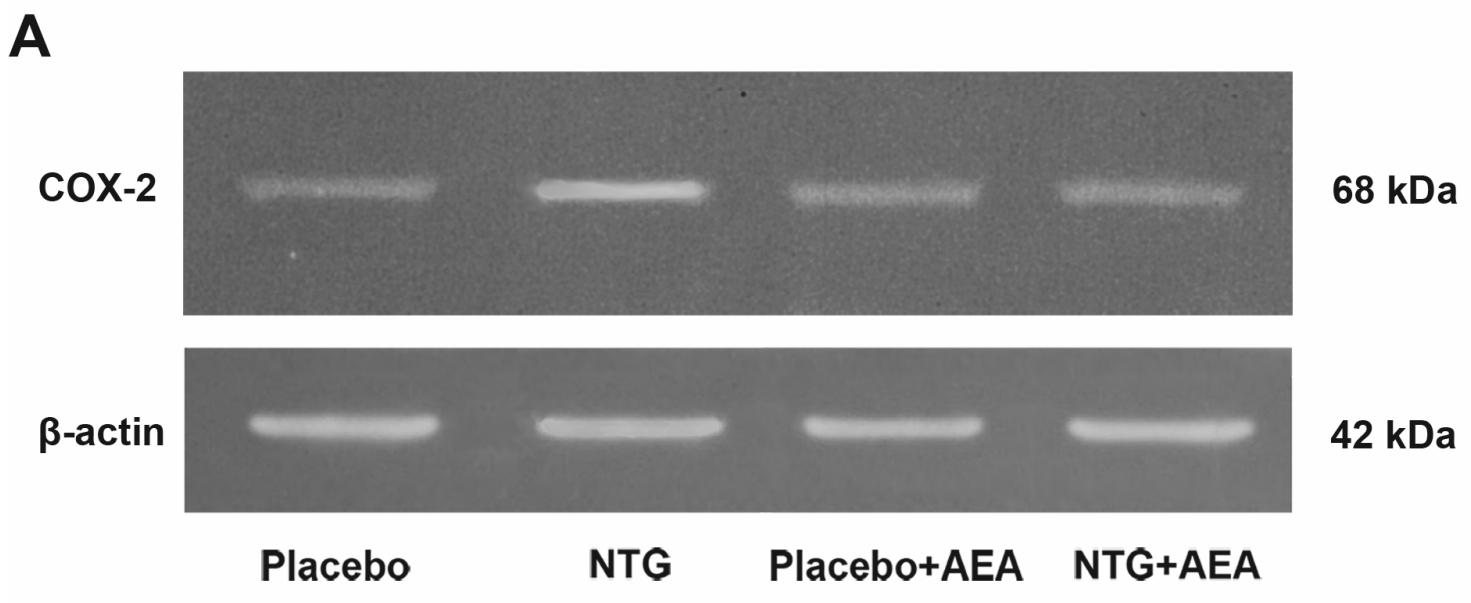

B

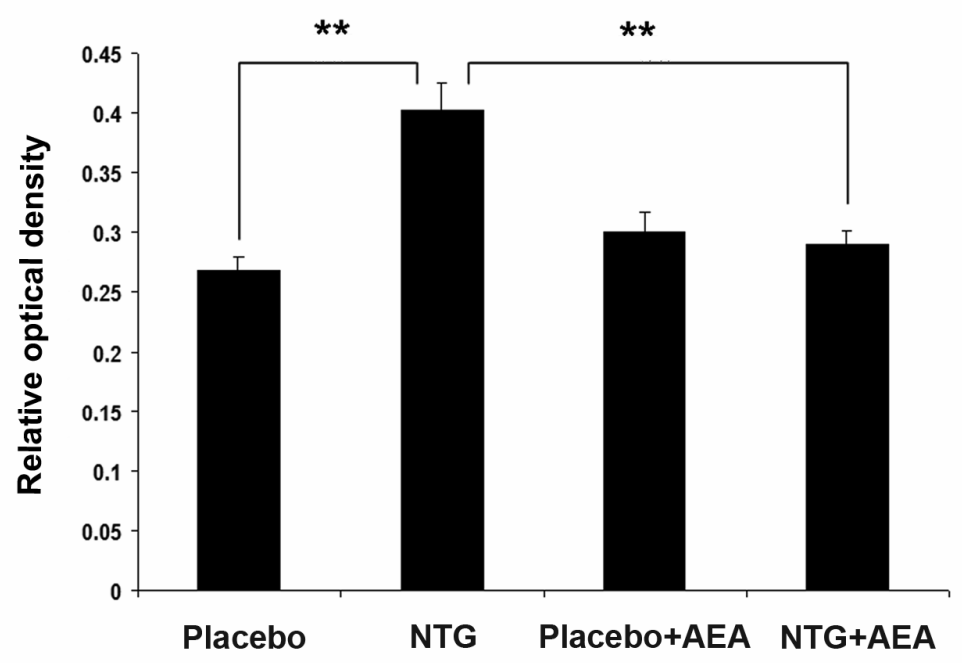

Figure 6. A. Western blot of COX-2 and $\beta$-actin expression in the $\mathrm{C} 1-\mathrm{C} 2$. B. Densitometry of the individual bands indicated that in the NTG-treated animals the expression of COX-2 was significantly higher than in the placebo group. No such effect was seen in the AEA-injected group. ${ }^{*}$ p $<0.01$; AEA: anandamide, C1-C2: upper cervical spinal cord, COX-2: cyclooxygenase-2, NTG: nitroglycerin 


\section{$V$. NTG induced a decrease in TDO2 expression}

A band characteristic of the TDO2 protein was identified at $50 \mathrm{kDa}$ in Western blot assay.

Densitometric analyses showed that the TDO2 bands were significantly decreased $(p<0.05)$ in the TNC after NTG administration as compared with the placebo-treated animals. (Figure 7.)
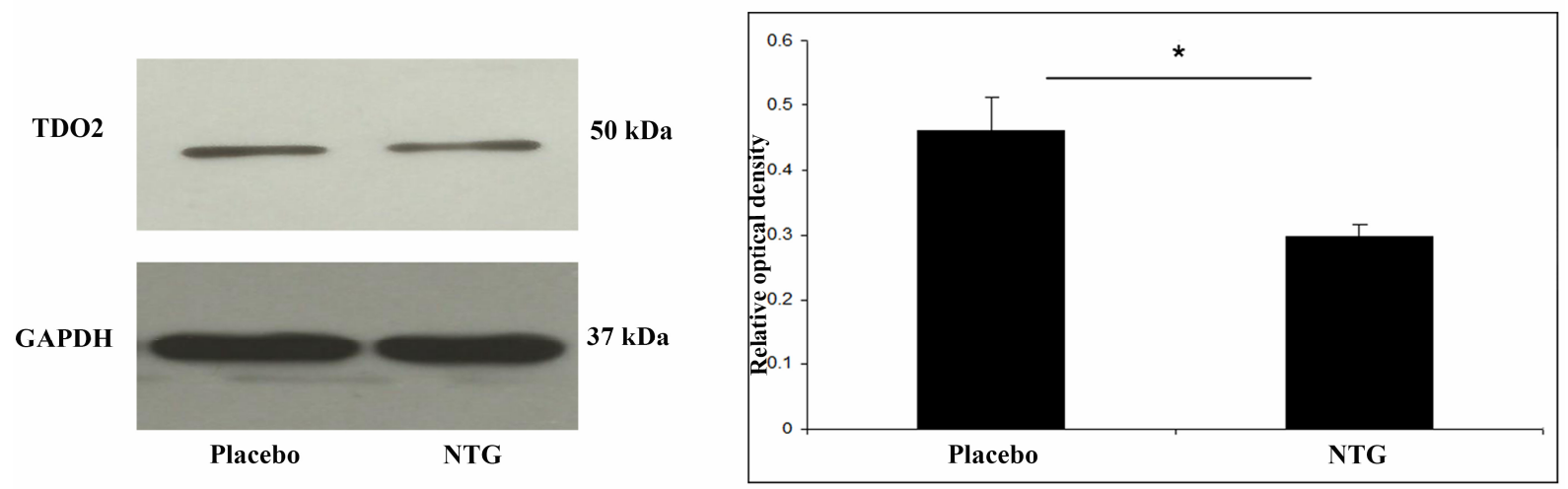

Figure 7. Western blot analysis of TDO2 and GAPDH protein from the TNC. The quantitative analysis shows that in the NTG group the relative optical density of TDO2 specific bands were significantly less pronounced compared with the placebo group. ${ }^{*} p<0.05$; GAPDH: glyceraldehyde 3-phosphate dehydrogenase, NTG: nitroglycerin, TDO2: tryptophan 2,3-dioxygenase 2, TNC: caudal trigeminal nucleus 


\section{NTG treatment resulted in a diminished IDO1 expression}

A band characteristic of the IDO1 protein was referred at $45 \mathrm{kDa}$ in Western blot assay. Densitometric analyses confirmed that the IDO1 bands were significantly weaker $(\mathrm{p}<0.05)$ in the TNC after NTG administration as compared with the placebo-treated animals. (Figure 8.)
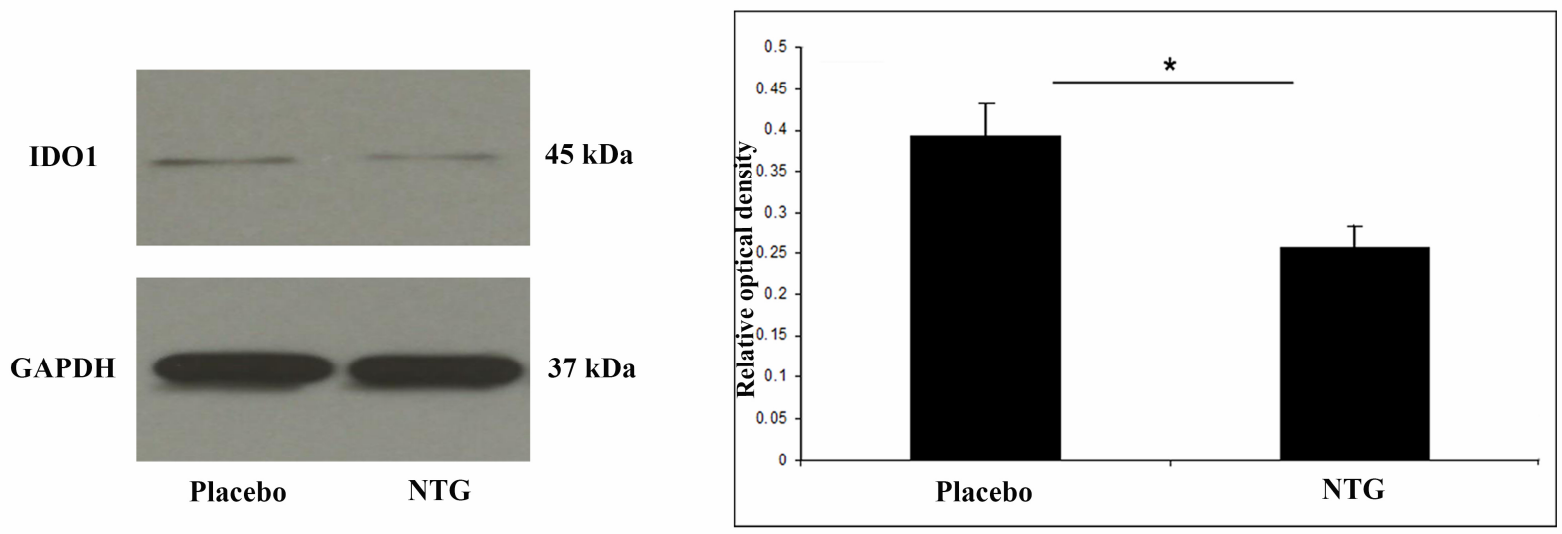

Figure 8. Western blot of IDO1 and GAPDH expression in the TNC. The quantitative analysis shows that in the NTG group, the relative optical density of IDO1 specific bands was significantly decreased compared with the placebo group. ${ }^{*}$ p $<0.05$; GAPDH: glyceraldehyde 3-phosphate dehydrogenase, IDO1: indoleamine 2,3dioxygenase, NTG: nitroglycerin, TNC: caudal trigeminal nucleus 


\section{NTG decreased KAT-II expression}

A band characteristic of the KAT-II protein was referred at $60 \mathrm{kDa}$ in Western blot assay. Densitometric analyses confirmed that the KAT-II bands were significantly weaker $(p<0.05)$ in segments C1-C2 after NTG administration as compared with the placebo-treated animals. (Figure 9.)
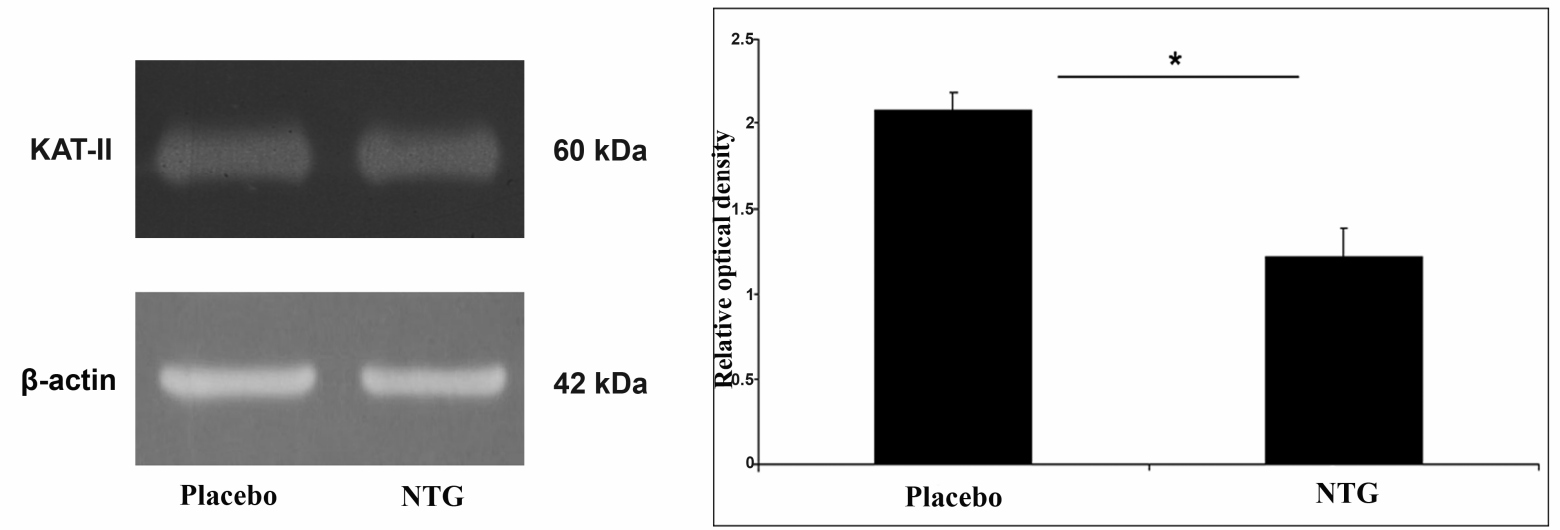

Figure 9. Western blot of KAT-II and $\beta$-actin expression in the C1-C2. Quantitative data demonstrate that in the NTG group, the relative optical density of KAT-II is significantly lower than in the placebo group. ${ }^{*} \mathrm{p}<0.05$; C1C2: upper cervical spinal cord, KAT-II: kynurenine-aminotransferase-II, NTG: nitroglycerin 
VIII. NTG was able to reduce the expression of $K Y N U$

We could identify a band at $35 \mathrm{kDa}$ characteristic for the KYNU protein. In animals, which had received NTG, the density of KYNU protein bands was weaker in TNC segments $(\mathrm{p}<$ 0.05 ) as compared with the placebo-treated group. (Figure 10.)
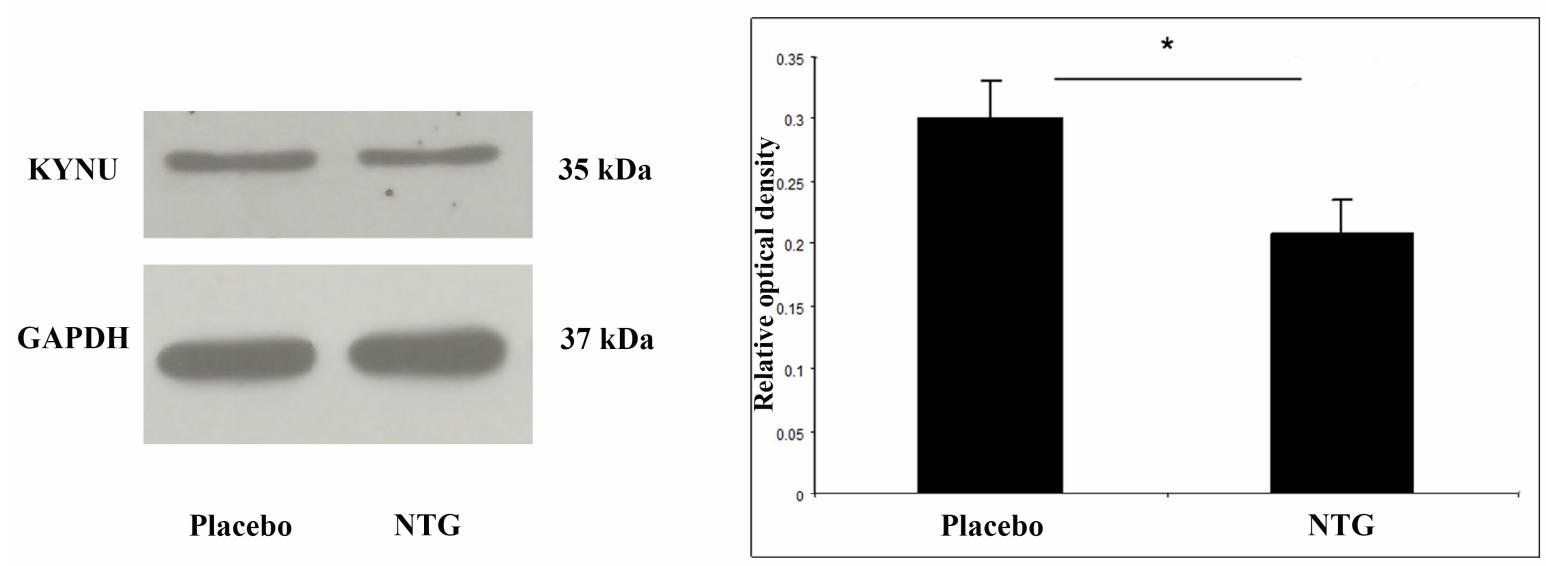

Figure 10. Representative Western blot bands and diagram of KYNU and GAPDH in the TNC. The quantitative analysis shows that in the NTG group, the relative optical density of KYNU specific bands were significantly smaller compared with the placebo group. ${ }^{*} p<0.05$; GAPDH: glyceraldehyde 3-phosphate dehydrogenase, KYNU: kynurenine hydrolase, NTG: nitroglycerin, TNC: caudal trigeminal nucleus 


\section{KMO expression was lower after NTG administration}

A band characteristic of the KMO protein was identified at $56 \mathrm{kDa}$ in Western blot assay. Densitometric analyses showed that the KMO bands were significantly decreased $(p<0.05)$ in segments TNC after NTG administration as compared with the placebo-treated animals. (Figure 11.)


Figure 11. Illustrative Western blot bands and diagram of KMO and GAPDH in the TNC. The quantitative analysis shows that in the NTG group, the relative optical density of KMO specific bands was significantly weaker compared with the placebo group. ${ }^{*} \mathrm{p}<0.05>$ GAPDH: glyceraldehyde 3-phosphate dehydrogenase, KMO: L-kynurenine 3-monooxygenase, NTG: nitroglycerin, TNC: caudal trigeminal nucleus 


\section{Discussion}

\section{Experiments with the sensitization markers}

TRPV1 is present in the terminals of primary sensory neurons in the dorsal part of spinal cord (Valtschanoff et al., 2001) and co-expressed with CB1 (Morisset et al., 2001). Experimental data indicate that TRPV1 contributes to peripheral sensitization, allodynia and hyperalgesia (Saloman et al., 2013), central blockade of this receptor is able to attenuate central terminal sensitization (Kim et al., 2014). Our results show that NTG significantly increases TRPV1 expression in the $\mathrm{C} 1-\mathrm{C} 2$ segments of the rat, thus it may be the indicator of sensitization phenomena in the trigeminal system in our experimental setting.

It is well established that NO donors can activate TRPV1 in several cell types (Leonelli et al., 2013; Miyamoto et al., 2009) and in inflammatory pain models increased receptor expression was also reported (Ji et al., 2002; Kao et al., 2012). This indicates that the NTG effect on TRPV1 expression is indirect - it may cause neurogenic inflammation (Reuter et al., 2001), and the inflammatory mediators - like serotonin, bradykinin, etc. - can activate TRPV1 by stimulating trigeminal nociceptive neurons (Strassman et al., 1996). Pro-inflammatory mediators, such as tumor necrosis factor $\alpha$, interleukin 1 (IL-1), interleukin 6 (IL-6) and bradykinin enhance TRPV1 (Malek et al., 2015). In the animal model of inflammation, Complete Freud's adjuvant increases TRPV1 mRNA expression in the dorsal root ganglion (Amaya et al., 2003), this also supports the idea that inflammation upregulates TRPV1 expression. To summarize, we may assume that NTG is able to activate TRPV1 mainly via inflammatory mediators. On the other hand, there are research data indicating that systemic administration of CGRP increases the expression of TRPV1 in the TG of rats (Chatchaisak et al., 2013), which might also play a role in this process. NTG can increase the release of CGRP by NO-mediated stimulation of $\mathrm{A} \delta$ and $\mathrm{C}$ fibers (Pardutz et al., 2002).

Our recent data also show that AEA, a CB receptor and TRPV1 agonist attenuates the effect of NTG on TRPV1 changes. Activation of ionotropic CBs can result in inhibition of nociceptors and antihyperalgesia and antinociception in certain pain models (Akopian et al., 2009). Intrathecal administration of AEA decreases thermal pain sensitivity and its effect can be altered with the TRPV1 antagonist capsazepine (Horvath et al., 2008). AEA may also 
cause a desensitization of TRPV1 in skeletal muscle arterioles (Lizanecz et al., 2006), suggesting that AEA is able to mitigate TRPV1 activity. On the other hand, AEA can inhibit neurogenic, CGRP- and NO-induced dural vasodilatation, and this involves pre- and postsynaptic mechanisms (Akerman et al., 2004b). Recent report shows that the AEA level changes are able to modulate CGRP mRNA-expression after NTG-treatment in human peripheral blood mononuclear cells (Peng et al., 2014). We do not know exactly the role of TRPV1 in the AEA modulated sensitization process, but based on the available literature data (Akerman et al., 2007; Akerman et al., 2004a), we hypothesize that the role of CB1 is more pronounced than TRPV1 in this context.

It is known that nNOS is a key player in nociception (Lin et al., 1999) and its role in the sensitization cascade is intensively studied. In our present experiment administration of NTG increased the expression of nNOS in the $\mathrm{C} 1-\mathrm{C} 2$, which is in line with earlier results (Pardutz et al., 2000). The most probable explanation for this phenomenon is, that NO activates small caliber fibres in the trigeminal system and the increase of nNOS expression in the second order trigeminal neurons induces a self-amplifying mechanism (Pardutz et al., 2000; Tassorelli et al., 1997). The present results indicate that AEA is able to inhibit this effect. Several studies have shown that there is an interaction between NO and cannabinoid system e.g. nNOS and CB1 are co-localized in neurons in lamina II of the spinal cord (Salio et al., 2002). NTG-induced hyperalgesia is associated with a fluctuation of the activity of endocannabinoid system in various brain areas of rats (Greco et al., 2010). Our data are in line with Hillard and co-workers findings, who reported that CB1 agonists inhibit KCl-induced activation of nNOS in cultured cerebellar granule cells (Hillard et al., 1999). In addition, Carney and co-workers have detected that cannabinoid agonist downregulated nNOS protein and mRNA in neuronal cells (Carney et al., 2009). These data suggest that NTG is able to generate sensitization process and AEA inhibits this effect by blocking nNOS.

In our experiment NTG increased NF- $\mathrm{BB}$ expression in the superficial layers of the dorsal horn in the C1-C2 segments. Similar effect was reported by Reuter et al., who demonstrated that NTG infusion is able to trigger the activation of NF- $\mathrm{KB}$ in dura mater (Reuter et al., 2002). It is not clear how NTG can activate NF- $\mathrm{KB}$-pathway, it might be related to a direct neuronal effect of NTG, or indirect effect via dural inflammation (Greco et al., 2005). Concerning the cellular mechanisms, it is important to note that both TRPV1 and nNOS 
might play a role in this effect. It was shown that $\mathrm{Ca}^{2+}$ influx through TRPV1 may modulate the nuclear translocation and increased the activity of NF-kB (Sappington and Calkins, 2008). On the other hand the increase in nNOS expression is accompanied by increased NF- $\kappa \mathrm{B}$ expression and activation (Parahova, 2009). Furthermore, Sancho and colleagues have noticed that AEA inhibits tumor necrosis factor- $\alpha$-induced activation, by inhibition of a cytokineinduced cascade (Sancho et al., 2003). In addition, Nakajima and co-workers have found that AEA also blocked lipopolysaccharide-induced activation, suggesting that AEA inhibits proinflammatory mediators by blocking NF- $\kappa$ B activation (Nakajima et al., 2006). Tassorelli and her group reported that parthenolide (inhibitor of NF- $\mathrm{kB}$ ) attenuated NTG-induced c-Fos activation in TNC (Tassorelli et al., 2005), which indicates that NF- $\mathrm{KB}$ may be important in the NTG-induced trigeminal activation and its inhibition is able to modulate the nociceptive process. Our data reconfirm, that NTG is able to activate $\mathrm{NF}-\kappa \mathrm{B}$, thus can trigger neurogenic inflammation, which has a key role in sensitization phenomena. Furthermore, we detected that AEA is able to reduce this effect. Endocannabinoids might operate a negative feedback control over the proinflammatory process by suppressing the activation of transcription factors involved in the inflammatory action (Berdyshev et al., 2001).

NO may also cause neurogenic inflammation by increasing NF- $\kappa B$ levels, which may lead to the upregulation of COX-2 in inflammatory pain (Lee et al., 2004). It is well-known, that NSAIDs, which exert their effects through the inhibition of COX-enzymes (Yaksh et al., 2001), are effective in the treatment of migraine and tension-type headache (Lange et al., 2000). In animal studies, it has been shown that COX-2 is involved in the NTG-induced activation and sensitization process of the trigeminal system. Pre-treatment with indomethacin (non-selective COX inhibitor) and NS398 (selective COX-2 inhibitor) reduced the NTGinduced c-Fos (Tassorelli et al., 1997), nNOS and calmodulin-dependent protein kinase II alpha expression-changes in the TNC (Varga et al., 2009; Varga et al., 2007). Tassorelli and colleagues have demonstrated that COX-2 expression is increased in the hypothalamus and caudal brain stem after NTG injection (Tassorelli et al., 2007), thus COX is one of the mediators of NTG-induced neuronal activation. Furthermore, NO is able to activate COXenzymes in fibroblasts, probably by an interaction with the iron-hem center of the enzyme (Salvemini et al., 1993). It is important to note, that AEA is one of the substrates of COX-2 producing prostaglandin and ethanolamids (Yu et al., 1997). In our study, we have found that 
AEA is able to inhibit the NTG-induced COX-2 increase. Our assumption is that it may be associated with a negative feedback mechanism, but it is possible that after the cleavage of AEA some metabolites may downregulate COX-2 expression. Since AEA is able to reduce cytokine-induced cascade and proinflammatory mediators (Nakajima et al., 2006), it is also possible, that the reduction of the inflammatory process is able to downregulate the $\mathrm{COX}-2$ expression.

\section{Studies of the Kynurenine pathway}

In our experiments NTG decreased the expression of the kynurenine pathway in the TNC and C1-C2 segments, which may indicate that fluctuation of these enzymes is involved in the NTG-triggered trigeminal activation. However, the question arises how NTG $/ \mathrm{NO}$ can influence the kynurenine pathway. It is well-known that the nitrergic-system is able to alter the kynurenine system, e.g. NO inhibits IDO expression by reversible binding to the active site in macrophages (Thomas et al., 2007) and IDO activity is down-regulated by NO production in bone marrow cells (Hara et al., 2008). The other hand, it is also known that the expression of KMO influences NO production in human HEK293 cells (Wilson et al., 2016). Moreover, Backhaus and her colleagues showed in a mass spectrometry and NMR study that there is a direct interaction between kynurenine metabolites, e.g., 3-hydroxykynurenine and 3hydroxyanthranilic acid and NO (Backhaus et al., 2008).

It is also important to note that kynurenines have a crucial role in immune regulation (Mandi and Vecsei, 2012). The transcriptional expression of IDO, KAT-II, KMO, KYNU is also under the control of interferons (Mandi and Vecsei, 2012), thus pro-inflammatory cytokines influence kynurenine pathway (Hassanain et al., 1993). Lögters and co-workers have shown that the kynurenine-tryptophan ratio was increased in the blood of patients with posttraumatic sepsis (Logters et al., 2009), proving that inflammation could modulate the kynurenine pathway.

In this context, it is pivotal that NO may cause neurogenic inflammation in the central nervous system. This is supported by observations, that NTG was able to increase the expression of NF- $\kappa \mathrm{B}$ in the trigeminocervical complex of rats (Greco et al., 2005; NagyGrocz et al., 2016), which is a key player in the inflammation process controlled by cytokines. 
In human studies, Tfelt-Hansen and his group demonstrated that infusion of NTG can trigger inflammatory response by inducing inflammatory mediators, which response was inhibited by the anti-inflammatory drug, prednisolone (Tfelt-Hansen et al., 2009).

On the other hand migraine can be characterized by an increase in glutamatergic function (Vecsei et al., 2013), yielding fully activated NMDA receptors by the high glutamate levels, which might be associated with low KYNA levels. Increased glutamate levels were found in the human cerebrospinal fluid, plasma and platelets of migraineurs (Cananzi et al., 1995; Peres et al., 2004).

Our findings are comparable with recent studies, which showed that chronic migraine and cluster headache are associated with altered levels of kynurenine metabolites, i.e., reduced levels of KYNA and L-KYN has been found in the serum of these patients (Curto et al., 2015a; Curto et al., 2015b). These findings are in accordance with the context of an increased release of glutamate might yielding to a hyperactivity of glutamate receptors.

To summarize the human and animal data, we can conclude that the kynurenine pathway is down-regulated under the different types of headaches and thus possibly providing less KYNA. These data are in line with the theory of hyperactive NMDA receptors having a role in the migraine pathophysiology since these receptors are key players in the mechanism of central sensitization (Sarchielli et al., 2007) and CSD (Pietrobon and Moskowitz, 2014). 


\section{Conclusion}

The present data indicate that (i) NTG treatment activates the trigeminal system and the observed changes can be interpreted as a central sensitization phenomenon. Furthermore, (ii) NTG induced alterations are reversed by the administration of AEA suggesting the involvement of CBs in this process. Item, (iii) NTG is able to down-regulate the kynurenine pathway, with a potential influence on the glutamatergic system as well, contributing to the development of trigeminal activation and sensitization in animals.

These data suggest that the endocannabinoid system plays a significant role in the cellular mechanism of trigeminal sensitization and thus it may modulate the pathomechanism of migraine. Our present data strongly confirm that the kynurenine system has a relevant role in the pathomechanism of the trigeminal activation and sensitization, thus in the migraine pathology, as well. In summary, influencing the kynurenine pathway provides a possible new target in the future therapy of migraine. 


\section{Acknowledgement}

First, I would like to express my sincere gratitude to my supervisor Dr. Árpád Párdutz for the endless support of my PhD study. His guidance helped me during my whole research activity including the preparation of manuscripts and this thesis. I greatly appreciate his mentoring and his trust in me.

My sincere thanks also goes to Professor László Vécsei for his invaluable advice and that he gave access to the laboratory and research facilities. He has greatly influenced me.

I am grateful to my closest colleagues in the lab Dr. Zsuzsanna Bohár and Dr. Annamária Fejes-Szabó for the stimulating discussions, their motivation, immense knowledge and for all the fun we have had during undergraduate and $\mathrm{PhD}$ years.

I would like to thank to the members of the Headache Research Group (especially Dr. Klaudia F. Laborc, Eleonóra Spekker, Dr. Délia Szok and Dr. János Tajti) for their advices.

In particular, I am indebted to Valéria Vékonyné Széll for histotechnical assistance and enlightening me with the beauty of laboratory work.

I am thankful to Dr. Dénes Zádori and Dr. Gábor Veres for their help.

My special thanks are due to Professor Éva Fekete and Professor József Toldi. They raised my interest in the field of anatomy and neurobiology.

I am very grateful to Dr. Mária Barnai, Dr. Katalin Jármay, Dr. Katalin Gábor, Dr. Gyöngyi Gunics and Dr. Gabriella Joó (Faculty of Health Sciences and Social Studies) for their support.

I also would like to express my heartfelt thanks to my parents, grand-parents, my sister and my brother for their love and support both financially and emotionally throughout my studies. I am very grateful and wish to thank my friends, most of all Andris, Lilla and Adrienn who are always besides me. 


\section{REFERENCES}

Afra, J., Proietti Cecchini, A., Sandor, P.S., Schoenen, J. (2000), Comparison of visual and auditory evoked cortical potentials in migraine patients between attacks. Clin Neurophysiol $111,1124-1129$.

Afridi, S., Kaube, H., Goadsby, P.J. (2005), Occipital activation in glyceryl trinitrate induced migraine with visual aura. J Neurol Neurosurg Psychiatry 76, 1158-1160.

Afridi, S.K., Kaube, H., Goadsby, P.J. (2004), Glyceryl trinitrate triggers premonitory symptoms in migraineurs. Pain 110, 675-680.

Akerman, S., Holland, P.R., Goadsby, P.J. (2007), Cannabinoid (CB1) receptor activation inhibits trigeminovascular neurons. J Pharmacol Exp Ther 320, 64-71.

Akerman, S., Kaube, H., Goadsby, P.J. (2004a), Anandamide acts as a vasodilator of dural blood vessels in vivo by activating TRPV1 receptors. Br J Pharmacol 142, 1354-1360.

Akerman, S., Kaube, H., Goadsby, P.J. (2004b), Anandamide is able to inhibit trigeminal neurons using an in vivo model of trigeminovascular-mediated nociception. J Pharmacol Exp Ther 309, 56-63.

Akopian, A.N., Ruparel, N.B., Jeske, N.A., Patwardhan, A., Hargreaves, K.M. (2009), Role of ionotropic cannabinoid receptors in peripheral antinociception and antihyperalgesia. Trends Pharmacol Sci 30, 79-84.

Amaya, F., Oh-hashi, K., Naruse, Y., Iijima, N., Ueda, M., Shimosato, G., Tominaga, M., Tanaka, Y., Tanaka, M. (2003), Local inflammation increases vanilloid receptor 1 expression within distinct subgroups of DRG neurons. Brain Res 963, 190-196.

Backhaus, C., Rahman, H., Scheffler, S., Laatsch, H., Hardeland, R. (2008), NO scavenging by 3-hydroxyanthranilic acid and 3-hydroxykynurenine: N-nitrosation leads via oxadiazoles to o-quinone diazides. Nitric Oxide 19, 237-244.

Bates, E.A., Nikai, T., Brennan, K.C., Fu, Y.H., Charles, A.C., Basbaum, A.I., Ptacek, L.J., Ahn, A.H. (2010), Sumatriptan alleviates nitroglycerin-induced mechanical and thermal allodynia in mice. Cephalalgia 30, 170-178.

Behan, W.M., McDonald, M., Darlington, L.G., Stone, T.W. (1999), Oxidative stress as a mechanism for quinolinic acid-induced hippocampal damage: protection by melatonin and deprenyl. Br J Pharmacol 128, 1754-1760.

Berdyshev, E.V., Schmid, P.C., Krebsbach, R.J., Schmid, H.H. (2001), Activation of PAF receptors results in enhanced synthesis of 2-arachidonoylglycerol (2-AG) in immune cells. FASEB J 15, 2171-2178. 
Bolay, H., Reuter, U., Dunn, A.K., Huang, Z., Boas, D.A., Moskowitz, M.A. (2002), Intrinsic brain activity triggers trigeminal meningeal afferents in a migraine model. Nat Med 8, 136142.

Borgelt, L.M., Franson, K.L., Nussbaum, A.M., Wang, G.S. (2013), The pharmacologic and clinical effects of medical cannabis. Pharmacotherapy 33, 195-209.

Burstein, R., Collins, B., Jakubowski, M. (2004), Defeating migraine pain with triptans: a race against the development of cutaneous allodynia. Ann Neurol 55, 19-26.

Burstein, R., Jakubowski, M., Rauch, S.D. (2011), The science of migraine. J Vestib Res 21, 305-314.

Burstein, R., Yarnitsky, D., Goor-Aryeh, I., Ransil, B.J., Bajwa, Z.H. (2000), An association between migraine and cutaneous allodynia. Ann Neurol 47, 614-624.

Cananzi, A.R., D'Andrea, G., Perini, F., Zamberlan, F., Welch, K.M. (1995), Platelet and plasma levels of glutamate and glutamine in migraine with and without aura. Cephalalgia 15, $132-135$.

Carney, S.T., Lloyd, M.L., MacKinnon, S.E., Newton, D.C., Jones, J.D., Howlett, A.C., Norford, D.C. (2009), Cannabinoid regulation of nitric oxide synthase I (nNOS) in neuronal cells. J Neuroimmune Pharmacol 4, 338-349.

Caterina, M.J., Rosen, T.A., Tominaga, M., Brake, A.J., Julius, D. (1999), A capsaicinreceptor homologue with a high threshold for noxious heat. Nature 398, 436-441.

Caterina, M.J., Schumacher, M.A., Tominaga, M., Rosen, T.A., Levine, J.D., Julius, D. (1997), The capsaicin receptor: a heat-activated ion channel in the pain pathway. Nature 389, 816-824.

Chan, K.Y., Baun, M., de Vries, R., van den Bogaerdt, A.J., Dirven, C.M., Danser, A.H., Jansen-Olesen, I., Olesen, J., Villalon, C.M., MaassenVanDenBrink, A., Gupta, S. (2011), Pharmacological characterization of VIP and PACAP receptors in the human meningeal and coronary artery. Cephalalgia 31, 181-189.

Chatchaisak, D., Srikiatkhachorn, A., Maneesri-le Grand, S., Govitrapong, P., Chetsawang, B. (2013), The role of calcitonin gene-related peptide on the increase in transient receptor potential vanilloid-1 levels in trigeminal ganglion and trigeminal nucleus caudalis activation of rat. J Chem Neuroanat 47, 50-56.

Chen, Z., Foster, M.W., Zhang, J., Mao, L., Rockman, H.A., Kawamoto, T., Kitagawa, K., Nakayama, K.I., Hess, D.T., Stamler, J.S. (2005), An essential role for mitochondrial aldehyde dehydrogenase in nitroglycerin bioactivation. Proc Natl Acad Sci U S A 102, 12159-12164. 
Chiariello, M., Gold, H.K., Leinbach, R.C., Davis, M.A., Maroko, P.R. (1976), Comparison between the effects of nitroprusside and nitroglycerin on ischemic injury during acute myocardial infarction. Circulation 54, 766-773.

Crawley, J.N., Corwin, R.L., Robinson, J.K., Felder, C.C., Devane, W.A., Axelrod, J. (1993), Anandamide, an endogenous ligand of the cannabinoid receptor, induces hypomotility and hypothermia in vivo in rodents. Pharmacol Biochem Behav 46, 967-972.

Curto, M., Lionetto, L., Negro, A., Capi, M., Fazio, F., Giamberardino, M.A., Simmaco, M., Nicoletti, F., Martelletti, P. (2015a), Altered kynurenine pathway metabolites in serum of chronic migraine patients. J Headache Pain 17, 47.

Curto, M., Lionetto, L., Negro, A., Capi, M., Perugino, F., Fazio, F., Giamberardino, M.A., Simmaco, M., Nicoletti, F., Martelletti, P. (2015b), Altered serum levels of kynurenine metabolites in patients affected by cluster headache. J Headache Pain 17, 27.

Csati, A., Edvinsson, L., Vecsei, L., Toldi, J., Fulop, F., Tajti, J., Warfvinge, K. (2015), Kynurenic acid modulates experimentally induced inflammation in the trigeminal ganglion. $\mathrm{J}$ Headache Pain 16, 99.

D'Andrea, G., Cananzi, A.R., Joseph, R., Morra, M., Zamberlan, F., Ferro Milone, F., Grunfeld, S., Welch, K.M. (1991), Platelet glycine, glutamate and aspartate in primary headache. Cephalalgia 11, 197-200.

Di Clemente, L., Coppola, G., Magis, D., Gerardy, P.Y., Fumal, A., De Pasqua, V., Di Piero, V., Schoenen, J. (2009), Nitroglycerin sensitises in healthy subjects CNS structures involved in migraine pathophysiology: evidence from a study of nociceptive blink reflexes and visual evoked potentials. Pain 144, 156-161.

Diaz-Insa, S., Goadsby, P.J., Zanchin, G., Fortea, J., Falques, M., Vila, C. (2011), The impact of allodynia on the efficacy of almotriptan when given early in migraine: data from the "Act when mild" study. Int J Neurosci 121, 655-661.

Dohrn, C.S., Mullett, M.A., Price, R.H., Beitz, A.J. (1994), Distribution of nitric oxide synthase-immunoreactive interneurons in the spinal trigeminal nucleus. J Comp Neurol 346, 449-460.

Edvinsson, L., Uddman, R. (2005), Neurobiology in primary headaches. Brain Res Brain Res Rev 48, 438-456.

Fejes-Szabo, A., Bohar, Z., Vamos, E., Nagy-Grocz, G., Tar, L., Veres, G., Zadori, D., Szentirmai, M., Tajti, J., Szatmari, I., Fulop, F., Toldi, J., Pardutz, A., Vecsei, L. (2014a), Pretreatment with new kynurenic acid amide dose-dependently prevents the nitroglycerineinduced neuronal activation and sensitization in cervical part of trigemino-cervical complex. $\mathbf{J}$ Neural Transm (Vienna) 121, 725-738.

Fejes-Szabo, A., Bohar, Z., Vamos, E., Nagy-Grocz, G., Tar, L., Veres, G., Zadori, D., Szentirmai, M., Tajti, J., Szatmari, I., Fulop, F., Toldi, J., Pardutz, A., Vecsei, L. (2014b), 
Pre-treatment with new kynurenic acid amide dose-dependently prevents the nitroglycerineinduced neuronal activation and sensitization in cervical part of trigemino-cervical complex. $\mathrm{J}$ Neural Transm 121, 725-738.

Furuyama, T., Kiyama, H., Sato, K., Park, H.T., Maeno, H., Takagi, H., Tohyama, M. (1993), Region-specific expression of subunits of ionotropic glutamate receptors (AMPA-type, KAtype and NMDA receptors) in the rat spinal cord with special reference to nociception. Brain Res Mol Brain Res 18, 141-151.

Gao, Y., Duan, Y.Z. (2010), Increased COX2 in the trigeminal nucleus caudalis is involved in orofacial pain induced by experimental tooth movement. Anat Rec (Hoboken) 293, 485-491.

Gao, Z., Liu, X., Yu, S., Zhang, Q., Chen, Q., Wu, Q., Liu, J., Sun, B., Fang, L., Lin, J., Zhu, B.M., Yan, X., Liang, F. (2014), Electroacupuncture at Acupoints Reverses Plasma Glutamate, Lipid, and LDL/VLDL in an Acute Migraine Rat Model: A (1) H NMR-Based Metabolomic Study. Evid Based Complement Alternat Med 2014, 659268.

Goadsby, P.J. (2005), Migraine, allodynia, sensitisation and all of that. Eur Neurol 53 Suppl $1,10-16$.

Goadsby, P.J., Zanchin, G., Geraud, G., de Klippel, N., Diaz-Insa, S., Gobel, H., Cunha, L., Ivanoff, N., Falques, M., Fortea, J. (2008), Early vs. non-early intervention in acute migraine'Act when Mild (AwM)'. A double-blind, placebo-controlled trial of almotriptan. Cephalalgia 28, 383-391.

Gozalov, A., Jansen-Olesen, I., Klaerke, D., Olesen, J. (2007), Role of BK(Ca) channels in cephalic vasodilation induced by CGRP, NO and transcranial electrical stimulation in the rat. Cephalalgia 27, 1120-1127.

Greco, R., Gasperi, V., Sandrini, G., Bagetta, G., Nappi, G., Maccarrone, M., Tassorelli, C. (2010), Alterations of the endocannabinoid system in an animal model of migraine: evaluation in cerebral areas of rat. Cephalalgia 30, 296-302.

Greco, R., Mangione, A.S., Siani, F., Blandini, F., Vairetti, M., Nappi, G., Sandrini, G., Buzzi, M.G., Tassorelli, C. (2014), Effects of CGRP receptor antagonism in nitroglycerininduced hyperalgesia. Cephalalgia 34, 594-604.

Greco, R., Tassorelli, C., Armentero, M.T., Sandrini, G., Nappi, G., Blandini, F. (2008), Role of central dopaminergic circuitry in pain processing and nitroglycerin-induced hyperalgesia. Brain Res 1238, 215-223.

Greco, R., Tassorelli, C., Cappelletti, D., Sandrini, G., Nappi, G. (2005), Activation of the transcription factor NF-kappaB in the nucleus trigeminalis caudalis in an animal model of migraine. Neurotoxicology 26, 795-800.

Guidetti, P., Schwarcz, R. (1999), 3-Hydroxykynurenine potentiates quinolinate but not NMDA toxicity in the rat striatum. Eur J Neurosci 11, 3857-3863. 
Guindon, J., Hohmann, A.G. (2009), The endocannabinoid system and pain. CNS Neurol Disord Drug Targets 8, 403-421.

Gundersen, H.J.G., Bagger, P., Bendtsen, T.F., Evans, S.M., Korbo, L., Marcussen, N., Moller, A., Nielsen, K., Nyengaard, J.R., Pakkenberg, B., Sorensen, F.B., Vesterby, A., West, M.J. (1988), The New Stereological Tools - Disector, Fractionator, Nucleator and Point Sampled Intercepts and Their Use in Pathological Research and Diagnosis. Apmis 96, 857881.

Hara, T., Ogasawara, N., Akimoto, H., Takikawa, O., Hiramatsu, R., Kawabe, T., Isobe, K., Nagase, F. (2008), High-affinity uptake of kynurenine and nitric oxide-mediated inhibition of indoleamine 2,3-dioxygenase in bone marrow-derived myeloid dendritic cells. Immunol Lett $116,95-102$.

Hassanain, H.H., Chon, S.Y., Gupta, S.L. (1993), Differential regulation of human indoleamine 2,3-dioxygenase gene expression by interferons-gamma and -alpha. Analysis of the regulatory region of the gene and identification of an interferon-gamma-inducible DNAbinding factor. J Biol Chem 268, 5077-5084.

Hayaishi, O., Rothberg, S., Mehler, A.H., Saito, Y. (1957), Studies on oxygenases; enzymatic formation of kynurenine from tryptophan. J Biol Chem 229, 889-896.

Heyes, M.P., Chen, C.Y., Major, E.O., Saito, K. (1997), Different kynurenine pathway enzymes limit quinolinic acid formation by various human cell types. Biochem J 326 ( Pt 2), 351-356.

Hillard, C.J., Muthian, S., Kearn, C.S. (1999), Effects of CB(1) cannabinoid receptor activation on cerebellar granule cell nitric oxide synthase activity. FEBS Lett 459, 277-281.

Horvath, G., Kekesi, G., Nagy, E., Benedek, G. (2008), The role of TRPV1 receptors in the antinociceptive effect of anandamide at spinal level. Pain 134, 277-284.

Hughes, D.I., Scott, D.T., Todd, A.J., Riddell, J.S. (2003), Lack of evidence for sprouting of Abeta afferents into the superficial laminas of the spinal cord dorsal horn after nerve section. $\mathrm{J}$ Neurosci 23, 9491-9499.

Iversen, H.K., Olesen, J. (1994), Nitroglycerin-induced headache is not dependent on histamine release: support for a direct nociceptive action of nitric oxide. Cephalalgia 14, 437442.

Ji, R.R., Samad, T.A., Jin, S.X., Schmoll, R., Woolf, C.J. (2002), p38 MAPK activation by NGF in primary sensory neurons after inflammation increases TRPV1 levels and maintains heat hyperalgesia. Neuron 36, 57-68.

Kao, D.J., Li, A.H., Chen, J.C., Luo, R.S., Chen, Y.L., Lu, J.C., Wang, H.L. (2012), CC chemokine ligand 2 upregulates the current density and expression of TRPV1 channels and Nav1.8 sodium channels in dorsal root ganglion neurons. J Neuroinflammation 9, 189. 
Kaube, H., Katsarava, Z., Przywara, S., Drepper, J., Ellrich, J., Diener, H.C. (2002), Acute migraine headache: possible sensitization of neurons in the spinal trigeminal nucleus? Neurology 58, 1234-1238.

Kim, Y.S., Chu, Y., Han, L., Li, M., Li, Z., Lavinka, P.C., Sun, S., Tang, Z., Park, K., Caterina, M.J., Ren, K., Dubner, R., Wei, F., Dong, X. (2014), Central terminal sensitization of TRPV1 by descending serotonergic facilitation modulates chronic pain. Neuron 81, 873887.

Knox, W.E., Mehler, A.H. (1950), The conversion of tryptophan to kynurenine in liver. I. The coupled tryptophan peroxidase-oxidase system forming formylkynurenine. J Biol Chem 187, 419-430.

Kress, M., Reeh, P.W. (1996), More sensory competence for nociceptive neurons in culture. Proc Natl Acad Sci U S A 93, 14995-14997.

Lange, R., Schwarz, J.A., Hohn, M. (2000), Acetylsalicylic acid effervescent $1000 \mathrm{mg}$ (Aspirin) in acute migraine attacks; a multicentre, randomized, double-blind, single-dose, placebo-controlled parallel group study. Cephalalgia 20, 663-667.

Lassen, L.H., Ashina, M., Christiansen, I., Ulrich, V., Olesen, J. (1997), Nitric oxide synthase inhibition in migraine. Lancet 349, 401-402.

Latremoliere, A., Woolf, C.J. (2009), Central sensitization: a generator of pain hypersensitivity by central neural plasticity. J Pain 10, 895-926.

Lauritzen, M. (1994), Pathophysiology of the migraine aura. The spreading depression theory. Brain 117 ( Pt 1), 199-210.

Lauritzen, M., Rice, M.E., Okada, Y., Nicholson, C. (1988), Quisqualate, kainate and NMDA can initiate spreading depression in the turtle cerebellum. Brain Res 475, 317-327.

Lee, K.M., Kang, B.S., Lee, H.L., Son, S.J., Hwang, S.H., Kim, D.S., Park, J.S., Cho, H.J. (2004), Spinal NF-kB activation induces COX-2 upregulation and contributes to inflammatory pain hypersensitivity. Eur J Neurosci 19, 3375-3381.

Leonelli, M., Martins, D.O., Britto, L.R. (2013), Retinal cell death induced by TRPV1 activation involves NMDA signaling and upregulation of nitric oxide synthases. Cell Mol Neurobiol 33, 379-392.

Lin, Q., Palecek, J., Paleckova, V., Peng, Y.B., Wu, J., Cui, M., Willis, W.D. (1999), Nitric oxide mediates the central sensitization of primate spinothalamic tract neurons. $J$ Neurophysiol 81, 1075-1085.

Lizanecz, E., Bagi, Z., Pasztor, E.T., Papp, Z., Edes, I., Kedei, N., Blumberg, P.M., Toth, A. (2006), Phosphorylation-dependent desensitization by anandamide of vanilloid receptor-1 (TRPV1) function in rat skeletal muscle arterioles and in Chinese hamster ovary cells expressing TRPV1. Mol Pharmacol 69, 1015-1023. 
Logters, T.T., Laryea, M.D., Altrichter, J., Sokolowski, J., Cinatl, J., Reipen, J., Linhart, W., Windolf, J., Scholz, M., Wild, M. (2009), Increased plasma kynurenine values and kynurenine-tryptophan ratios after major trauma are early indicators for the development of sepsis. Shock 32, 29-34.

Lukacs, M., Warfvinge, K., Kruse, L.S., Tajti, J., Fulop, F., Toldi, J., Vecsei, L., Edvinsson, L. (2016), KYNA analogue SZR72 modifies CFA-induced dural inflammation- regarding expression of pERK1/2 and IL-1beta in the rat trigeminal ganglion. J Headache Pain 17, 64.

Ma, Q.P., Woolf, C.J. (1995), Noxious stimuli induce an N-methyl-D-aspartate receptordependent hypersensitivity of the flexion withdrawal reflex to touch: implications for the treatment of mechanical allodynia. Pain 61, 383-390.

Maccarrone, M., Bari, M., Lorenzon, T., Bisogno, T., Di Marzo, V., Finazzi-Agro, A. (2000), Anandamide uptake by human endothelial cells and its regulation by nitric oxide. J Biol Chem 275, 13484-13492.

Malek, N., Pajak, A., Kolosowska, N., Kucharczyk, M., Starowicz, K. (2015), The importance of TRPV1-sensitisation factors for the development of neuropathic pain. Mol Cell Neurosci 65, 1-10.

Mandi, Y., Vecsei, L. (2012), The kynurenine system and immunoregulation. J Neural Transm (Vienna) 119, 197-209.

Markovics, A., Kormos, V., Gaszner, B., Lashgarara, A., Szoke, E., Sandor, K., Szabadfi, K., Tuka, B., Tajti, J., Szolcsanyi, J., Pinter, E., Hashimoto, H., Kun, J., Reglodi, D., Helyes, Z. (2012), Pituitary adenylate cyclase-activating polypeptide plays a key role in nitroglycerolinduced trigeminovascular activation in mice. Neurobiol Dis 45, 633-644.

Martinez, F., Castillo, J., Rodriguez, J.R., Leira, R., Noya, M. (1993), Neuroexcitatory amino acid levels in plasma and cerebrospinal fluid during migraine attacks. Cephalalgia 13, 89-93.

Mazario, J., Gaitan, G., Herrero, J.F. (2001), Cyclooxygenase-1 vs. cyclooxygenase-2 inhibitors in the induction of antinociception in rodent withdrawal reflexes. Neuropharmacology 40, 937-946.

Miyamoto, T., Dubin, A.E., Petrus, M.J., Patapoutian, A. (2009), TRPV1 and TRPA1 mediate peripheral nitric oxide-induced nociception in mice. PLoS One 4, e7596.

Morisset, V., Ahluwalia, J., Nagy, I., Urban, L. (2001), Possible mechanisms of cannabinoidinduced antinociception in the spinal cord. Eur J Pharmacol 429, 93-100.

Moskowitz, M.A. (2008), [Molecular mechanism of migraine]. Rinsho Shinkeigaku 48, 798.

Moskowitz, M.A., Nozaki, K., Kraig, R.P. (1993), Neocortical spreading depression provokes the expression of c-fos protein-like immunoreactivity within trigeminal nucleus caudalis via trigeminovascular mechanisms. J Neurosci 13, 1167-1177. 
Nagy-Grocz, G., Laborc, K.F., Veres, G., Bajtai, A., Bohar, Z., Zadori, D., Fejes-Szabo, A., Spekker, E., Vecsei, L., Pardutz, A. (2017), The Effect of Systemic Nitroglycerin Administration on the Kynurenine Pathway in the Rat. Front Neurol 8, 278.

Nagy-Grocz, G., Tar, L., Bohar, Z., Fejes-Szabo, A., Laborc, K.F., Spekker, E., Vecsei, L., Pardutz, A. (2016), The modulatory effect of anandamide on nitroglycerin-induced sensitization in the trigeminal system of the rat. Cephalalgia 36, 849-861.

Nakajima, Y., Furuichi, Y., Biswas, K.K., Hashiguchi, T., Kawahara, K., Yamaji, K., Uchimura, T., Izumi, Y., Maruyama, I. (2006), Endocannabinoid, anandamide in gingival tissue regulates the periodontal inflammation through NF-kappaB pathway inhibition. FEBS Lett 580, 613-619.

Olesen, J., Gustavsson, A., Svensson, M., Wittchen, H.U., Jonsson, B. (2012), The economic cost of brain disorders in Europe. Eur J Neurol 19, 155-162.

Pan, L., Song, K., Hu, F., Sun, W., Lee, I. (2013), Nitric oxide induces apoptosis associated with TRPV1 channel-mediated $\mathrm{Ca}(2+)$ entry via S-nitrosylation in osteoblasts. Eur J Pharmacol 715, 280-285.

Parahova, J., S. Vrankova, A. Barta, M. Kovacsova, D. Bartko, O. Pechanova (2009), The cross-talk of nuclear factor kappaB and nitric oxide in the brain. Activitas Nervosa Superior Rediviva 51, 123-126.

Pardutz, A., Hoyk, Z., Varga, H., Vecsei, L., Schoenen, J. (2007), Oestrogen-modulated increase of calmodulin-dependent protein kinase II (CamKII) in rat spinal trigeminal nucleus after systemic nitroglycerin. Cephalalgia 27, 46-53.

Pardutz, A., Krizbai, I., Multon, S., Vecsei, L., Schoenen, J. (2000), Systemic nitroglycerin increases nNOS levels in rat trigeminal nucleus caudalis. Neuroreport 11, 3071-3075.

Pardutz, A., Multon, S., Malgrange, B., Parducz, A., Vecsei, L., Schoenen, J. (2002), Effect of systemic nitroglycerin on CGRP and 5-HT afferents to rat caudal spinal trigeminal nucleus and its modulation by estrogen. Eur J Neurosci 15, 1803-1809.

Peng, L.M., Chen, X.P., Shi, R.Z., Chen, L., Li, Y.J., Yang, T.L. (2014), Involvement of anandamide transporter in calcitonin gene-related peptide expression stimulated by nitroglycerin and influence of ALDH2 Glu504Lys polymorphism. J Cardiovase Pharmacol 64, 460-464.

Peres, M.F., Zukerman, E., Senne Soares, C.A., Alonso, E.O., Santos, B.F., Faulhaber, M.H. (2004), Cerebrospinal fluid glutamate levels in chronic migraine. Cephalalgia 24, 735-739.

Pertwee, R.G. (1997), Pharmacology of cannabinoid CB1 and CB2 receptors. Pharmacol Ther 74, 129-180.

Pertwee, R.G. (2001), Cannabinoid receptors and pain. Prog Neurobiol 63, 569-611. 
Pettit, D.A., Anders, D.L., Harrison, M.P., Cabral, G.A. (1996), Cannabinoid receptor expression in immune cells. Adv Exp Med Biol 402, 119-129.

Pietrobon, D., Moskowitz, M.A. (2014), Chaos and commotion in the wake of cortical spreading depression and spreading depolarizations. Nat Rev Neurosci 15, 379-393.

Pradhan, A.A., Smith, M.L., McGuire, B., Tarash, I., Evans, C.J., Charles, A. (2014), Characterization of a novel model of chronic migraine. Pain 155, 269-274.

Ramachandran, R., Bhatt, D.K., Ploug, K.B., Olesen, J., Jansen-Olesen, I., Hay-Schmidt, A., Gupta, S. (2012), A naturalistic glyceryl trinitrate infusion migraine model in the rat. Cephalalgia 32, 73-84.

Read, S.J., Smith, M.I., Hunter, A.J., Parsons, A.A. (1997), Enhanced nitric oxide release during cortical spreading depression following infusion of glyceryl trinitrate in the anaesthetized cat. Cephalalgia 17, 159-165.

Reuter, U., Bolay, H., Jansen-Olesen, I., Chiarugi, A., Sanchez del Rio, M., Letourneau, R., Theoharides, T.C., Waeber, C., Moskowitz, M.A. (2001), Delayed inflammation in rat meninges: implications for migraine pathophysiology. Brain 124, 2490-2502.

Reuter, U., Chiarugi, A., Bolay, H., Moskowitz, M.A. (2002), Nuclear factor-kappaB as a molecular target for migraine therapy. Ann Neurol 51, 507-516.

Reyes Ocampo, J., Lugo Huitron, R., Gonzalez-Esquivel, D., Ugalde-Muniz, P., JimenezAnguiano, A., Pineda, B., Pedraza-Chaverri, J., Rios, C., Perez de la Cruz, V. (2014), Kynurenines with neuroactive and redox properties: relevance to aging and brain diseases. Oxid Med Cell Longev 2014, 646909.

Robbins, M.S., Tarshish, S., Solomon, S., Grosberg, B.M. (2009), Cluster attacks responsive to recreational cannabis and dronabinol. Headache 49, 914-916.

Rothrock, J.F., Mar, K.R., Yaksh, T.L., Golbeck, A., Moore, A.C. (1995), Cerebrospinal fluid analyses in migraine patients and controls. Cephalalgia 15, 489-493.

Salio, C., Fischer, J., Franzoni, M.F., Conrath, M. (2002), Pre- and postsynaptic localizations of the CB1 cannabinoid receptor in the dorsal horn of the rat spinal cord. Neuroscience 110, 755-764.

Saloman, J.L., Chung, M.K., Ro, J.Y. (2013), P2X(3) and TRPV1 functionally interact and mediate sensitization of trigeminal sensory neurons. Neuroscience 232, 226-238.

Salvemini, D., Misko, T.P., Masferrer, J.L., Seibert, K., Currie, M.G., Needleman, P. (1993), Nitric oxide activates cyclooxygenase enzymes. Proc Natl Acad Sci U S A 90, 7240-7244.

Sancho, R., Calzado, M.A., Di Marzo, V., Appendino, G., Munoz, E. (2003), Anandamide inhibits nuclear factor-kappaB activation through a cannabinoid receptor-independent pathway. Mol Pharmacol 63, 429-438. 
Sappington, R.M., Calkins, D.J. (2008), Contribution of TRPV1 to microglia-derived IL-6 and NFkappaB translocation with elevated hydrostatic pressure. Invest Ophthalmol Vis Sci 49, 3004-3017.

Sarchielli, P., Di Filippo, M., Nardi, K., Calabresi, P. (2007), Sensitization, glutamate, and the link between migraine and fibromyalgia. Curr Pain Headache Rep 11, 343-351.

Schytz, H.W., Birk, S., Wienecke, T., Kruuse, C., Olesen, J., Ashina, M. (2009), PACAP38 induces migraine-like attacks in patients with migraine without aura. Brain 132, 16-25.

Sicuteri, F., Del Bene, E., Poggioni, M., Bonazzi, A. (1987), Unmasking latent dysnociception in healthy subjects. Headache 27, 180-185.

Siniatchkin, M., Gerber, W.D., Kropp, P., Vein, A. (1999), How the brain anticipates an attack: a study of neurophysiological periodicity in migraine. Funct Neurol 14, 69-77.

Smitherman, C., Gadda, G. (2013), Evidence for a transient peroxynitro acid in the reaction catalyzed by nitronate monooxygenase with propionate 3-nitronate. Biochemistry 52, 26942704.

Soliman, A.C., Yu, J.S., Coderre, T.J. (2005), mGlu and NMDA receptor contributions to capsaicin-induced thermal and mechanical hypersensitivity. Neuropharmacology 48, 325-332.

Strassman, A.M., Raymond, S.A., Burstein, R. (1996), Sensitization of meningeal sensory neurons and the origin of headaches. Nature 384, 560-564.

Tajti, J., Uddman, R., Moller, S., Sundler, F., Edvinsson, L. (1999), Messenger molecules and receptor mRNA in the human trigeminal ganglion. J Auton Nerv Syst 76, 176-183.

Tallaksen-Greene, S.J., Young, A.B., Penney, J.B., Beitz, A.J. (1992), Excitatory amino acid binding sites in the trigeminal principal sensory and spinal trigeminal nuclei of the rat. Neurosci Lett 141, 79-83.

Tassorelli, C., Blandini, F., Costa, A., Preza, E., Nappi, G. (2002), Nitroglycerin-induced activation of monoaminergic transmission in the rat. Cephalalgia 22, 226-232.

Tassorelli, C., Greco, R., Armentero, M.T., Blandini, F., Sandrini, G., Nappi, G. (2007), A role for brain cyclooxygenase- 2 and prostaglandin-E2 in migraine: effects of nitroglycerin. Int Rev Neurobiol 82, 373-382.

Tassorelli, C., Greco, R., Morazzoni, P., Riva, A., Sandrini, G., Nappi, G. (2005), Parthenolide is the component of tanacetum parthenium that inhibits nitroglycerin-induced Fos activation: studies in an animal model of migraine. Cephalalgia 25, 612-621.

Tassorelli, C., Joseph, S.A. (1995), Systemic nitroglycerin induces Fos immunoreactivity in brainstem and forebrain structures of the rat. Brain Res 682, 167-181. 
Tassorelli, C., Joseph, S.A., Nappi, G. (1997), Neurochemical mechanisms of nitroglycerininduced neuronal activation in rat brain: a pharmacological investigation. Neuropharmacology $36,1417-1424$.

Tfelt-Hansen, P., Daugaard, D., Lassen, L.H., Iversen, H.K., Olesen, J. (2009), Prednisolone reduces nitric oxide-induced migraine. Eur J Neurol 16, 1106-1111.

Thomas, S.R., Terentis, A.C., Cai, H., Takikawa, O., Levina, A., Lay, P.A., Freewan, M., Stocker, R. (2007), Post-translational regulation of human indoleamine 2,3-dioxygenase activity by nitric oxide. J Biol Chem 282, 23778-23787.

Tominaga, M., Caterina, M.J., Malmberg, A.B., Rosen, T.A., Gilbert, H., Skinner, K., Raumann, B.E., Basbaum, A.I., Julius, D. (1998), The cloned capsaicin receptor integrates multiple pain-producing stimuli. Neuron 21, 531-543.

Torfgard, K., Ahlner, J., Axelsson, K.L., Norlander, B., Bertler, A. (1989), Tissue distribution of glyceryl trinitrate and the effect on cGMP levels in rat. Pharmacol Toxicol 64, 369-372.

Tuka, B., Helyes, Z., Markovics, A., Bagoly, T., Nemeth, J., Mark, L., Brubel, R., Reglodi, D., Pardutz, A., Szolcsanyi, J., Vecsei, L., Tajti, J. (2012), Peripheral and central alterations of pituitary adenylate cyclase activating polypeptide-like immunoreactivity in the rat in response to activation of the trigeminovascular system. Peptides 33, 307-316.

Tuka, B., Helyes, Z., Markovics, A., Bagoly, T., Szolcsanyi, J., Szabo, N., Toth, E., Kincses, Z.T., Vecsei, L., Tajti, J. (2013), Alterations in PACAP-38-like immunoreactivity in the plasma during ictal and interictal periods of migraine patients. Cephalalgia 33, 1085-1095.

Ulugol, A., Ozyigit, F., Yesilyurt, O., Dogrul, A. (2006), The additive antinociceptive interaction between WIN 55,212-2, a cannabinoid agonist, and ketorolac. Anesth Analg 102, 443-447.

Valtschanoff, J.G., Rustioni, A., Guo, A., Hwang, S.J. (2001), Vanilloid receptor VR1 is both presynaptic and postsynaptic in the superficial laminae of the rat dorsal horn. J Comp Neurol $436,225-235$.

Vamos, E., Fejes, A., Koch, J., Tajti, J., Fulop, F., Toldi, J., Pardutz, A., Vecsei, L. (2010), Kynurenate derivative attenuates the nitroglycerin-induced CamKIIalpha and CGRP expression changes. Headache 50, 834-843.

Vamos, E., Pardutz, A., Varga, H., Bohar, Z., Tajti, J., Fulop, F., Toldi, J., Vecsei, L. (2009), l-kynurenine combined with probenecid and the novel synthetic kynurenic acid derivative attenuate nitroglycerin-induced nNOS in the rat caudal trigeminal nucleus. Neuropharmacology 57, 425-429.

Van Sickle, M.D., Duncan, M., Kingsley, P.J., Mouihate, A., Urbani, P., Mackie, K., Stella, N., Makriyannis, A., Piomelli, D., Davison, J.S., Marnett, L.J., Di Marzo, V., Pittman, Q.J., Patel, K.D., Sharkey, K.A. (2005), Identification and functional characterization of brainstem cannabinoid CB2 receptors. Science 310, 329-332. 
Varga, H., Pardutz, A., Vamos, E., Bohar, Z., Bago, F., Tajti, J., Bari, F., Vecsei, L. (2009), Selective inhibition of cyclooxygenase-2 attenuates nitroglycerin-induced calmodulindependent protein kinase II alpha in rat trigeminal nucleus caudalis. Neurosci Lett 451, 170173.

Varga, H., Pardutz, A., Vamos, E., Plangar, I., Egyud, E., Tajti, J., Bari, F., Vecsei, L. (2007), Cox-2 inhibitor attenuates NO-induced nNOS in rat caudal trigeminal nucleus. Headache 47, $1319-1325$.

Vecsei, L., Majlath, Z., Balog, A., Tajti, J. (2015), Drug targets of migraine and neuropathy: treatment of hyperexcitability. CNS Neurol Disord Drug Targets 14, 664-676.

Vecsei, L., Szalardy, L., Fulop, F., Toldi, J. (2013), Kynurenines in the CNS: recent advances and new questions. Nat Rev Drug Discov 12, 64-82.

Watanabe, Y., Yoshida, R., Sono, M., Hayaishi, O. (1981), Immunohistochemical localization of indoleamine 2,3-dioxygenase in the argyrophilic cells of rabbit duodenum and thyroid gland. J Histochem Cytochem 29, 623-632.

Weiller, C., May, A., Limmroth, V., Juptner, M., Kaube, H., Schayck, R.V., Coenen, H.H., Diener, H.C. (1995), Brain stem activation in spontaneous human migraine attacks. Nat Med $1,658-660$.

White, R., Hiley, C.R. (1998), The actions of some cannabinoid receptor ligands in the rat isolated mesenteric artery. Br J Pharmacol 125, 533-541.

Wilson, K., Auer, M., Binnie, M., Zheng, X., Pham, N.T., Iredale, J.P., Webster, S.P., Mole, D.J. (2016), Overexpression of human kynurenine-3-monooxygenase protects against 3hydroxykynurenine-mediated apoptosis through bidirectional nonlinear feedback. Cell Death Dis 7, e2197.

Wilson, R.I., Nicoll, R.A. (2002), Endocannabinoid signaling in the brain. Science 296, 678682.

Yaksh, T.L., Dirig, D.M., Conway, C.M., Svensson, C., Luo, Z.D., Isakson, P.C. (2001), The acute antihyperalgesic action of nonsteroidal, anti-inflammatory drugs and release of spinal prostaglandin E2 is mediated by the inhibition of constitutive spinal cyclooxygenase-2 (COX2) but not COX-1. J Neurosci 21, 5847-5853.

Yu, M., Ives, D., Ramesha, C.S. (1997), Synthesis of prostaglandin E2 ethanolamide from anandamide by cyclooxygenase-2. J Biol Chem 272, 21181-21186.

Zhu, X., Han, Y., Xiong, W., Wang, H., Li, J., Liu, W., Fan, Z. (2011), [Heat coagulation of middle meningeal artery affects plasma CGRP and substance $\mathrm{P}$ levels in migraine rat triggered by nitroglycerin]. Lin Chung Er Bi Yan Hou Tou Jing Wai Ke Za Zhi 25, 460-462, 468. 
I. 


\title{
The modulatory effect of anandamide on nitroglycerin-induced sensitization in the trigeminal system of the rat
}

Cephalalgia

2016, Vol. 36(9) 849-86I

(C) International Headache Society 2015 Reprints and permissions: sagepub.co.uk/journalsPermissions.nav DOI: I0.II77/0333I024I56/3766 cep.sagepub.com

(S)AGE

\author{
Gábor Nagy-Grócz', Lilla Tar², Zsuzsanna Bohár ${ }^{3}$, \\ Annamária Fejes-Szabó', Klaudia Flóra Laborc', \\ Eleonóra Spekker', László Vécsei ${ }^{1,3}$ and Árpád Párdutz'
}

\begin{abstract}
Background: One of the human and animal models of migraine is the systemic administration of the nitric oxide donor (NO) nitroglycerin (NTG). NO can provoke migraine-like attacks in migraineurs and initiates a self-amplifying process in the trigeminal system, probably leading to central sensitization. Recent studies suggest that the endocannabinoid system is involved in nociceptive signal processing and cannabinoid receptor (CB) agonists are able to attenuate nociception in animal models of pain.

Aim: The purpose of the present study was to investigate the modulatory effects of a CB agonist anandamide (AEA) on the NTG-induced expression of transient receptor potential vanilloid type I (TRPVI), neuronal nitric oxide synthase (nNOS), nuclear factor kappa B (NF-кB), cyclooxygenase-2 (COX-2) and kynurenine aminotransferase-II (KAT-II) in the upper cervical spinal cord $(\mathrm{Cl}-\mathrm{C} 2)$ of the rat, where most of the trigeminal nociceptive afferents convey.

Methods: A half hour before and one hour after NTG $(10 \mathrm{mg} / \mathrm{kg})$ or placebo injection, adult male Sprague-Dawley rats $(n=44)$ were treated with AEA $(2 \times 5 \mathrm{mg} / \mathrm{kg})$. Four hours after placebo/NTG injection, the animals were perfused and the cervical spinal cords were removed for immunohistochemistry and Western blotting.

Results and conclusion: Our results show that NTG is able to increase TRPVI, nNOS, NF-KB and COX-2 and decrease KAT-II expression in the $\mathrm{Cl}-\mathrm{C} 2$ segments. On the other hand, we have found that AEA modulates the NTGinduced changes, thus it influences the activation and central sensitization process in the trigeminal system, probably via $\mathrm{CBs}$.
\end{abstract}

\section{Keywords}

Migraine, trigeminal system, nitroglycerin, anandamide, TRPVI, nNOS, NF-kB, COX-2, KAT-II

Date received: 30 March 2015; revised: 13 July 2015; 3 September 2015; accepted: 18 September 2015

\section{Introduction}

Migraine belongs to the group of primary headaches, and it is one of the most abundant neurological syndromes, which affects $15 \%$ of the European population (1). Despite intensive research, the exact pathomechanism of the disorder is not fully understood, but it is well known that activation and sensitization of the trigeminal system is essential during the attack (2). Continuous activation of peripheral trigeminal afferents leads firstly to peripheral (first-order) sensitization. Sustained inputs can lead to second-order, and ultimately to third-order central sensitization (3). Previous data have shown that after the onset of central sensitization during the migraine attack, the acute treatment becomes less effective (4), although this theory has been contested recently, stating that the severity of headache might be a better indicator than the symptoms of

\footnotetext{
'Department of Neurology, Faculty of Medicine, Albert Szent-Györgyi Clinical Center, University of Szeged, Hungary

${ }^{2}$ Department of Neurology, University of Ulm, Germany

${ }^{3}$ MTA-SZTE Neuroscience Research Group, University of Szeged,

Hungary
}

\section{Corresponding author:}

László Vécsei, Department of Neurology, Faculty of Medicine, Albert

Szent-Györgyi Clinical Center, University of Szeged, Hungary

Semmelweis Street 6, H-6725 Szeged, Hungary.

Email: vecsei.laszlo@med.u-szeged.hu 
sensitization $(5,6)$; it is generally accepted that the latter plays an essential role in the genesis of migraine (7).

One of the models of migraine is the systemic administration of nitroglycerin (NTG), generating a shortlasting headache in humans via the rapid vasodilatory effect of nitric oxide (NO) followed by a typical migraine without aura in migraine patients (8).

In rats, NTG is able to increase c-Fos-immunoreactivity in the caudal trigeminal nucleus (TNC) suggesting the activation of the second-order trigeminal neurons there (9). NO is also involved in the central sensitization process in the trigeminal system (10), probably acting via the activation of trigeminal $\mathrm{A} \delta$ and $\mathrm{C}$ fibers, since the destruction of the latter with capsaicin abolishes the effect of NTG (11).

Cannabinoid receptors (CBs) are G-protein-coupled receptors that have two subtypes: $\mathrm{CB} 1$ and $\mathrm{CB} 2$. $\mathrm{CB} 1$ is present in the central nervous system, liver and lung, and $\mathrm{CB} 2$ is expressed primarily in the immune system (12).

Animal models of pain have shown that fluctuations in the endocannabinoid levels in the nervous system are related to pain processing and antinociception (13). $\mathrm{CB} 1$ is present in the trigeminal ganglion (TG) and on the axon terminals of primary sensory neurons in the nociceptive areas in the spinal cord in rats (14). CB1 is able to inhibit the responses of trigeminal neurons with A- and C-fiber inputs from the dura mater (15), pointing to the importance of the endocannabinoid system in pain processing (16).

Although the psychoactive properties of cannabinoids (17) restrict their therapeutic application, the interactions between the endocannabinoid system and pain mediation is intensively studied in several laboratories.

$\mathrm{N}$-Arachidonylethanolamide or anandamide (AEA) is the first discovered endocannabinoid, and is an agonist of $\mathrm{CBs}$ and transient receptor potential vanilloid type 1 (TRPV1), which is a nonselective cation channel activated by numerous stimuli, such as heat and vanilloids $(18,19)$. AEA has vasodilatory actions $(20)$ that are not mediated by CBs (21). It is well known that AEA is able to reduce NTG-induced hyperalgesia and c-Fos expression in the TNC in rats (22), which means that AEA is capable of modulating the activation of the trigeminal system.

TRPV1 is present in the spinal cord and is considered as a molecular integrator of chemical and physical stimuli that elicit pain (23). In addition, NO donors can activate TRPV1 resulting in an increase of intracellular calcium concentration in different cell types $(24,25)$, which suggests that TRPV1 may be modulated by NO.

NO is synthesized from arginine by nitric oxide synthase, a neuronal isoform of which (nNOS) has an outmost importance in nociception and sensitization and is present in the trigeminal system (26). NO donors may trigger a self-amplifying process at the level of central projection site of the trigeminal system by increasing endogenous NO synthesis, which might be relevant in the central sensitization phenomenon (7).

Nuclear factor kappa B (NF-kB) has a crucial role in the inflammation process by controlling many genes including cytokines. Several studies have shown that proinflammatory cytokines contribute to the development of pain and hyperalgesia (27). Cyclooxygenase-2 $(\mathrm{COX}-2)$ is present in the dorsal horn of the spinal cord too and it has a substantial role in the processing of pain (28). Gao and Duan have found that COX-2 expression increased in the TNC after orofacial nociception (29).

Kynurenine aminotransferase-II (KAT-II) is a key enzyme in the kynurenine pathway that converts L-kynurenine (L-KYN) to kynurenic acid (KYNA), a known ionotropic glutamate receptor antagonist molecule (30) that can also block $\alpha$-7-nicotinic acetylcholine receptors (31). In an NTG-induced animal model of migraine L-KYN, KYNA and KYNA analogs inhibited trigeminal activation and sensitization (32-34).

Thus modulatory effects of cannabinoids can be suggested on trigeminal activation both on peripheral and central levels. In the present paper we studied the effect of NTG injection on the TRPV1, nNOS, NF- $\kappa$ B, COX-2 and KAT-II expression levels in the superficial laminae of $\mathrm{C} 1-\mathrm{C} 2$ and its modulation by the $\mathrm{CB}$ agonist AEA.

\section{Materials and methods}

\section{Animals}

The procedures used in this study followed the guidelines for the Use of Animals in Research of the International Association for the Study of Pain and the directive of the European Economic Community (86/609/ECC). They were permitted by the Committee of the Animal Research of University of Szeged (I-74-12/2012) and the Scientific Ethics Committee for Animal Research of the Protection of Animals Advisory Board (XI./352/2012). Forty-four adult male Sprague-Dawley rats weighing 200-250 g were used. The animals were raised and maintained under standard laboratory conditions with tap water and regular rat chow available ad libitium on a 12-hour dark12-hour light cycle.

\section{Drug administration}

The animals were divided into four groups $(n=6$ per group for immunohistochemistry, $n=5$ per group for 
Western blot analysis). The animals in the first group, called the placebo group, received only the vehicle solution (physiological saline) as treatment. In the second group, the rats were treated with an intraperitoneal injection of NTG $(10 \mathrm{mg} / \mathrm{kg}$ bodyweight, Pohl Boskamp). In the third and fourth groups, the animals received intraperitoneal AEA $(2 \times 5 \mathrm{mg} / \mathrm{kg}$ bodyweight, Sigma Aldrich) a half hour before and one hour after the placebo or NTG treatment. Greco and colleagues have demonstrated that single $20 \mathrm{mg} / \mathrm{kg}$ doses of AEA before NTG administration is able to reduce NTGinduced c-Fos expression in the TNC (22). Since in our other running experiments (not reported here) we obtained results showing the efficacy of AEA at lower dosages, we used $2 \times 5 \mathrm{mg} / \mathrm{kg}$ of AEA in this context using two injections because of the short half-life of the drug (35). AEA was dissolved in physiological saline. In the case of the first and second groups, animals were treated with physiological saline instead of AEA.

\section{Immunohistochemistry}

Four hours after the placebo/NTG injection, the rats were perfused transcardially with $100 \mathrm{ml}$ phosphatebuffered saline (PBS, 0.1 M, pH 7.4), followed by $500 \mathrm{ml} \mathrm{4 \%}$ paraformaldehyde in phosphate buffer under chloral hydrate $(0.4 \mathrm{~g} / \mathrm{kg}$ bodyweight $)$ anesthesia. The $\mathrm{C} 1-\mathrm{C} 2$ segments of the cervical spinal cord between -5 and $-11 \mathrm{~mm}$ from the obex were removed and postfixed overnight for immunohistochemistry in the same fixative. After cryoprotection, $30 \mu \mathrm{m}$ cryostat sections were cut and serially collected in wells containing cold PBS. The free-floating sections were rinsed in PBS and immersed in $0.3 \% \mathrm{H}_{2} \mathrm{O}_{2}$ in methanol or PBS for 30 minutes. After several rinses in PBS containing $1 \%$ Triton $\mathrm{X}-100$, sections of $\mathrm{C} 1-\mathrm{C} 2$ were kept overnight at room temperature in anti-TRPV1 antibody (Santa Cruz, s.c.28759) at a dilution of 1:500, or for two nights at $4{ }^{\circ} \mathrm{C}$ in anti-nNOS antibody (EuroProxima, 2263B220-1) at a dilution of 1:5000, or for two nights at $4{ }^{\circ} \mathrm{C}$ in anti-NF- $\kappa \mathrm{B}$ antibody (Abcam, ab97726) at a dilution of 1:100. The immunocytochemical reaction was visualized by the Vectastain AvidinBiotin kit of Vector Laboratories (PK6101), and nickel ammonium sulfate-intensified 3,3'-diaminobenzidine. The specificity of the immune reaction was controlled by omitting the primary antisera.

\section{Western blot analysis}

Four hours after the placebo/NTG injection, the animals were perfused transcardially with $100 \mathrm{ml}$ PBS and the dorsal horns of the $\mathrm{C} 1-\mathrm{C} 2$ segments were extracted. Until the measurements, the samples were stored at $-80^{\circ} \mathrm{C}$. The samples were sonicated in ice-cold lysis buffer containing $50 \mathrm{mM}$ Tris- $\mathrm{HCl}, 150 \mathrm{mM} \mathrm{NaCl}$, $0.1 \%$ igepal, $0.1 \%$ cholic acid, $2 \mu \mathrm{g} / \mathrm{ml}$ leupeptin, $2 \mathrm{mM}$ phenylmethylsulphonyl fluoride, $1 \mu \mathrm{g} / \mathrm{ml}$ pepstatin, $2 \mathrm{mM}$ ethylenediaminetetraacetic acid (EDTA) and $0.1 \%$ sodium dodecyl sulfate (SDS). The lysates were centrifuged at 12,000 revolutions per minute (RPM) for 10 minutes at $4^{\circ} \mathrm{C}$ and supernatants were aliquoted and stored at $-20^{\circ} \mathrm{C}$ until use. Protein concentration was defined with BCA Protein Assay Kit using bovine serum albumin as a standard. Prior to loading, each sample was mixed with sample buffer, and denaturated by boiling for 3 minutes. Equal amounts of protein samples $(20 \mu \mathrm{g} / \mathrm{lane})$ were separated by standard SDS polyacrylamide gel electrophoresis on $10 \%$ TrisGlycine gel and electrotransferred onto Amersham Hybond-ECL nitrocellulose membrane $(0.45 \mu \mathrm{m}$ pore size). We used the Page Ruler Prestained Protein Ladder $(10-170 \mathrm{kDa})$ to define approximate molecular weights. Following the transfer, membranes were blocked for one hour at room temperature in Trisbuffered saline containing Tween 20 (TBST) and 5\% nonfat dry milk powder. Then, they were incubated in TBST containing $1 \%$ nonfat dry milk and nNOS antibody (BD Biosciences, 610308, dilution: 1:2000, incubation: overnight at room temperature), or $\mathrm{COX}-2$ antibody (Proteintech, 12375-1-AP, dilution: 1:1000, incubation: overnight at room temperature), or KATII antibody (Santa Cruz, sc-67376, dilution: 1:10,000, incubation: overnight at room temperature) or $\beta$-actin antibody (Calbiochem, CP01, dilution: 1:100 000, incubation: overnight at room temperature). The next day, the membranes were incubated in TBST containing $1 \%$ nonfat dry milk and horseradish peroxidase-conjugated anti-rabbit or anti-mouse secondary antibody (Santa Cruz Biotechnology, sc-2030, sc-2031) for two hours at room temperature. Protein bands were visualized after incubation of membranes with the SuperSignal West Pico Chemiluminescent Substrate using Carestream Kodak BioMax Light film.

\section{Data evaluation}

All evaluations were implemented by an observer blind to the experimental groups. The detailed methods were described previously $(34,36,37)$.

Immunohistochemistry (TRPVI, nNOS, NF- $\kappa$ B). The photomicrographs of the stained sections of $\mathrm{C} 1-\mathrm{C} 2$ were taken using a Zeiss AxioImager microscope supplied with an AxioCam MRc Rev. 3 camera (Carl Zeiss Microscopy, Jena, Germany).

The area covered by TRPV1-immunoreactive fibers and nNOS-immunoreactive cells was determined by Image Pro Plus $6.2^{\circledR}$ image analysis software (Media Cybernetics). After image acquisition, the laminae I-II 
in the dorsal horn were defined manually as areas of interest and a threshold gray level was validated with the image analysis software as described in an earlier study $(32,36)$. The program calculated the area innervated by the immunoreactive fibers and cells as the number of pixels with densities above the threshold; the data were expressed as area fractions (\%) of the corresponding immunolabelled structures.

We used the unbiased optical disector method to calculate the volume densities of the NF- $\mathrm{KB}$-immunoreactive cells (37).

Western blot analysis (nNOS, COX-2, KAT-II). For densitometric analyses, films were scanned and quantified using Java Image J $1.47 \mathrm{v}$ analysis software (National Institutes of Health). The results were normalized to $\beta$-actin.

\section{Statistical analysis}

Statistical analysis of measurements were performed in SPSS Statistics software (version 20.0 for Windows, SPSS Inc) using one-way analysis of variance (ANOVA) followed by the Tukey or Tamhane post hoc test depending on variances of data, with $p<0.05$ taken as statistically significant. Group values are reported as means \pm SEM.

\section{Results}

NTG induced an increase in TRPVI expression in the $\mathrm{Cl}-\mathrm{C2}$, and $A E A$ inhibited this phenomenon

On transverse sections of the $\mathrm{C} 1-\mathrm{C} 2$ segments, there were abundant TRPV1-positive fibers in the superficial

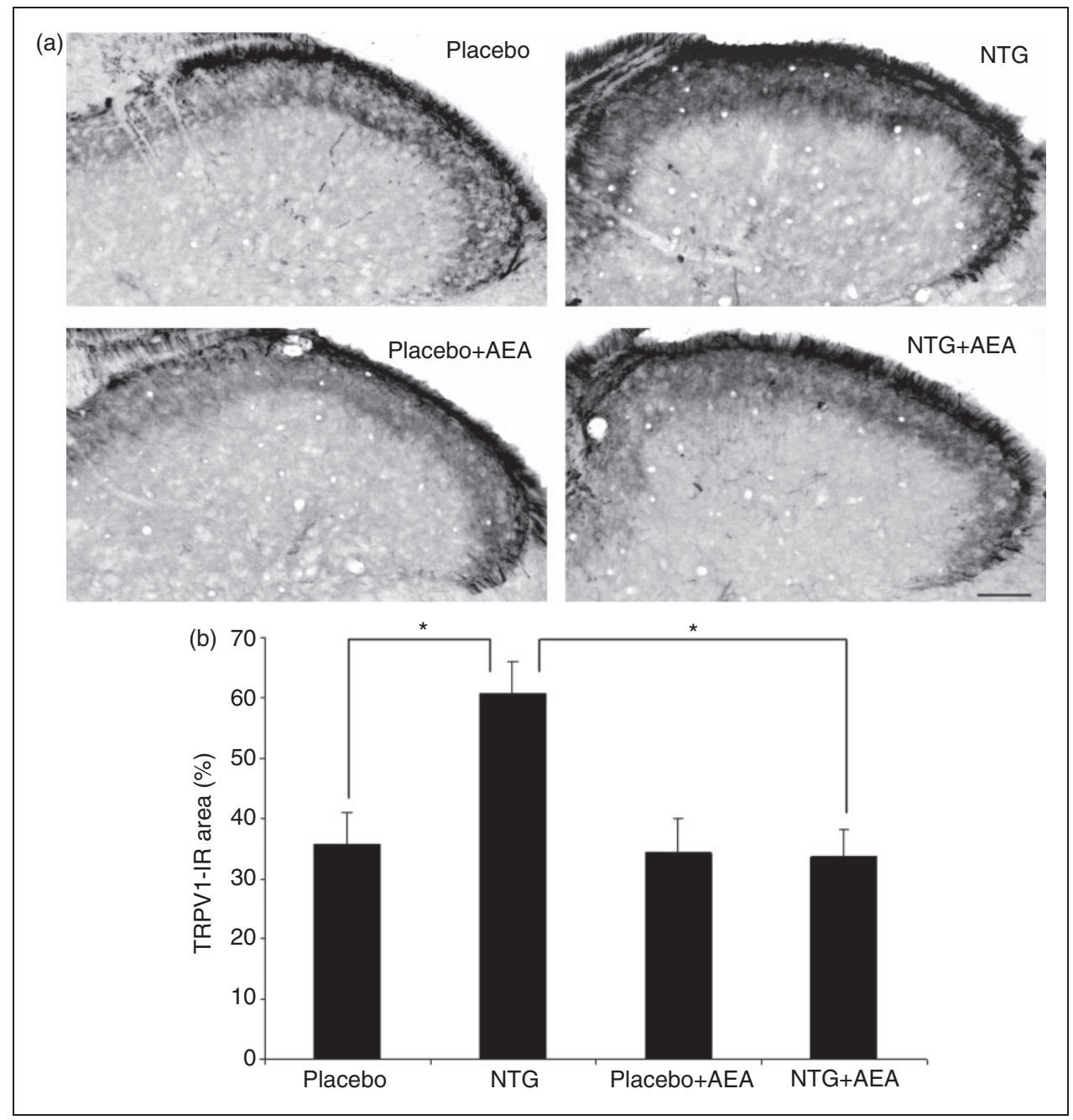

Figure I. (a) Representative photomicrographs of the TRPVI expression in the $\mathrm{CI}-\mathrm{C} 2$ segments. (b) Changes in area fractions of TRPVI-immunoreactive fibers in superficial laminae I and II of the CI-C2 segments. In the NTG group, the area covered by TRPVI was significantly higher than in the placebo group. AEA seemed to block this effect. Bar graph data presented here and in succeeding figures are means \pm SEM. Scale bar: $100 \mu \mathrm{m},{ }^{*} p<0.05$. TRPVI: transient receptor potential vanilloid type I; IR: immunoreactive; NTG: nitroglycerin; AEA: anandamide. 
layers of the dorsal horn. The TRPV1-immunoreactive area in the NTG-treated group was significantly higher compared to the placebo-treated group $(p<0.05)$. The NTG-induced increase was attenuated by treatment with AEA $(p<0.05)$ (Figure 1).

\section{NTG increased nNOS expression in the $\mathrm{Cl}-\mathrm{C2}$, and $A E A$ attenuated this effect}

On transverse sections of the $\mathrm{C} 1-\mathrm{C} 2$ segments, nNOSimmunoreactive neurons and processes with cytoplasmic staining can be observed in the superficial layers of the dorsal horn. In the NTG group, the area fraction of nNOS-immunoreactive structures was significantly higher than in the placebo-treated group $(p<0.01)$. AEA treatment resulted in a decrease of nNOS-immunopositive structures $(p<0.001)$ (Figure 2$)$.
Western blot analysis of the $\mathrm{C} 1-\mathrm{C} 2$ region confirmed the results obtained by nNOS immunohistochemistry. A band characteristic of the nNOS protein was identified at $155 \mathrm{kDa}$. Densitometric analyses confirmed that the nNOS bands were significantly enhanced $(p<0.01)$ in $\mathrm{C} 1-\mathrm{C} 2$ after NTG administration as compared with the placebo-treated animals. This effect was blocked by the treatment with AEA $(p<0.05)$ (Figure 3).

\section{NTG treatment enhanced NF- $\kappa B$ expression, and $A E A$ mitigated this phenomenon}

In transverse sections of the $\mathrm{C} 1-\mathrm{C} 2$ region, a high number of NF- $\kappa \mathrm{B}$-positive cells can be seen in the superficial layers of the dorsal horn. In the NTG-treated animals the volume density of the NF- $\mathrm{BB}$-positive

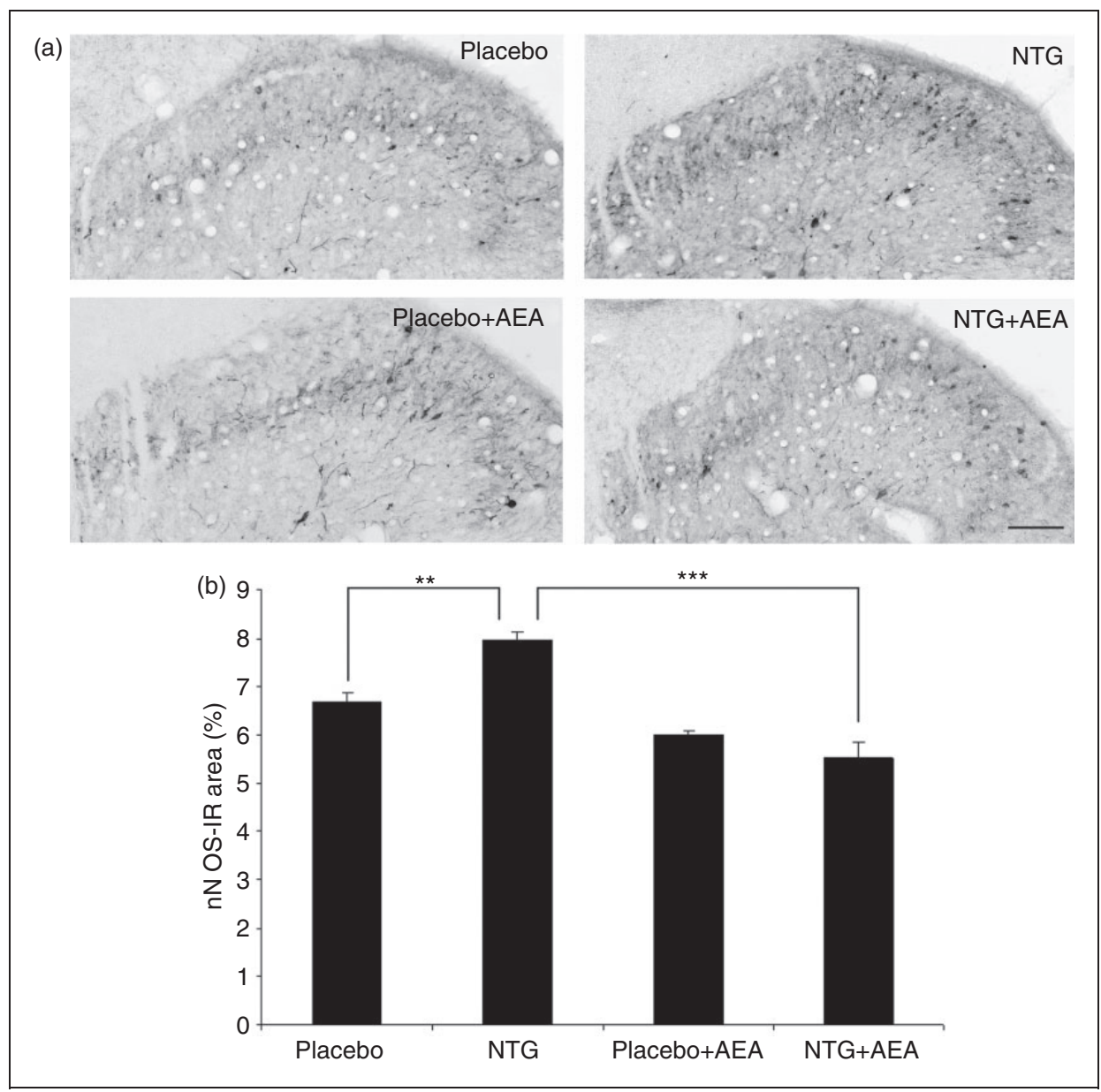

Figure 2. (a) Representative photomicrographs of nNOS expression in the $\mathrm{Cl}-\mathrm{C} 2$ segments. (b) Changes in the $\mathrm{nNOS}$-immunoreactive area fractions. In the NTG group, the area fraction of nNOS-IR structures was increased compared to the placebo-treated group. AEA was able to attenuate this effect. Scale bar: $100 \mu \mathrm{m},{ }^{* *} p<0.0 \mathrm{I}$; ${ }^{* * *} p<0.00 \mathrm{I}$. nNOS: neuronal nitric oxide synthase; IR: immunoreactive; NTG: nitroglycerin; AEA: anandamide. 


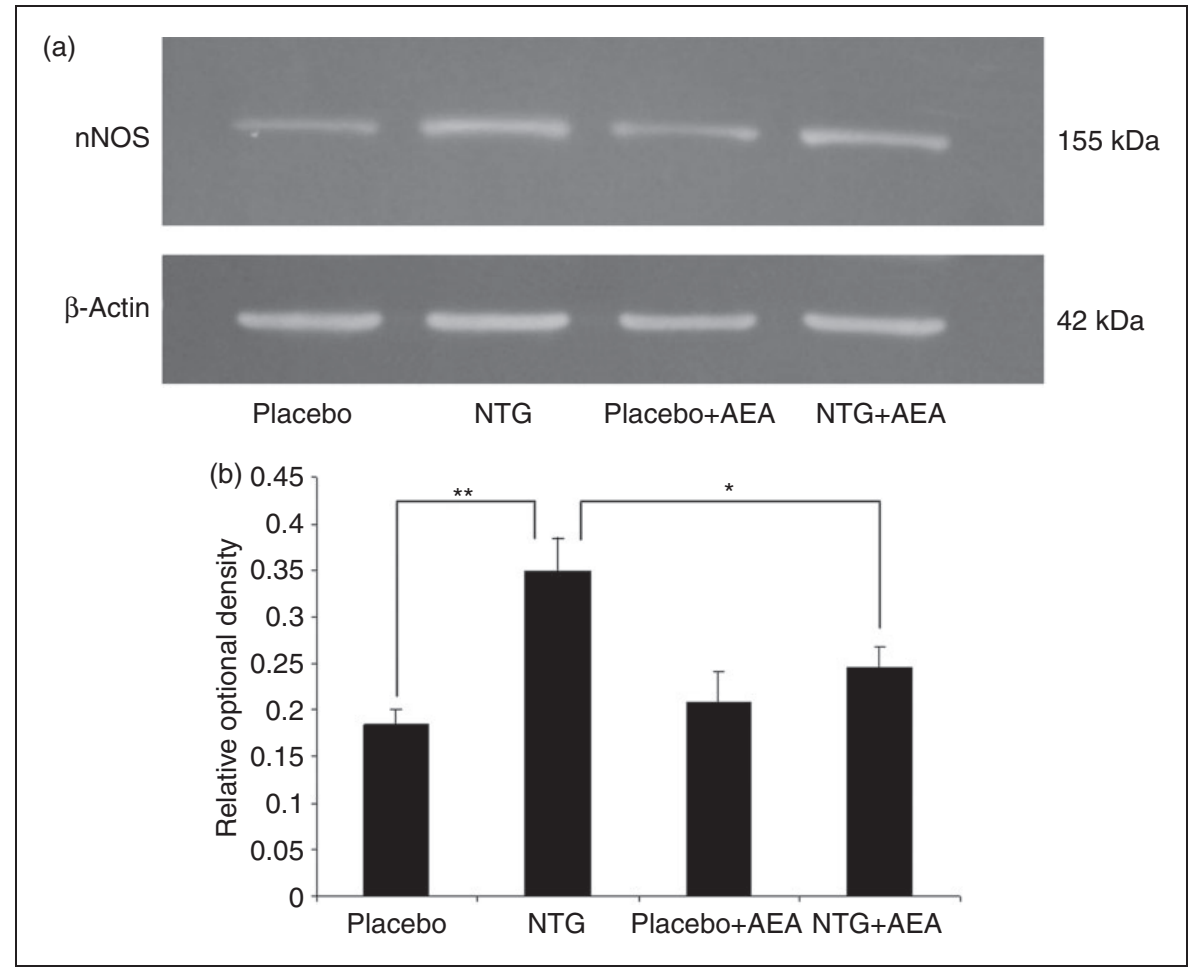

Figure 3. (a) Western blot of $\mathrm{nNOS}$ and $\beta$-actin expression in the $\mathrm{Cl}-\mathrm{C} 2$. (b) The quantitative analysis shows that in the NTG group, the relative optical density of the nNOS-specific band was significantly higher than in the placebo group. AEA treatment weakened this effect. ${ }^{*} p<0.05 ;{ }^{* *} p<0.01$. nNOS: neuronal nitric oxide synthase; NTG: nitroglycerin; AEA: anandamide.

cells was significantly higher than in the placebo group $(p<0.05)$. This value decreased in the AEA-injected group $(p<0.05)$ (Figure 4).

\section{NTG enhanced expression of COX-2 enzyme, and $A E A$ inhibited this action}

A band characteristic of the COX-2 protein was identified at $68 \mathrm{kDa}$ in Western blot assay. Densitometric analyses showed that the COX-2 bands were significantly enhanced $(p<0.01)$ in segments $\mathrm{C} 1-\mathrm{C} 2$ after NTG administration as compared with the placebo-treated animals. The effect of NTG was decreased by the AEA treatment $(p<0.01)$ (Figure 5).

\section{NTG decreased KAT-II expression, which was alleviated by AEA}

A band characteristic of the KAT-II protein was referred at $60 \mathrm{kDa}$ in Western blot assay. Densitometric analyses confirmed that the KAT-II bands were significantly weaker $(p<0.05)$ in segments C1-C2 after NTG administration as compared with the placebo-treated animals. This effect was reversed by treatment with AEA $(p<0.05)$ (Figure 6).

\section{Discussion}

The present data indicate that NTG treatment activates the trigeminal system, and the observed changes can be interpreted as a central sensitization phenomenon. The NTG-induced alterations are reversed by the administration of AEA suggesting the involvement of CBs in this process.

It is generally accepted that the trigeminal pain processing and sensitization is an extremely complex phenomenon involving numerous cellular and molecular components but the associated pathways are not fully known. Figure 7 shows a schematic and simplified flow diagram that indicates that the connections are sometimes indirect and the signaling molecules may modulate the complex response at different target points.

\section{TRPVI}

TRPV1 is present in the terminals of primary sensory neurons in the dorsal part of the spinal cord (38) and co-expressed with CB1 (39). Experimental data indicate that TRPV1 contributes to the peripheral sensitization, allodynia and hyperalgesia (40); central blockade of this receptor is able to attenuate central terminal sensitization 




Figure 4. (a) Photomicrographs of the NF- $\kappa B$ expression in the $\mathrm{Cl}-\mathrm{C} 2$ segment. (b) The diagram shows that NTG treatment resulted in a significant increase in the volume density of NF- $\kappa B$-immunoreactive cells. This effect was not observed in AEA-injected animals. Scale bar: $50 \mu \mathrm{m},{ }^{*} p<0.05$. NF- $\kappa$ B: nuclear factor kappa B; IR: immunoreactive; NTG: nitroglycerin; AEA: anandamide.

(41). Our results show that NTG significantly increases TRPV1 expression in the C1-C2 segments of the rat, thus it may be the indicator of sensitization phenomena in the trigeminal system in our experimental setting.

It is well evidenced that $\mathrm{NO}$ donors can activate TRPV1 in several cell types $(24,42)$, and in inflammatory pain models increased receptor expression was also reported $(43,44)$. This indicates that the NTG effect on TRPV1 expression is indirect - it may cause neurogenic inflammation (45), and the inflammatory mediators like serotonin (5-HT) and bradykinin (BK) can activate TRPV1 by stimulating trigeminal nociceptive neurons (46). Pro-inflammatory mediators, such as tumor necrosis factor $\alpha$, interleukin 1 (IL-1), interleukin 6 (IL-6) and BK enhance TRPV1 (47). In the animal model of inflammation, Complete Freud's adjuvant increases TRPV1 messenger RNA (mRNA) expression in the dorsal root ganglion (48), this also supports the idea that inflammation upregulates TRPV1 expression. To summarize, we may assume that NTG is able to activate TRPV1 mainly via inflammatory mediators.
On the other hand, there are research data indicating that systemic administration of calcitonin gene-related peptide (CGRP) increases the expression of TRPV1 in the TG of rats (49), which might also play a role in this process.

Our recent data also show that $\mathrm{AEA}$, a $\mathrm{CB}$ receptor and TRPV1 agonist, attenuates the effect of NTG on TRPV1 changes. Activation of ionotropic CBs can result in inhibition of nociceptors and antihyperalgesia and antinociception in certain pain models (50). Intrathecal administration of AEA decreases thermal pain sensitivity and its effect can be altered with the TRPV1 antagonist capsazepine (51). AEA may also cause a desensitization of TRPV1 in skeletal muscle arterioles (52), suggesting that AEA is able to mitigate TRPV1 activity. On the other hand, AEA can inhibit neurogenic, CGRP- and NO-induced dural vasodilation, and this involves pre- and postsynaptic mechanisms (53). A recent report shows that the AEA level changes are able to modulate CGRP mRNA expression after NTG-treatment in human peripheral blood 


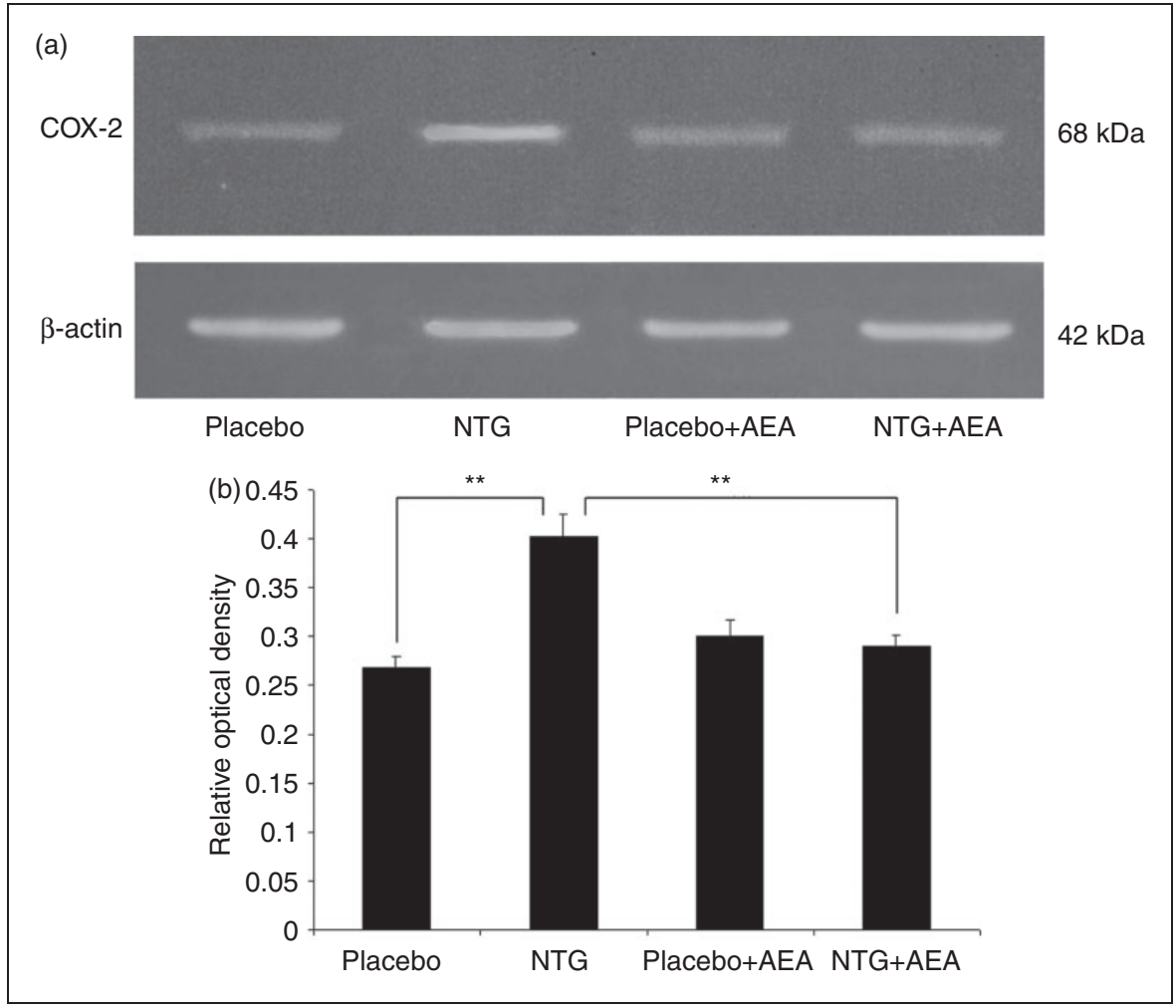

Figure 5. (a) Western blot of COX-2 and $\beta$-actin expression in the $\mathrm{Cl}-\mathrm{C} 2$. (b) Densitometry of the individual bands indicated that in the NTG-treated animals the expression of COX-2 was significantly higher than in the placebo group. No such effect was seen in the AEA-injected group. **p $<0.01$. COX-2: cyclooxygenase-2; NTG: nitroglycerin; AEA: anandamide.

mononuclear cells (54). We do not know exactly the role of TRPV1 in the AEA-modulated sensitization process, but based on the available literature data $(15,55)$, we hypothesize that the role of $\mathrm{CB} 1$ is more pronounced than TRPV1 in this context.

\section{$n N O S$}

It is known that nNOS is a key player in nociception (56) and its role in the sensitization cascade is intensively studied. In our present experiment administration of NTG increased the expression of nNOS in the $\mathrm{C} 1-\mathrm{C} 2$, which is in line with earlier results (10). The most probable explanation for this phenomenon is that NO activates small-caliber fibers in the trigeminal system and the increase of nNOS expression in the second-order trigeminal neurons induces a self-amplifying mechanism $(10,11)$. The present results indicate that AEA is able to inhibit this effect. Several studies have shown that there is an interaction between $\mathrm{NO}$ and the cannabinoid system, e.g. nNOS and $\mathrm{CB} 1$ are colocalized in neurons in lamina II of the spinal cord (57); NTG-induced hyperalgesia is associated with a fluctuation of the endocannabinoid system in various brain areas of rats (22). Our data are in line with the findings of Hillard and colleagues, who reported that
$\mathrm{CB} 1$ agonists inhibit $\mathrm{KCl}$-induced activation of $\mathrm{nNOS}$ in cultured cerebellar granule cells (58). In addition, Carney and colleagues have detected that cannabinoid agonist downregulated nNOS protein and mRNA in neuronal cells (59). These data suggest that NTG is able to generate a sensitization process and AEA inhibits this effect by blocking nNOS.

\section{$N F-\kappa B$}

In our experiment $\mathrm{NTG}$ increased $\mathrm{NF}-\kappa \mathrm{B}$ expression in the superficial layers of the dorsal horn in the $\mathrm{C} 1-\mathrm{C} 2$ segments. A similar effect was reported by Reuter et al., who demonstrated that NTG infusion is able to trigger the activation of $N F-\kappa B$ in dura mater (60). It is not clear how NTG can activate the NF-кB-pathway; it might be related to a direct neuronal effect of NTG, or an indirect effect via dural inflammation (61). Concerning the cellular mechanisms it is important to note that both TRPV1 and nNOS might play a role in this effect. It was shown that $\mathrm{Ca}^{2+}$ influx through TRPV1 may modulate the nuclear translocation and increased the activity of $N F-\kappa B$ (62). On the other hand the increase in nNOS expression is accompanied by increased NF- $\mathrm{B}$ expression and activation (63). Furthermore, Sancho and colleagues have noticed 


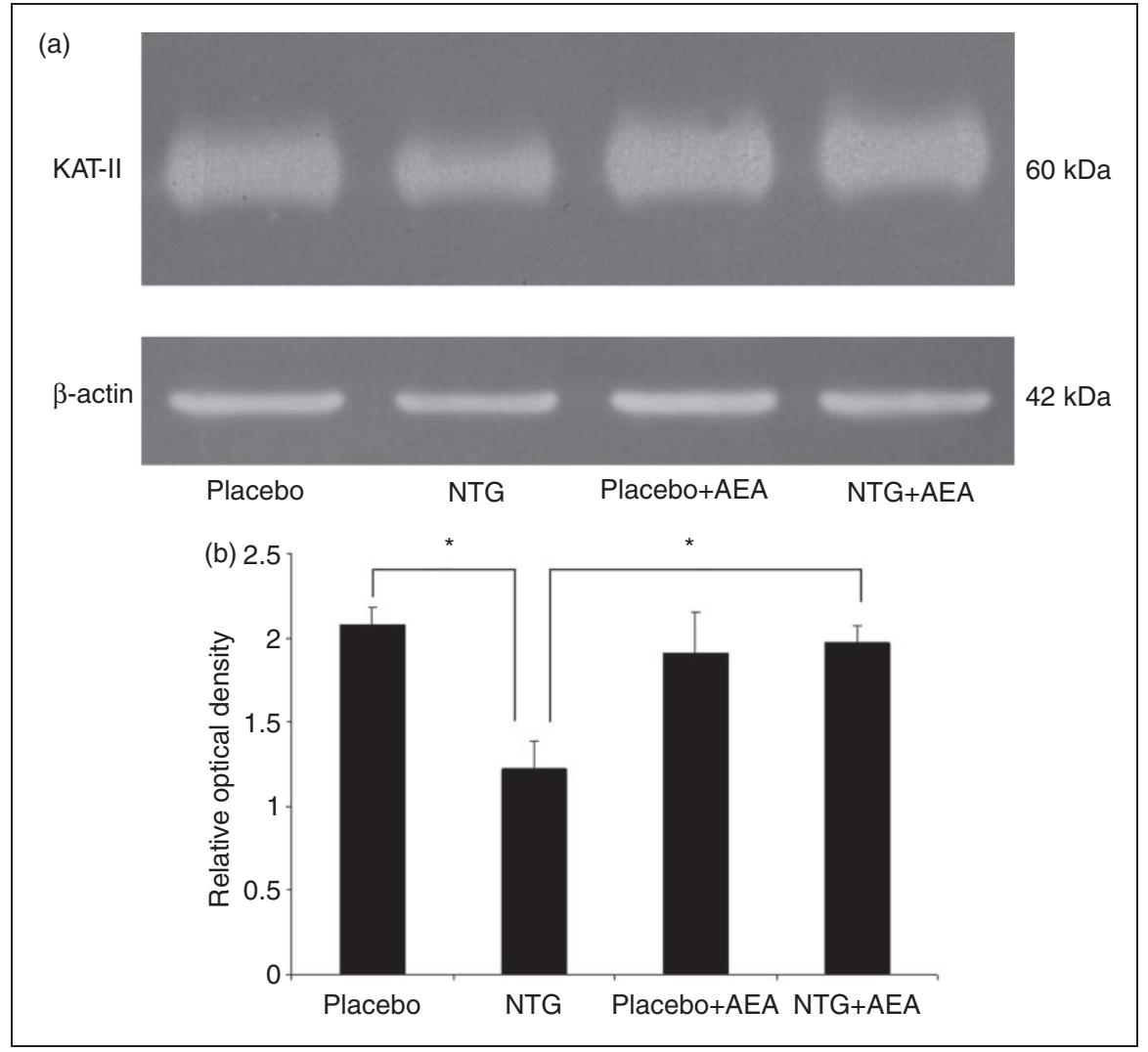

Figure 6. (a) Western blot of KAT-II and $\beta$-actin expression in the $\mathrm{CI}-\mathrm{C} 2$. (b) Quantitative data demonstrate that in the NTG group, the relative optical density of KAT-II is significantly lower than in the placebo group. AEA reduced this effect. *p $<0.05$. KAT-II: kynurenine aminotransferase-II; NTG: nitroglycerin; AEA: anandamide.

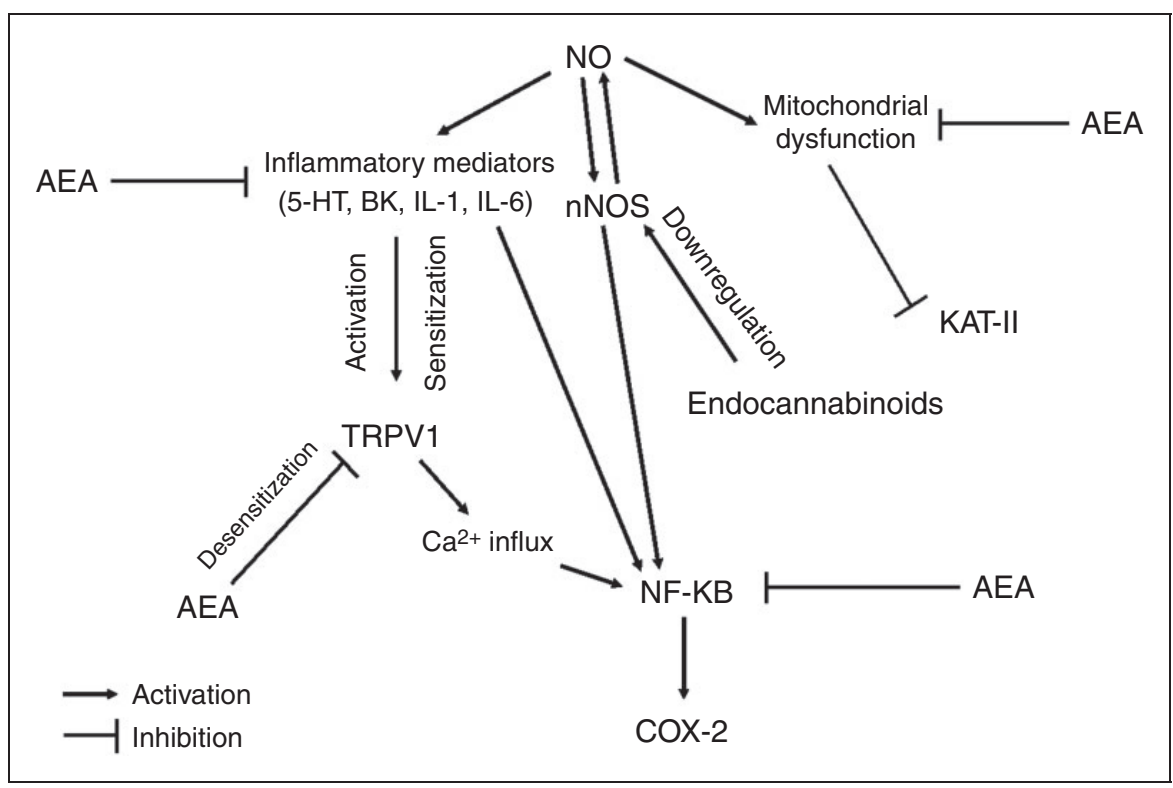

Figure 7. Schematic illustration of the interactions among the NO-influenced molecules involved in the trigeminal pain processing and sensitization showing the possible sites of action for cannabinoids. 
that AEA inhibits tumor necrosis factor- $\alpha$-induced activation by inhibition of a cytokine-induced cascade (64). In addition, Nakajima and colleagues have found that AEA also blocked lipopolysaccharide-induced activation, suggesting that AEA inhibits proinflammatory mediators by blocking NF- $\kappa \mathrm{B}$ activation (65). Tassorelli and her group reported that parthenolide (inhibitor of NF- $\mathrm{KB}$ ) attenuated NTG-induced c-Fos activation in TNC (66), which indicates that NF- $\kappa \mathrm{B}$ may be important in the NTG-induced trigeminal activation and its inhibition is able to modulate the nociceptive process. Our data reconfirm that NTG is able to activate $\mathrm{NF}-\kappa \mathrm{B}$, and thus can trigger neurogenic inflammation, which has a key role in sensitization phenomena. Furthermore, we detected that AEA is able to reduce this effect. Endocannabinoids might operate a negative feedback control over the proinflammatory process by suppressing the activation of transcription factors involved in the inflammatory action (67).

\section{COX-2}

NO may also cause neurogenic inflammation by increasing NF- $\kappa \mathrm{B}$ levels, which may lead to the upregulation of COX-2 in inflammatory pain (68). It is well known that nonsteroidal anti-inflammatory drugs (NSAIDs), which exert their effects through the inhibition of COX-enzymes (69), are effective in the treatment of migraine and tension-type headache (70). In animal studies, it has been shown that COX-2 is involved in the NTG-induced activation and sensitization process of the trigeminal system. Pre-treatment with indomethacin (non-selective COX inhibitor) and NS398 (selective COX-2 inhibitor) reduced the NTGinduced c-Fos (11), nNOS and calmodulin-dependent protein kinase II alpha expression-changes in the TNC $(71,72)$. Tassorelli and colleagues have demonstrated that COX-2 expression is increased in the hypothalamus and caudal brain stem after NTG injection (73), thus COX is one of the mediators of NTG-induced neuronal activation. Furthermore, NO is able to activate COX-enzymes in fibroblasts, probably by an interaction with the iron-hem center of the enzyme (74). It is important to note that AEA is one of the substrates of COX-2 producing prostaglandin and ethanolamids (75). In our study, we have found that AEA is able to inhibit the NTG-induced COX-2 increase. The cellular and molecular background of this effect remains to be determined. Our assumption is that it may be associated with a negative feedback mechanism, but it is possible that after the cleavage of AEA some metabolites may downregulate COX-2 expression. Since AEA is able to reduce cytokine-induced cascade and proinflammatory mediators, it is also possible that the reduction of the inflammatory process is able to downregulate the COX-2 expression.

\section{KAT-II}

In our experiments NTG decreased KAT-II expression in the $\mathrm{C} 1-\mathrm{C} 2$ segments, which may indicate that fluctuation of KAT is involved in the NTG-triggered trigeminal activation. Recent studies have shown that migraine is associated with mitochondrial dysfunction (76). It has also been demonstrated that an NO donor is able to downregulate the respiratory chain complex and cause release of the mitochondrial cytochrome $\mathrm{C}$, thus causing a mitochondrial dysfunction (77). The decrease in KAT-II activity might be associated with mitochondrial damage as shown in the striatum of patients suffering in Huntington's disease (78). This is in line with our earlier data showing that administration of mitochondrial complex II inhibitor 3-nitropropionic acid is able to reduce KAT-II activity in rats (79). On the other hand, NTG may cause neurogenic inflammation and the released pro-inflammatory cytokines can modulate the kynurenine pathway (80), which may also contribute to the change in KAT-II expression. Nevertheless, in another model of trigeminal activation (electrical stimulation of the TG), decreased KAT-immunoreactivity in dural macrophages, Schwann cells and mastocytes was found in rats (81), suggesting a prominent role of this enzyme in the process of trigeminal activation.

In the present experiment, we have detected that AEA is able to mitigate NTG-induced KAT-II expression decrease. AEA and the other endocannabinoid molecule 2-arachidonoylglicerol cause reduction of calcium-induced cytochrome $\mathrm{C}$ release from mitochondria and protect mitochondria from cytochrome-mediated damage, which leads to DNA fragmentation and apoptosis $(82,83)$. Taken together, it is possible that NTG may cause mitochondrial dysfunction, and AEA is able to inhibit this effect probably by decreasing cytochrome $\mathrm{C}$ release.

\section{Conclusions}

In conclusion, our results show that AEA has a modulating effect on central sensitization markers in our experimental setting. These data suggest that the endocannabinoid system plays a significant role in the cellular mechanism of trigeminal sensitization and thus it may modulate the pathomechanism of migraine. 


\section{Article highlights}

- Systemic administration of nitroglycerin is able to activate and sensitize the trigeminal system in rats.

- This phenomenon is reflected by alteration of the expression of biological markers (transient receptor potential vanilloid type 1 (TRPV1), neuronal nitric oxide synthase (nNOS), nuclear factor kappa B (NF$\kappa \mathrm{B})$, cyclooxygenase-2 (COX-2) and kynurenine aminotransferase-II (KAT-II)) of this process.

- Anandamide, a cannabinoid receptor agonist, is able to modulate these changes caused by nitroglycerin.

- Cannabinoid receptors are involved in the activation and sensitization of the trigeminal system.

\section{Acknowledgement}

We are indebted to Mrs Valéria Vékony for histotechnical assistance.

\section{Declaration of conflicting interests}

The authors declared no potential conflicts of interest with respect to the research, authorship, and/or publication of this article.

\section{Funding}

This work was supported by the Hungarian Brain Research Program (grant no. KTIA_13_NAP-A-III/9); the EUROHEADPAIN (FP7-Health 2013-Innovation; grant no. 602633); the TÁMOP-4.2.2.A-11/1/KONV-2012-0052; and the European Union and the State of Hungary, cofinanced by the European Social Fund in the framework of TÁMOP 4.2.4.A/2-11-1-2012-0052.

Dr Árpád Párdutz was supported by the Bolyai Scholarship Programme of the Hungarian Academy of Sciences.

\section{References}

1. Stovner L, Hagen K, Jensen R, et al. The global burden of headache: A documentation of headache prevalence and disability worldwide. Cephalalgia 2007; 27: 193-210.

2. Edvinsson L and Uddman R. Neurobiology in primary headaches. Brain Res Brain Res Rev 2005; 48: 438-456.

3. Goadsby PJ. Migraine, allodynia, sensitisation and all of that. Eur Neurol 2005; 53(Suppl 1): 10-16.

4. Burstein R, Collins B and Jakubowski M. Defeating migraine pain with triptans: A race against the development of cutaneous allodynia. Ann Neurol 2004; 55: 19-26.

5. Diaz-Insa S, Goadsby PJ, Zanchin G, et al. The impact of allodynia on the efficacy of almotriptan when given early in migraine: Data from the "Act when mild" study. Int J Neurosci 2011; 121: 655-661.

6. Goadsby PJ, Zanchin G, Geraud G, et al. Early vs. nonearly intervention in acute migraine-'Act when Mild (AwM)'. A double-blind, placebo-controlled trial of almotriptan. Cephalalgia 2008; 28: 383-391.

7. Burstein R, Yarnitsky D, Goor-Aryeh I, et al. An association between migraine and cutaneous allodynia. Ann Neurol 2000; 47: 614-624.
8. Sicuteri F, Del Bene E, Poggioni M, et al. Unmasking latent dysnociception in healthy subjects. Headache 1987; 27: $180-185$.

9. Tassorelli C and Joseph SA. Systemic nitroglycerin induces Fos immunoreactivity in brainstem and forebrain structures of the rat. Brain Res 1995; 682: 167-181.

10. Pardutz A, Krizbai I, Multon S, et al. Systemic nitroglycerin increases nNOS levels in rat trigeminal nucleus caudalis. Neuroreport 2000; 11: 3071-3075.

11. Tassorelli C, Joseph SA and Nappi G. Neurochemical mechanisms of nitroglycerin-induced neuronal activation in rat brain: A pharmacological investigation. Neuropharmacology 1997; 36: 1417-1424.

12. Pettit DA, Anders DL, Harrison MP, et al. Cannabinoid receptor expression in immune cells. Adv Exp Med Biol 1996; 402: 119-129.

13. Guindon $\mathbf{J}$ and Hohmann AG. The endocannabinoid system and pain. CNS Neurol Disord Drug Targets 2009; 8: 403-421.

14. Pertwee RG. Cannabinoid receptors and pain. Prog Neurobiol 2001; 63: 569-611.

15. Akerman S, Holland PR and Goadsby PJ. Cannabinoid (CB1) receptor activation inhibits trigeminovascular neurons. J Pharmacol Exp Ther 2007; 320: 64-71.

16. Wilson RI and Nicoll RA. Endocannabinoid signaling in the brain. Science 2002; 296: 678-682.

17. Crawley JN, Corwin RL, Robinson JK, et al. Anandamide, an endogenous ligand of the cannabinoid receptor, induces hypomotility and hypothermia in vivo in rodents. Pharmacol Biochem Behav 1993; 46: 967-972.

18. Caterina MJ, Rosen TA, Tominaga M, et al. A capsaicinreceptor homologue with a high threshold for noxious heat. Nature 1999; 398: 436-441.

19. Caterina MJ, Schumacher MA, Tominaga M, et al. The capsaicin receptor: A heat-activated ion channel in the pain pathway. Nature 1997; 389: 816-824.

20. Pertwee RG. Pharmacology of cannabinoid CB1 and CB2 receptors. Pharmacol Ther 1997; 74: 129-180.

21. White R and Hiley CR. The actions of some cannabinoid receptor ligands in the rat isolated mesenteric artery. Br J Pharmacol 1998; 125: 533-541.

22. Greco R, Gasperi V, Sandrini G, et al. Alterations of the endocannabinoid system in an animal model of migraine: Evaluation in cerebral areas of rat. Cephalalgia 2010; 30: 296-302. 
23. Tominaga M, Caterina MJ, Malmberg AB, et al. The cloned capsaicin receptor integrates multiple painproducing stimuli. Neuron 1998; 21: 531-543.

24. Miyamoto T, Dubin AE, Petrus MJ, et al. TRPV1 and TRPA1 mediate peripheral nitric oxide-induced nociception in mice. PLoS One 2009; 4: e7596.

25. Pan L, Song K, Hu F, et al. Nitric oxide induces apoptosis associated with TRPV1 channel-mediated $\mathrm{Ca}(2+)$ entry via S-nitrosylation in osteoblasts. Eur $J$ Pharmacol 2013; 715: 280-285.

26. Dohrn CS, Mullett MA, Price RH, et al. Distribution of nitric oxide synthase-immunoreactive interneurons in the spinal trigeminal nucleus. J Comp Neurol 1994; 346: 449-460.

27. Kress M and Reeh PW. More sensory competence for nociceptive neurons in culture. Proc Natl Acad Sci U S A 1996; 93: 14995-14997.

28. Mazario J, Gaitan G and Herrero JF. Cyclooxygenase-1 vs. cyclooxygenase-2 inhibitors in the induction of antinociception in rodent withdrawal reflexes. Neuropharmacology 2001; 40: 937-946.

29. Gao Y and Duan YZ. Increased COX2 in the trigeminal nucleus caudalis is involved in orofacial pain induced by experimental tooth movement. Anat Rec (Hoboken) 2010; 293: 485-491.

30. Birch PJ, Grossman CJ and Hayes AG. Kynurenate and FG9041 have both competitive and non-competitive antagonist actions at excitatory amino acid receptors. Eur J Pharmacol 1988; 151: 313-315.

31. Hilmas C, Pereira EF, Alkondon M, et al. The brain metabolite kynurenic acid inhibits alpha7 nicotinic receptor activity and increases non-alpha7 nicotinic receptor expression: Physiopathological implications. J Neurosci 2001; 21: 7463-7473.

32. Fejes-Szabó A, Bohár Z, Vámos E, et al. Pre-treatment with new kynurenic acid amide dose-dependently prevents the nitroglycerine-induced neuronal activation and sensitization in cervical part of trigemino-cervical complex. J Neural Transm 2014; 121: 725-738.

33. Knyihar-Csillik E, Mihaly A, Krisztin-Peva B, et al. The kynurenate analog SZR-72 prevents the nitroglycerolinduced increase of c-fos immunoreactivity in the rat caudal trigeminal nucleus: Comparative studies of the effects of SZR-72 and kynurenic acid. Neurosci Res 2008; 61: 429-432.

34. Vámos E, Párdutz A, Varga H, et al. L-kynurenine combined with probenecid and the novel synthetic kynurenic acid derivative attenuate nitroglycerin-induced nNOS in the rat caudal trigeminal nucleus. Neuropharmacology 2009; 57: 425-429.

35. Snider NT, Nast JA, Tesmer LA, et al. A cytochrome P450-derived epoxygenated metabolite of anandamide is a potent cannabinoid receptor 2-selective agonist. Mol Pharmacol 2009; 75: 965-972.

36. Vámos E, Fejes A, Koch J, et al. Kynurenate derivative attenuates the nitroglycerin-induced CamKIIalpha and CGRP expression changes. Headache 2010; 50: 834-843.

37. Gundersen HJ, Bagger P, Bendtsen TF, et al. The new stereological tools: Disector, fractionator, nucleator and point sampled intercepts and their use in pathological research and diagnosis. APMIS 1988; 96: 857-881.

38. Valtschanoff JG, Rustioni A, Guo A, et al. Vanilloid receptor VR1 is both presynaptic and postsynaptic in the superficial laminae of the rat dorsal horn. J Comp Neurol 2001; 436: 225-235.

39. Morisset V, Ahluwalia J, Nagy I, et al. Possible mechanisms of cannabinoid-induced antinociception in the spinal cord. Eur J Pharmacol 2001; 429: 93-100.

40. Saloman JL, Chung MK and Ro JY. P2X(3) and TRPV1 functionally interact and mediate sensitization of trigeminal sensory neurons. Neuroscience 2013; 232: 226-238.

41. Kim YS, Chu Y, Han L, et al. Central terminal sensitization of TRPV1 by descending serotonergic facilitation modulates chronic pain. Neuron 2014; 81: 873-887.

42. Leonelli M, Martins DO and Britto LR. Retinal cell death induced by TRPV1 activation involves NMDA signaling and upregulation of nitric oxide synthases. Cell Mol Neurobiol 2013; 33: 379-392.

43. Ji RR, Samad TA, Jin SX, et al. p38 MAPK activation by NGF in primary sensory neurons after inflammation increases TRPV1 levels and maintains heat hyperalgesia. Neuron 2002; 36: 57-68.

44. Kao DJ, Li AH, Chen JC, et al. CC chemokine ligand 2 upregulates the current density and expression of TRPV1 channels and Nav1.8 sodium channels in dorsal root ganglion neurons. J Neuroinflammation 2012; 9: 189.

45. Reuter U, Bolay H, Jansen-Olesen I, et al. Delayed inflammation in rat meninges: Implications for migraine pathophysiology. Brain 2001; 124(Pt 12): 2490-2502.

46. Strassman AM, Raymond SA and Burstein R. Sensitization of meningeal sensory neurons and the origin of headaches. Nature 1996; 384: 560-564.

47. Malek N, Pajak A, Kolosowska N, et al. The importance of TRPV1-sensitisation factors for the development of neuropathic pain. Mol Cell Neurosci 2015; 65: 1-10.

48. Amaya F, Oh-hashi K, Naruse Y, et al. Local inflammation increases vanilloid receptor 1 expression within distinct subgroups of DRG neurons. Brain Res 2003; 963 : 190-196.

49. Chatchaisak D, Srikiatkhachorn A, Maneesri-le Grand S, et al. The role of calcitonin gene-related peptide on the increase in transient receptor potential vanilloid-1 levels in trigeminal ganglion and trigeminal nucleus caudalis activation of rat. J Chem Neuroanat 2013; 47: 50-56.

50. Akopian AN, Ruparel NB, Jeske NA, et al. Role of ionotropic cannabinoid receptors in peripheral antinociception and antihyperalgesia. Trends Pharmacol Sci 2009; 30: 79-84.

51. Horvath G, Kekesi G, Nagy E, et al. The role of TRPV1 receptors in the antinociceptive effect of anandamide at spinal level. Pain 2008; 134: 277-284.

52. Lizanecz E, Bagi Z, Pásztor ET, et al. Phosphorylationdependent desensitization by anandamide of vanilloid receptor-1 (TRPV1) function in rat skeletal muscle arterioles and in Chinese hamster ovary cells expressing TRPV1. Mol Pharmacol 2006; 69: 1015-1023.

53. Akerman S, Kaube $\mathrm{H}$ and Goadsby PJ. Anandamide is able to inhibit trigeminal neurons using an in vivo model 
of trigeminovascular-mediated nociception. J Pharmacol Exp Ther 2004; 309: 56-63.

54. Peng LM, Chen XP, Shi RZ, et al. Involvement of anandamide transporter in calcitonin gene-related peptide expression stimulated by nitroglycerin and influence of ALDH2 Glu504Lys polymorphism. $J$ Cardiovasc Pharmacol 2014; 64: 460-464.

55. Akerman S, Kaube $\mathrm{H}$ and Goadsby PJ. Anandamide acts as a vasodilator of dural blood vessels in vivo by activating TRPV1 receptors. $\mathrm{Br} J$ Pharmacol 2004; 142: 1354-1360.

56. Lin Q, Palecek J, Paleckova V, et al. Nitric oxide mediates the central sensitization of primate spinothalamic tract neurons. J Neurophysiol 1999; 81: 1075-1085.

57. Salio C, Fischer J, Franzoni MF, et al. Pre- and postsynaptic localizations of the $\mathrm{CB} 1$ cannabinoid receptor in the dorsal horn of the rat spinal cord. Neuroscience 2002; 110: 755-764.

58. Hillard CJ, Muthian S and Kearn CS. Effects of CB(1) cannabinoid receptor activation on cerebellar granule cell nitric oxide synthase activity. FEBS Lett 1999; 459: 277-281.

59. Carney ST, Lloyd ML, MacKinnon SE, et al. Cannabinoid regulation of nitric oxide synthase I (nNOS) in neuronal cells. J Neuroimmune Pharmacol 2009; 4: 338-349.

60. Reuter U, Chiarugi A, Bolay H, et al. Nuclear factorkappaB as a molecular target for migraine therapy. Ann Neurol 2002; 51: 507-516.

61. Greco R, Tassorelli C, Cappelletti D, et al. Activation of the transcription factor NF-kappaB in the nucleus trigeminalis caudalis in an animal model of migraine. Neurotoxicology 2005; 26: 795-800.

62. Sappington RM and Calkins DJ. Contribution of TRPV1 to microglia-derived IL-6 and NFkappaB translocation with elevated hydrostatic pressure. Invest Ophthalmol Vis Sci 2008; 49: 3004-3017.

63. Parohova J, Vrankova S, Barta A, et al. The cross-talk of nuclear factor kappaB and nitric oxide in the brain. Activitas Nervosa Superior Rediviva 2009; 51: 123-126.

64. Sancho R, Calzado MA, Di Marzo V, et al. Anandamide inhibits nuclear factor-kappaB activation through a cannabinoid receptor-independent pathway. Mol Pharmacol 2003; 63: 429-438.

65. Nakajima Y, Furuichi Y, Biswas KK, et al. Endocannabinoid, anandamide in gingival tissue regulates the periodontal inflammation through NF-kappaB pathway inhibition. FEBS Lett 2006; 580: 613-619.

66. Tassorelli C, Greco R, Morazzoni P, et al. Parthenolide is the component of tanacetum parthenium that inhibits nitroglycerin-induced Fos activation: Studies in an animal model of migraine. Cephalalgia 2005; 25: 612-621.

67. Berdyshev EV, Schmid PC, Krebsbach RJ, et al. Activation of PAF receptors results in enhanced synthesis of 2arachidonoylglycerol (2-AG) in immune cells. FASEB $J$ 2001; 15: 2171-2178.

68. Lee KM, Kang BS, Lee HL, et al. Spinal NF-kB activation induces COX-2 upregulation and contributes to inflammatory pain hypersensitivity. Eur $J$ Neurosci 2004; 19: 3375-3381.

69. Yaksh TL, Dirig DM, Conway CM, et al. The acute antihyperalgesic action of nonsteroidal, anti-inflammatory drugs and release of spinal prostaglandin E2 is mediated by the inhibition of constitutive spinal cyclooxygenase-2 (COX-2) but not COX-1. J Neurosci 2001; 21: 5847-5853.

70. Lange R, Schwarz JA and Hohn M. Acetylsalicylic acid effervescent $1000 \mathrm{mg}$ (Aspirin) in acute migraine attacks; a multicentre, randomized, double-blind, single-dose, placebo-controlled parallel group study. Cephalalgia 2000; 20: 663-667.

71. Varga H, Pardutz A, Vámos E, et al. Selective inhibition of cyclooxygenase-2 attenuates nitroglycerin-induced calmodulin-dependent protein kinase II alpha in rat trigeminal nucleus caudalis. Neurosci Lett 2009; 451: 170-173.

72. Varga H, Pardutz A, Vámos E, et al. Cox-2 inhibitor attenuates NO-induced nNOS in rat caudal trigeminal nucleus. Headache 2007; 47: 1319-1325.

73. Tassorelli C, Greco R, Armentero MT, et al. A role for brain cyclooxygenase-2 and prostaglandin-E2 in migraine: Effects of nitroglycerin. Int Rev Neurobiol 2007; 82: 373-382.

74. Salvemini D, Misko TP, Masferrer JL, et al. Nitric oxide activates cyclooxygenase enzymes. Proc Natl Acad Sci U S A 1993; 90: 7240-7244.

75. Yu M, Ives D and Ramesha CS. Synthesis of prostaglandin E2 ethanolamide from anandamide by cyclooxygenase-2. J Biol Chem 1997; 272: 21181-21186.

76. Stuart $\mathrm{S}$ and Griffiths LR. A possible role for mitochondrial dysfunction in migraine. Mol Genet Genomics 2012; 287: 837-844.

77. Ushmorov A, Ratter F, Lehmann V, et al. Nitric-oxideinduced apoptosis in human leukemic lines requires mitochondrial lipid degradation and cytochrome $\mathrm{C}$ release. Blood 1999; 93: 2342-2352.

78. Vécsei L, Szalárdy L, Fülöp F, et al. Kynurenines in the CNS: Recent advances and new questions. Nat Rev Drug Discov 2013; 12: 64-82.

79. Csillik A, Knyihár E, Okuno E, et al. Effect of 3-nitropropionic acid on kynurenine aminotransferase in the rat brain. Exp Neurol 2002; 177: 233-241.

80. Mandi $\mathrm{Y}$ and Vecsei L. The kynurenine system and immunoregulation. J Neural Transm 2012; 119: 197-209.

81. Knyihár-Csillik E, Chadaide Z, Okuno E, et al. Kynurenine aminotransferase in the supratentorial dura mater of the rat: Effect of stimulation of the trigeminal ganglion. Exp Neurol 2004; 186: 242-247.

82. Catanzaro G, Rapino C, Oddi S, et al. Anandamide increases swelling and reduces calcium sensitivity of mitochondria. Biochem Biophys Res Commun 2009; 388: 439-442.

83. Zaccagnino P, D'Oria S, Romano LL, et al. The endocannabinoid 2-arachidonoylglicerol decreases calcium induced cytochrome c release from liver mitochondria. J Bioenerg Biomembr 2012; 44: 273-280. 
II. 


\title{
The Effect of Systemic Nitroglycerin Administration on the Kynurenine Pathway in the Rat
}

\author{
Gábor Nagy-Grócz ${ }^{1,2}$, Klaudia F. Laborc ${ }^{3}$, Gábor Veres ${ }^{1}$, Attila Bajtai $^{3}$, Zsuzsanna Bohár $^{1,3}$, \\ Dénes Zádori ${ }^{3}$, Annamária Fejes-Szabó ${ }^{1}$, Eleonóra Spekker ${ }^{3}$, László Vécsei ${ }^{1,3 *}$ and \\ Árpád Párdutz ${ }^{3}$
}

${ }^{1}$ MTA-SZTE Neuroscience Research Group, University of Szeged, Szeged, Hungary, ${ }^{2}$ Faculty of Health Sciences and Social Studies, University of Szeged, Szeged, Hungary, ${ }^{3}$ Department of Neurology, Faculty of Medicine, Albert Szent-Györgyi Clinical Center, University of Szeged, Szeged, Hungary

OPEN ACCESS

Edited by: Anna Andreou, Imperial College London, United Kingdom

Reviewed by: Marcelo M. Valença, Federal University of

Pernambuco, Brazil Stefan Evers,

Universität Münster, Germany

*Correspondence: László Vécsei vecsei.laszlo@med.u-szeged.hu

Specialty section: This article was submitted to Headache Medicine and Facial Pain, a section of the journal Frontiers in Neurology

Received: 15 February 2017 Accepted: 29 May 2017 Published: 14 June 2017

Citation:

Nagy-Grócz G, Laborc KF, Veres G,

Bajtai A, Bohár Z, Zádori D,

Fejes-Szabó A, Spekker E, Vécsei L and Párdutz Á (2017) The Effect of

Systemic Nitroglycerin Administration on the Kynurenine Pathway in the Rat.

Front. Neurol. 8:278.

doi: 10.3389/fneur.2017.00278
The primary headache disorders include migraine, which is one of the most frequent neurological disorders, which influences more than $14 \%$ of the whole population. Despite the research efforts, its exact pathomechanism is not fully revealed, but evidence points to the role of glutamate and its receptors. Kynurenic acid is an endogenous glutamate receptor antagonist produced by the kynurenine pathway (KP). Tryptophan 2,3-dioxygenase (TDO) and indoleamine 2,3-dioxygenase (IDO) convert L-tryptophan to $N$-formylL-kynurenine, to be further transformed to L-kynurenine. Kynurenine aminotransferase-II (KAT-II), L-kynurenine hydrolase (KYNU), and L-kynurenine 3-monooxygenase (KMO) are key enzymes in the later steps of the KP. Nitroglycerin (NTG) administration serves as both human and animal model of migraine, causing the activation and sensitization in the trigeminal system. A previous study demonstrated a reduction of KAT-II expression following NTG administration in animals. The goal of current tests was to identify the potential modulatory effect of NTG on other metabolizing enzymes of the KP in the caudal trigeminal nucleus (TNC) of rats. Four hours following the intraperitoneal injection of NTG $(10 \mathrm{mg} / \mathrm{kg})$, the rats were perfused transcardially and the TNC was extracted for Western blotting. Western blot studies revealed that the expression of TDO2, IDO1, $\mathrm{KYNU}$, and KMO decreased in the TNC. The results demonstrated that NTG is able to downregulate the $\mathrm{KP}$, with a potential influence on the glutamatergic system as well, contributing to the development of trigeminal activation and sensitization in animals.

\section{Keywords: migraine, nitroglycerin, kynurenic acid, L-kynurenine, kynurenine pathway}

\section{INTRODUCTION}

Migraine is a common primary headache characterized by severe head pain and numerous concomitant symptoms, e.g., vomiting, nausea, photophobia, and phonophobia. The disease affects about $14 \%$ of the total population (1). The exact pathophysiology of the disorder is not fully understood, but it is

\footnotetext{
Abbreviations: GAPDH, glyceraldehyde 3-phosphate dehydrogenase; IDO, indoleamine 2,3-dioxygenase; KAT-II, kynurenine aminotransferase-II; KMO, L-kynurenine 3-monooxygenase; KYNA, kynurenic acid; KYNU, L-kynurenine hydrolase; KP, kynurenine pathway; L-KYN, L-kynurenine; NMDA, $N$-methyl-D-aspartate; NO, nitric oxide; NTG, nitroglycerin PBS, phosphate-buffered saline; QUIN, quinolinic acid; TBST, Tris-buffered saline containing Tween 20; TDO, tryptophan 2,3-dioxygenase; TNC, caudal trigeminal nucleus; Trp, tryptophan.
} 
well known that the activation and sensitization of the trigeminal system is essential during the attack (2). Several lines of evidence have been put forth to support the hypothesis that glutamate receptors, principally $N$-methyl-D-aspartate (NMDA) receptors, have a pivotal aspect in these phenomena (3). Kynurenic acid (KYNA) is a neuroprotective metabolite that interacts with glutamate receptors, aryl hydrocarbon receptor, and G protein-coupled receptor 35 and elicits anti-glutamatergic actions. Series of data confirm that KYNA and its analogs have anti-nociceptive effects in several migraine models (4-6), probably by attenuating the trigeminal activation and sensitization. The initial process in the kynurenine pathway (KP) is the transformation of tryptophan (Trp) to $\mathrm{N}$-formyl-L-kynurenine by tryptophan 2,3-dioxygenase (TDO1, 2) and indoleamine 2,3-dioxygenase (IDO1,2): the rate-limiting enzymes of Trp metabolism. $N$-formyl-L-kynurenine is further converted by formamidase to L-kynurenine ( $\mathrm{L}-\mathrm{KYN})$, which is converted to KYNA by kynurenine aminotransferases (KATs), to 3-hydroxykynurenine by L-kynurenine 3-monooxygenase (KMO), and to anthranilic acid by L-kynurenine hydrolase (KYNU). The other metabolite of the KP is quinolinic acid (QUIN). In contrast to KYNA, QUIN is an agonist of the NMDA receptors and can provoke neuronal death and also causes lipid peroxidation and generates reactive oxygen species $(7,8)$ (Figure 1).

Systemic administration of nitroglycerin (NTG) can be utilized as a human and animal model of migraine. NTG is enzymatically converted to nitric oxide (NO) in the body, probably by a mitochondrial aldehyde dehydrogenase (9). The administration of NTG is able to activate and sensitize the trigeminal system in humans and animals (10-12). In our previous study, it was demonstrated that NTG decreased the expression of kynurenine aminotransferase-II (KAT-II) (13), which converts L-KYN to KYNA in the brain thus reducing KYNA levels, contributing to the hyperactivity of NMDA receptors.

The goal of this study was to explore the issue of NTG on the expression levels of TDO2, IDO1, KYNU, and KMO enzymes in the caudal trigeminal nucleus (TNC).

\section{MATERIALS AND METHODS}

\section{Animals}

We followed the directives for the Use of Animals in Research of the International Association for the Study of Pain and the policy of the European Economic Community (86/609/ECC). They were authorized by the local ethical committee of University of Szeged and the Scientific Ethics Committee for Animal Research of the Protection of Animals Advisory Board (XXIV./352/2012). 44 adult male Sprague-Dawley rats of 200-250 g bodyweight were used. The rodents were raised and maintained under standard laboratory conditions with tap water and regular rat chow available ad libitum on a $12 \mathrm{~h}$ dark-12 h light cycle.

\section{Drug Administration}

The animals were separated into two groups $(n=5)$. The animals in the first group, called placebo group, received only the vehicle solution (physiological saline) as treatment. In the second group, the rats were treated with an intraperitoneal injection of NTG (10 mg/kg bodyweight, Pohl Boskamp).

\section{Western Blot Analysis}

Four hours after the placebo/NTG injection, the animals were perfused transcardially with $100 \mathrm{~mL}$ phosphate-buffered saline and the dorsal horns of TNC segments $(+1$ and $-5 \mathrm{~mm}$ from the obex) were extracted. The samples were stored at $-80^{\circ} \mathrm{C}$ and they were sonicated in ice cold lysis buffer containing $50 \mathrm{mM}$ Tris- $\mathrm{HCl}$, $150 \mathrm{mM} \mathrm{NaCl}, 0.1 \%$ igepal, $0.1 \%$ cholic acid, $2 \mu \mathrm{g} / \mathrm{mL}$ leupeptin, $2 \mathrm{mM}$ phenylmethylsulfonyl fluoride, $1 \mu \mathrm{g} / \mathrm{mL}$ pepstatin, $2 \mathrm{mM}$ EDTA, and $0.1 \%$ sodium dodecyl sulfate. The homogenates were centrifuged for $10 \mathrm{~min}$ at $12,000 \mathrm{RPM}$ at $4^{\circ} \mathrm{C}$ and supernatants were aliquoted and stored at $-20^{\circ} \mathrm{C}$ until use. BCA Protein Assay Kit was used to measure protein concentration. Samples were mixed with sample buffer and were boiled for $3 \mathrm{~min}$. Standard SDS polyacrylamide gel electrophoresis was performed with equal amounts of protein samples $(20 \mu \mathrm{g} / \mathrm{lane})$ loaded on $10 \%$ Tris-glycine gel and electrotransferred onto Amersham Hybond-ECL nitrocellulose membrane $(0.45 \mu \mathrm{m}$ pore size). Page Ruler Prestained Protein Ladder $(10-170 \mathrm{kDa})$ was used to define approximate molecular weights. Non-specific binding was eliminated by blocking in Trisbuffered saline containing Tween 20 (TBST) and 5\% non-fat dry milk for $1 \mathrm{~h}$ at room temperature. Then, membranes were incubated in TBST containing 1\% non-fat dry milk and TDO antibody (LifeSpan BioSciences, LS-C111058, dilution: 1:500, incubation: overnight at room temperature), IDO antibody (Abcam, ab106134, dilution: 1:500, incubation: overnight at room temperature), KYNU antibody (Abcam, ab96365, dilution: 1:500, incubation: overnight at room temperature), KMO antibody (Abcam, ab83929, dilution: 1:4,000, incubation: overnight at room temperature), or glycerinaldehyde 3-phosphate dehydrogenase (GAPDH) antibody (Cell Signaling Technologies, 8884, dilution: 1:1,000, incubation: overnight at room temperature). On the following day, a horseradish peroxidase-conjugated anti-rabbit secondary antibody (Santa Cruz Biotechnology, sc-2030) in TBST containing 1\% non-fat dry milk was applied for $2 \mathrm{~h}$ at room temperature. SuperSignal West Pico Chemiluminescent Substrate was used to visualize bands on Carestream Kodak BioMax Light film. Western blot protocol was developed based on previous experiments $(4,14-16)$.

An observer blinded to the experimental groups carried out the measurements. The detailed methods were described previously (13).

Films were quantified by Java Image $1.47 \mathrm{v}$ analysis software (National Institutes of Health). The data were standardized to GAPDH.

\section{Statistical Analysis}

Statistical analysis was carried out by SPSS Statistics software (Version 20.0 for Windows, SPSS Inc.). Normality was checked by Kolmogorov-Smirnov test, and group means were compared by independent $t$-test, with $p<0.05$ taken as statistically significant. Group values are presented as means \pm SEM.

\section{RESULTS}

\section{NTG Induced a Decrease in TDO2 Expression in the TNC}

TDO2 protein was identified at $50 \mathrm{kDa}$ in Western blot assay. Densitometric analyses showed that the TDO2 bands were 




FIGURE 1 | The kynurenine pathway.

significantly decreased $(p<0.05)$ in the TNC after NTG administration as correlated with the placebo-treated animals (Figure 2).

\section{NTG Treatment Resulted in a Diminished ID01 Expression}

A band characteristic of the IDO1 protein was referred at $45 \mathrm{kDa}$ in Western blot assay. Densitometric analyses confirmed that the
IDO1 bands were significantly weaker $(p<0.05)$ in the TNC after NTG administration as correlated with the placebo-treated animals (Figure 3).

\section{NTG Was Able to Reduce the Expression of KYNU}

We could determine a band at $35 \mathrm{kDa}$ characteristic for the KYNU protein. In animals, which had received NTG, the density 

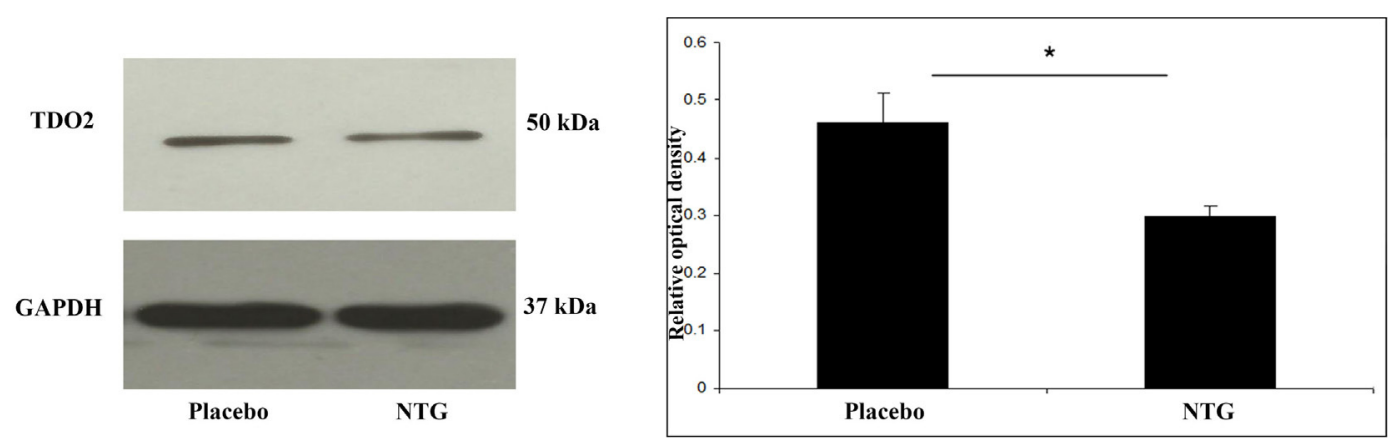

FIGURE 2 | Western blot analysis of TDO2 and GAPDH protein from the TNC. The quantitative analysis shows that in the NTG group the relative optical density of TDO2 specific bands were significantly less pronounced compared with the placebo group. ${ }^{*} p<0.05$; GAPDH, glyceraldehyde 3-phosphate dehydrogenase; NTG, nitroglycerin; TDO2, tryptophan 2,3-dioxygenase 2; TNC, caudal trigeminal nucleus.
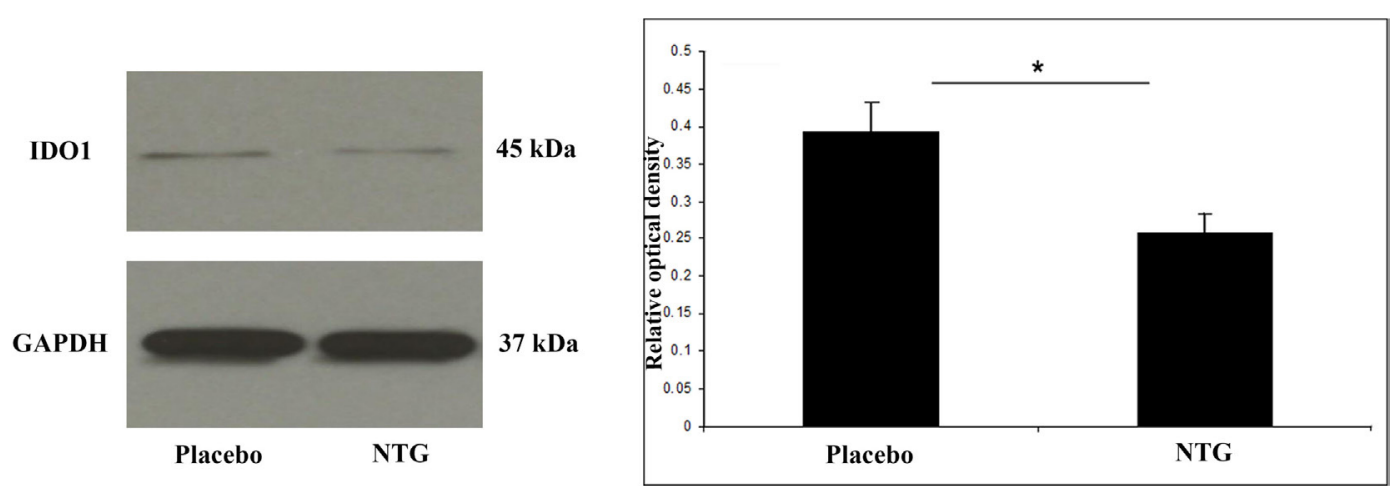

FIGURE 3 | Western blot of IDO1 and GAPDH expression in the TNC. The quantitative analysis shows that in the NTG group, the relative optical density of IDO1-specific bands was significantly decreased compared with the placebo group. ${ }^{*} p<0.05$; GAPDH, glyceraldehyde 3-phosphate dehydrogenase; IDO1, indoleamine 2,3-dioxygenase; NTG, nitroglycerin; TNC, caudal trigeminal nucleus.

of KYNU protein bands was weaker in TNC segments $(p<0.05)$ as compared with the placebo-treated group (Figure 4).

\section{KMO Expression Was Lower after NTG Administration}

L-Kynurenine 3-monooxygenase protein was identified at $56 \mathrm{kDa}$ in Western blot assay. Densitometric analyses showed that the KMO bands were significantly decreased $(p<0.05)$ in segments TNC after NTG administration as correlated with the placebotreated animals (Figure 5).

\section{DISCUSSION}

The current data demonstrated that NTG is able to decrease the expression of the KP enzymes in rat TNC. However, the question arises how NTG/NO can influence the KP. It is well known that the nitrergic system is able to alter the KP, e.g., NO can inhibit IDO expression via reversible binding to the active site in macrophages (17) and IDO activity is downregulated by NO production in bone marrow cells (18). The other hand, it is also known that the expression of $\mathrm{KMO}$ influences $\mathrm{NO}$ production in human HEK293 cells (19). Moreover, Backhaus and her colleagues showed in a mass spectrometry and NMR study that there is a direct interaction between kynurenine metabolites (e.g., 3-hydroxykynurenine and 3-hydroxyanthranilic acid) and NO (20).

It is also important to note that kynurenines have a crucial role in immune regulation (21). The transcriptional expression of IDO, KMO, and KYNU is also under the control of interferons (21), thus pro-inflammatory cytokines influence KP (22). Lögters and co-workers have shown that the ratio of kynureninetryptophan was increased in the blood of patients with posttraumatic sepsis (23), which pointed out that inflammation could modulate KP.

In this context, it is crucial that NO may cause neurogenic inflammation in the central nervous system. This is supported by observations that NTG was able to increase the expression of nuclear factor $\kappa \mathrm{B}$ in the trigeminocervical complex of rats $(13,24)$, which is a key player in the inflammation process controlled by cytokines. In human studies, Tfelt-Hansen and his group demonstrated that infusion of NTG can trigger inflammatory 


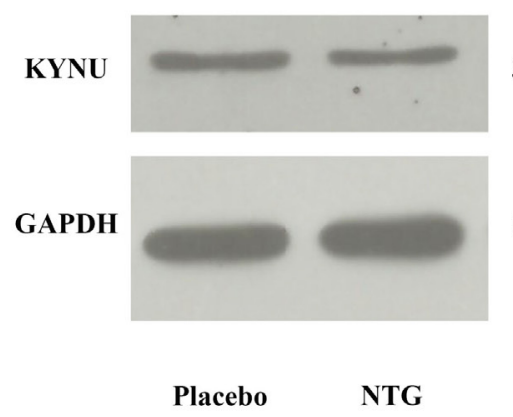

$35 \mathrm{kDa}$

37 kDa

Placebo NTG

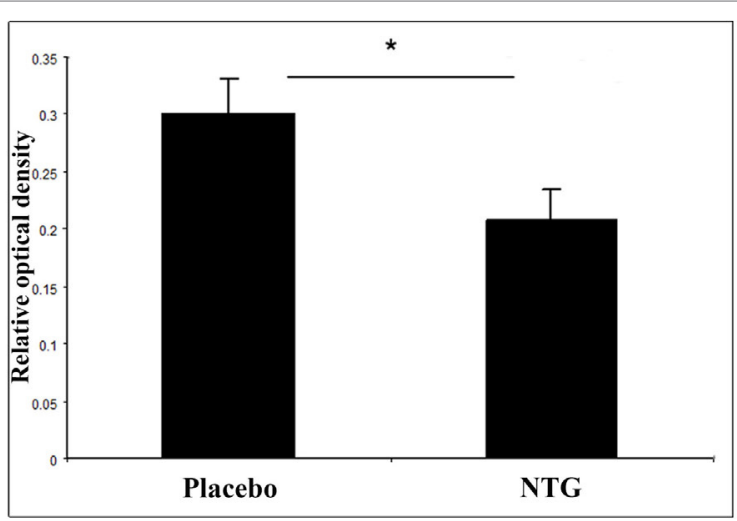

FIGURE 4 | Representative Western blot bands and diagram of KYNU and GAPDH in the TNC. The quantitative analysis shows that in the NTG group, the relative optical density of KYNU-specific bands were significantly smaller compared with the placebo group. ${ }^{*} p<0.05$; GAPDH, glyceraldehyde 3-phosphate dehydrogenase; KYNU, kynurenine hydrolase; NTG, nitroglycerin; TNC, caudal trigeminal nucleus.
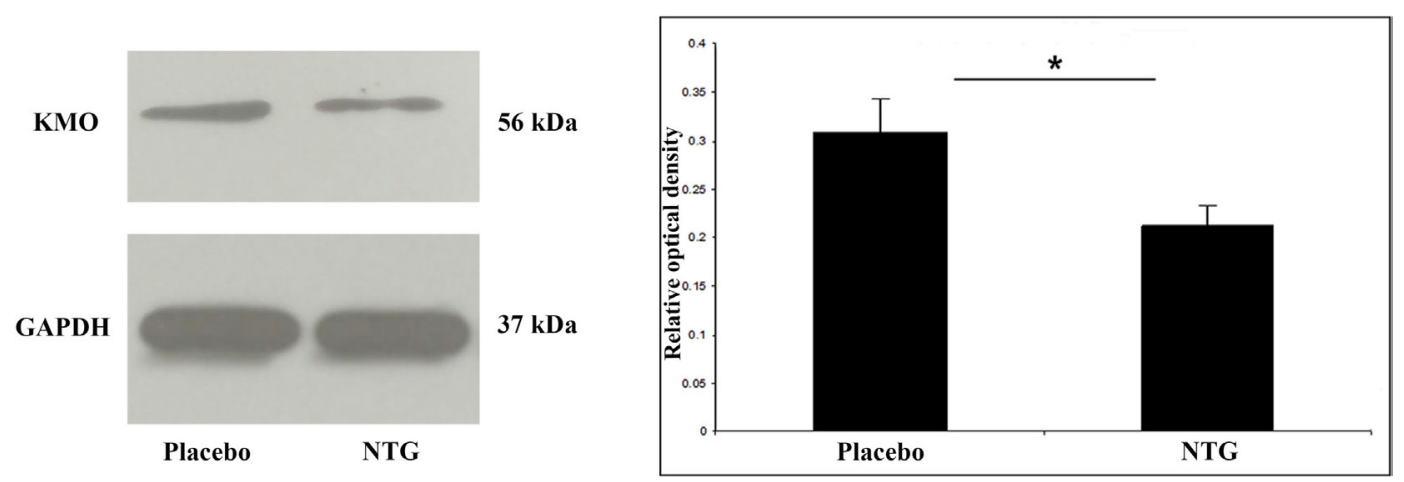

FIGURE 5 | Illustrative Western blot bands and diagram of KMO and GAPDH in the TNC. The quantitative analysis shows that in the NTG group, the relative optical density of $\mathrm{KMO}$ specific bands was significantly weaker compared with the placebo group. ${ }^{*} p<0.05$; GAPDH, glyceraldehyde 3-phosphate dehydrogenase; KMO, L-kynurenine 3-monooxygenase; NTG, nitroglycerin; TNC, caudal trigeminal nucleus.

response by inducing inflammatory mediators, which response was inhibited by the anti-inflammatory drug, prednisolone (25).

In the previous study, we demonstrated that NTG was able to decrease the expression of KAT-II, which produces KYNA. Our present and earlier Western blot data showed that NTG could reduce the expression levels of the KP enzymes.

Our findings are comparable with recent studies, which showed that the chronic migraine and cluster headaches are associated with altered levels of kynurenine metabolites, i.e., reduced levels of KYNA and L-KYN have been found in the serum of these patients $(26,27)$. These findings are in accordance with the theory of an increased release of glutamate probably yielding to a hyperactivity of glutamate receptors.

Migraine can be characterized by an increase in glutamatergic function (28), yielding fully activated NMDA receptors by the high glutamate levels, which might combine with small KYNA levels. Increased glutamate levels were found in the human cerebrospinal fluid, platelets, and plasma of migraine sufferers $(29,30)$.
To summarize the human and animal data, we can conclude that the KP is downregulated under the different types of headaches and thus possibly providing less KYNA. These data are in line with the theory of hyperactive NMDA receptors having a crucial role in the migraine pathophysiology. These receptors are key players in the mechanism of central sensitization (31), which have a pivotal role in the pathophysiology of migraine. Our present data strongly confirm that the KP has a relevant role in the pathomechanism of the trigeminal activation and sensitization, thus in the migraine pathology as well. In summary, influencing the KP provides a possible new target in the future therapy of migraine.

\section{ETHICS STATEMENT}

We followed the directives for the Use of Animals in Research of the International Association for the Study of Pain and the policy of the European Economic Community (86/609/ECC). They were authorized by the local ethical committee of University of 
Szeged and the Scientific Ethics Committee for Animal Research of the Protection of Animals Advisory Board (XXIV./352/2012).

\section{AUTHOR CONTRIBUTIONS}

GN-G: participated in the design and implementation of experiments, statistical analysis, interpreted data, and wrote the manuscript. KL, GV, AB, ZB, DZ, AF-S, and ES: participated in the implementation of the experiments and statistical analysis. LV: participated in the design of the experiments and in the final approval of the version to be published. ÁP: participated in the conception and design of the experiments and in the interpretation of the data and writing. All authors: critical revision of the manuscript.

\section{REFERENCES}

1. Stovner LJ, Andree C. Prevalence of headache in Europe: a review for the Eurolight project. J Headache Pain (2010) 11(4):289-99. doi:10.1007/ s10194-010-0217-0

2. Edvinsson L, Uddman R. Neurobiology in primary headaches. Brain Res Brain Res Rev (2005) 48(3):438-56. doi:10.1016/j.brainresrev.2004. 09.007

3. Woolf CJ, Salter MW. Neuronal plasticity: increasing the gain in pain. Science (2000) 288(5472):1765-9. doi:10.1126/science.288.5472.1765

4. Fejes-Szabo A, Bohar Z, Vamos E, Nagy-Grocz G, Tar L, Veres G, et al. Pre-treatment with new kynurenic acid amide dose-dependently prevents the nitroglycerine-induced neuronal activation and sensitization in cervical part of trigemino-cervical complex. J Neural Transm (Vienna) (2014) 121(7):725-38. doi:10.1007/s00702-013-1146-2

5. Csati A, Edvinsson L, Vecsei L, Toldi J, Fulop F, Tajti J, et al. Kynurenic acid modulates experimentally induced inflammation in the trigeminal ganglion. J Headache Pain (2015) 16:99. doi:10.1186/s10194-015-0581-x

6. Lukacs M, Warfvinge K, Kruse LS, Tajti J, Fulop F, Toldi J, et al. KYNA analogue SZR72 modifies CFA-induced dural inflammation-regarding expression of pERK1/2 and IL-1beta in the rat trigeminal ganglion. J Headache Pain (2016) 17(1):64. doi:10.1186/s10194-016-0654-5

7. Behan WM, McDonald M, Darlington LG, Stone TW. Oxidative stress as a mechanism for quinolinic acid-induced hippocampal damage: protection by melatonin and deprenyl. Br J Pharmacol (1999) 128(8):1754-60. doi:10.1038/ sj.bjp. 0702940

8. Guidetti P, Schwarcz R. 3-Hydroxykynurenine potentiates quinolinate but not NMDA toxicity in the rat striatum. Eur J Neurosci (1999) 11(11):3857-63. doi:10.1046/j.1460-9568.1999.00806.x

9. Chen Z, Foster MW, Zhang J, Mao L, Rockman HA, Kawamoto T, et al. An essential role for mitochondrial aldehyde dehydrogenase in nitroglycerin bioactivation. Proc Natl Acad Sci U S A (2005) 102(34):12159-64. doi:10.1073/ pnas.0503723102

10. Tassorelli C, Joseph SA. NADPH-diaphorase activity and Fos expression in brain nuclei following nitroglycerin administration. Brain Res (1995) 695(1):37-44. doi:10.1016/0006-8993(95)00732-6

11. Tassorelli C, Joseph SA. Systemic nitroglycerin induces Fos immunoreactivity in brainstem and forebrain structures of the rat. Brain Res (1995) 682(1-2):167-81. doi:10.1016/0006-8993(95)00348-T

12. Di Clemente L, Coppola G, Magis D, Gerardy PY, Fumal A, De Pasqua V, et al. Nitroglycerin sensitises in healthy subjects CNS structures involved in migraine pathophysiology: evidence from a study of nociceptive blink reflexes and visual evoked potentials. Pain (2009) 144(1-2):156-61. doi:10.1016/j. pain.2009.04.018

13. Nagy-Grocz G, Tar L, Bohar Z, Fejes-Szabo A, Laborc KF, Spekker E, et al. The modulatory effect of anandamide on nitroglycerin-induced sensitization in the trigeminal system of the rat. Cephalalgia (2016) 36(9):849-61. doi: $10.1177 / 0333102415613766$

\section{ACKNOWLEDGMENTS}

This work was supported by the Hungarian Brain Research Program (Grant No. KTIA_13_NAP-A-III/9), the EUROHEADPAIN (FP7-Health 2013-Innovation; Grant No. 602633), and GINOP2.3.2-15-2016-00034. Methods section is developed based on previous experiments, which is already present in theses and is in line with the author's university policy, and can be accessed online. GN-G was supported through the UNKPÚNKP-16-3 New National Excellence Program of the Ministry of Human Capacities. ÁP and DZ were supported by the Bolyai Scholarship Programme of the Hungarian Academy of Sciences. We are indebted to Mrs. Valéria Vékony for histotechnical assistance.

14. Fejes-Szabo A. Modulatory Effect of Synthetic Kynurenic Acid Derivatives on the Nitroglycerin-Induced Trigeminal Activation and Sensitization in Rats [Dissertation]. University of Szeged (2014).

15. Fejes-Szabo A, Bohar Z, Nagy-Grocz G, Vamos E, Tar L, Podor B, et al. Effect of probenecid on the pain-related behaviour and morphological markers in orofacial formalin test of the rat. CNS Neurol Disord Drug Targets (2015) 14(3):350-9. doi:10.2174/1871527314666150225141229

16. Bohár Z. Activation Pattern and Modulation of Pain Related Structures in Animal Models of Migraine [Dissertation]. Universtiy of Szeged (2016).

17. Thomas SR, Terentis AC, Cai H, Takikawa O, Levina A, Lay PA, et al. Posttranslational regulation of human indoleamine 2,3-dioxygenase activity by nitric oxide. J Biol Chem (2007) 282(33):23778-87. doi:10.1074/jbc.M700669200

18. Hara T, Ogasawara N, Akimoto H, Takikawa O, Hiramatsu R, Kawabe T, et al. High-affinity uptake of kynurenine and nitric oxide-mediated inhibition of indoleamine 2,3-dioxygenase in bone marrow-derived myeloid dendritic cells. Immunol Lett (2008) 116(1):95-102. doi:10.1016/j.imlet.2007. 11.016

19. Wilson K, Auer M, Binnie M, Zheng X, Pham NT, Iredale JP, et al. Overexpression of human kynurenine-3-monooxygenase protects against 3-hydroxykynurenine-mediated apoptosis through bidirectional nonlinear feedback. Cell Death Dis (2016) 7:e2197. doi:10.1038/cddis.2016.87

20. Backhaus C, Rahman H, Scheffler S, Laatsch H, Hardeland R. NO scavenging by 3-hydroxyanthranilic acid and 3-hydroxykynurenine: $\mathrm{N}$-nitrosation leads via oxadiazoles to o-quinone diazides. Nitric Oxide (2008) 19(3):237-44. doi:10.1016/j.niox.2008.07.002

21. Mandi Y, Vecsei L. The kynurenine system and immunoregulation. J Neural Transm (Vienna) (2012) 119(2):197-209. doi:10.1007/s00702-011-0681-y

22. Hassanain HH, Chon SY, Gupta SL. Differential regulation of human indoleamine 2,3-dioxygenase gene expression by interferons-gamma and -alpha. Analysis of the regulatory region of the gene and identification of an interferongamma-inducible DNA-binding factor. J Biol Chem (1993) 268(7):5077-84.

23. Lögters TT, Laryea MD, Altrichter J, Sokolowski J, Cinatl J, Reipen J, et al. Increased plasma kynurenine values and kynurenine-tryptophan ratios after major trauma are early indicators for the development of sepsis. Shock (2009) 32(1):29-34. doi:10.1097/SHK.0b013e31819714fa

24. Greco R, Tassorelli C, Cappelletti D, Sandrini G, Nappi G. Activation of the transcription factor NF-kappaB in the nucleus trigeminalis caudalis in an animal model of migraine. Neurotoxicology (2005) 26(5):795-800. doi:10.1016/j. neuro.2005.02.005

25. Tfelt-Hansen P, Daugaard D, Lassen LH, Iversen HK, Olesen J. Prednisolone reduces nitric oxide-induced migraine. Eur J Neurol (2009) 16(10):1106-11. doi:10.1111/j.1468-1331.2009.02654.x

26. Curto M, Lionetto L, Negro A, Capi M, Fazio F, Giamberardino MA, et al. Altered kynurenine pathway metabolites in serum of chronic migraine patients. J Headache Pain (2015) 17:47. doi:10.1186/s10194-016-0638-5

27. Curto M, Lionetto L, Negro A, Capi M, Perugino F, Fazio F, et al. Altered serum levels of kynurenine metabolites in patients affected by cluster headache. J Headache Pain (2015) 17:27. doi:10.1186/s10194-016-0620-2 
28. Vecsei L, Szalardy L, Fulop F, Toldi J. Kynurenines in the CNS: recent advances and new questions. Nat Rev Drug Discov (2013) 12(1):64-82. doi:10.1038/nrd3793

29. Cananzi AR, D’Andrea G, Perini F, Zamberlan F, Welch KM. Platelet and plasma levels of glutamate and glutamine in migraine with and without aura. Cephalalgia (1995) 15(2):132-5. doi:10.1046/j.1468-2982.1995.015002132.x

30. Peres MF, Zukerman E, Senne Soares CA, Alonso EO, Santos BF, Faulhaber MH. Cerebrospinal fluid glutamate levels in chronic migraine. Cephalalgia (2004) 24(9):735-9. doi:10.1111/j.1468-2982.2004.00750.x

31. Sarchielli P, Di Filippo M, Nardi K, Calabresi P. Sensitization, glutamate, and the link between migraine and fibromyalgia. Curr Pain Headache Rep (2007) 11(5):343-51. doi:10.1007/s11916-007-0216-2
Conflict of Interest Statement: The authors declare that the research was conducted in the absence of any commercial or financial relationships that could be construed as a potential conflict of interest.

Copyright (๑) 2017 Nagy-Grócz, Laborc, Veres, Bajtai, Bohár, Zádori, Fejes-Szabó, Spekker, Vécsei and Párdutz. This is an open-access article distributed under the terms of the Creative Commons Attribution License (CC BY). The use, distribution or reproduction in other forums is permitted, provided the original author(s) or licensor are credited and that the original publication in this journal is cited, in accordance with accepted academic practice. No use, distribution or reproduction is permitted which does not comply with these terms. 